$\frac{162}{6.7-78}$

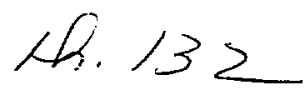

UCRL-52424

()

\title{
SAFETY ANALYSIS REPORT ON MODEL UC-609 SHIPPING PACKAGE
}

\author{
R. R. Sandberg
}

August 1977

MASTER

Work performed under the auspices of the U.S. Departmeit of

Energy by the UCLLL under contract number W-7405-ENG-48.

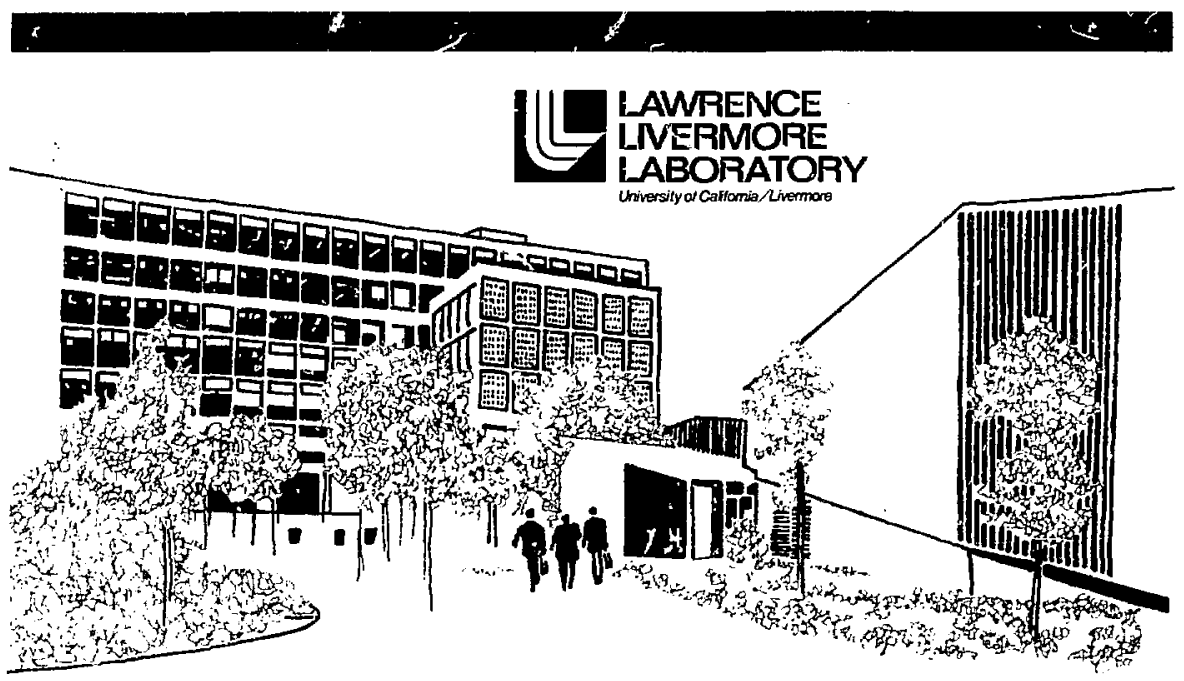

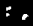




\section{NOTICE}

"This report wes prepared as an account of work sponsored by the United States Government. Neither the United States nor the United States Department of Energy, nor any of their employees, nor any of thelr contractorn, subcontractore, or their employecs, makes any warranty, express or implied, or cusumes any lefal liability or responslbility for tho accuracy, completeness or usofulnes of any informetion, apparatus, produce or process disclosed, or represents thet its use would not infringe privately-owned rights."

\section{NOTICE}

Reference to a company or product name does not imply approval or recommendation of the product by the University of Califormia or the U.S. Department of Energy to the exclusion of others that may be suitable.

Printed in the United States of America Available from

National Technieal Information Service

U.S. Department of Commerce

528.5 Port Royal Road

Springfield, VA 22161

Price: Printed Copy $\$$ : Microfiche $\$ 3.00$

\begin{tabular}{|c|c|c|c|}
\hline Page Range & $\begin{array}{c}\text { Y.-smestic } \\
\text { Price } \\
\end{array}$ & Page Range & $\begin{array}{c}\text { Domestic } \\
\text { Price }\end{array}$ \\
\hline $001 \cdot 025$ & S 4.00 & $326-350$ & $\$ 12.00$ \\
\hline $026-050$ & 4.50 & $351-375$ & 12.50 \\
\hline $051-075$ & 5.25 & $376-400$ & 13.00 \\
\hline $076-100$ & 6.00 & $401-425$ & 13.25 \\
\hline $101-125$ & 6.50 & $426-450$ & 14.00 \\
\hline $126 \cdots 150$ & 7.25 & $451-475$ & 14.50 \\
\hline $151 \cdot 175$ & B. 00 & $476-500$ & 15.00 \\
\hline $176-200$ & 9.00 & $50 t-525$ & 15.25 \\
\hline $201-225$ & 9.25 & $536-550$ & 15.50 \\
\hline $226-250$ & 9.50 & $551-575$ & 16.25 \\
\hline $251-275$ & 10.75 & $576-600$ & I6.50 \\
\hline $276-300$ & 11.00 & $601-u p$ & \\
\hline $301-325$ & 11.75 & & \\
\hline
\end{tabular}

1 Add $\$ 2.50$ tor each additonal 100 ospe incrament tron 601 pagas up. 


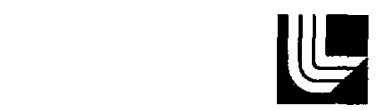

LAWRENCE LIVERMORE LABORATORY

University of Caftomia Livermore, Califomia 94550

UCRL-52424

\section{SAFETY ANALYSIS REPORT ON MODEL UC-609 SHIPPING PACKAGE}

R. R. Sandberg

MS, date: August 1977

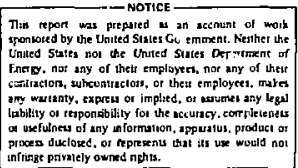




\section{CONTENTS}

Abstract

1.0 Introduction

1.1 General Information

1.2 Package Description

1.2.1 Packaging

1.2.2 Operating Features

1.2.3 Contents of Packaging

2.0 Structural Evaluation

2.1 Structural Design

2.1.1 Structura! Members

2.1.2 Design Criteria

2.2 Weights and Center of Gravity

2.3 Mechanical Properties of Materials

2.4 Genera! Standards for All Packages

2.4.1 Chemical and Galvanic Reactions ... . . . . . . . . . . . . .

2.4 .2 Positive Closure . . . . . . . . . . . . . . . . . . . .

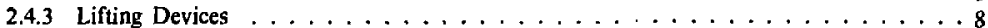

2.4 .4 Tie-Down Devices $\ldots \ldots \ldots \ldots \ldots \ldots$

2.5 Standarus for Type-B and Large-Quantity Packaging . . . . . . . . . . . . . . 9

2.5 .1 Load Resistance . . . . . . . . . . . . . . . . . . .

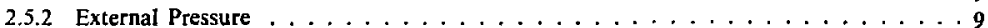

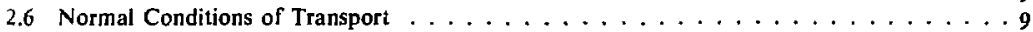

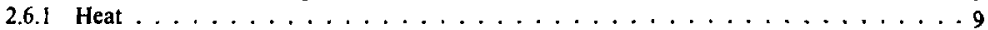

2.u.1.1 Summary of Pressures and Temperatures . . . . . . . . . . . . . 9

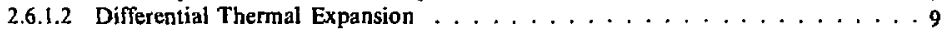

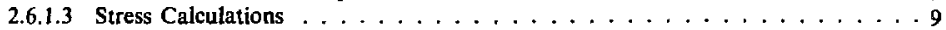

2.6.1.3.1 Cylindrical Section ................... 10

2.6.1.3.2 Formed Ellipsoidial Heads .................. 10

2.6.1.3.3 Cover Bolts . . . . . . . . . . . . . . . . . 10

2.6.1.3.4 Flanges ....................... 11

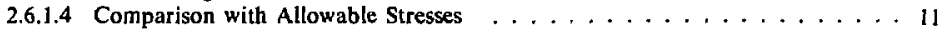

2.6 .2 Cold . . . . . . . . . . . . . . . . . . . . . 11

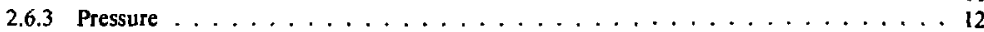

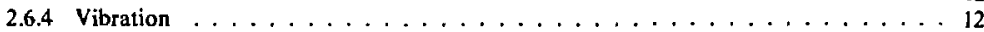

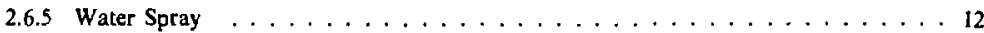

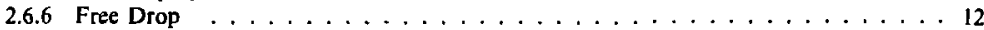

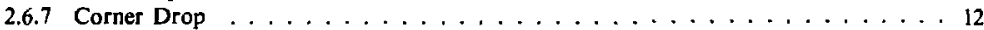

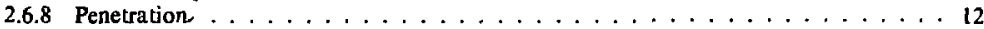

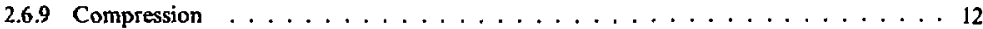

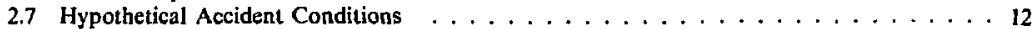

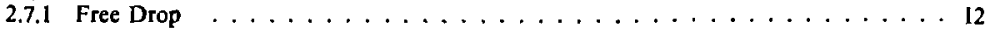

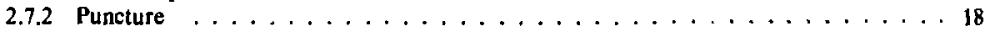

2.7 .3 Thermal . . . . . . . . . . . . . . . . . . . . 18

2.7.3.1 Summary of Pressures and Temperatures . . . . . . . . . . . 18

2.7.3.2 Differential Thermal Expansion . . . . . . . . . . . . . . . 18

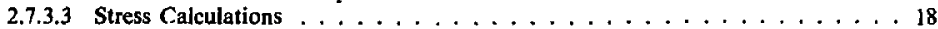

2.7.3.4 Comparison with Allowable Stresses $\ldots \ldots \ldots \ldots$

2.7 .4 Water Immersion . . . . . . . . . . . . . . . . . 19

2.7 .5 Summary of Damage . . . . . . . . . . . . . . . . 19

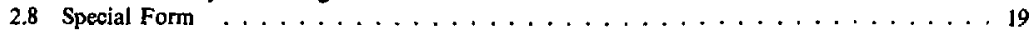

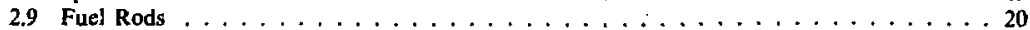

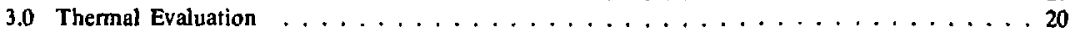

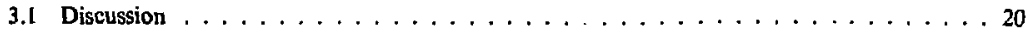




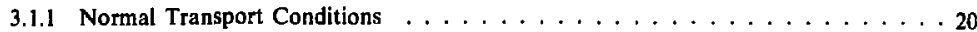

3.1.2 Hypothetical Accident Conditions . . . . . . . . . . . . . . 20

3.2 Summary of Thermal Properties of Materials . . . . . . . . . . . . . . 21

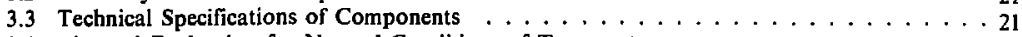

3.4 Thermal Evaluation for Normal Conditions of Transport . . . . . . . . . . . 21

3.4 .1 Thermal Model . . . . . . . . . . . . . . . . . . . 21

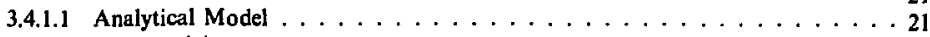

3.4 .1 .2 Test Model . . . . . . . . . . . . . . . . . . . . . . . . . . . . . . . . . . . . .

3.4 .2 Maximum Temperatures . . . . . . . . . . . . . . . 25

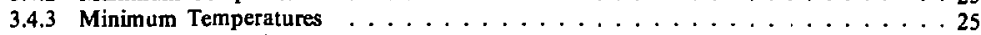

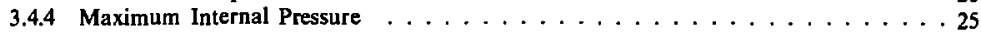

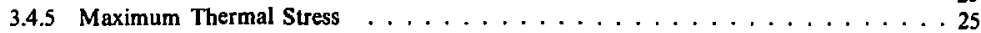

3.4.6 Evaluation of Package Performance . . . . . . . . . . . . 26

3.5 Hypothetical Thermal Accident Evaluation . . . . . . . . . . . . . 26

3.5 .1 Thermal Model . . . . . . . . . . . . . . . . . . . 26

3.5.1.1 Analytical Model . . . . . . . . . . . . . . . . . . . . . . . . . . . . . .

3.5 .1 .2 Test Model . . . . . . . . . . . . . . . . . . . 26

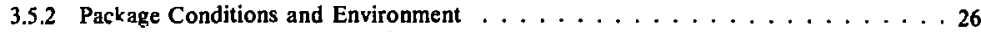

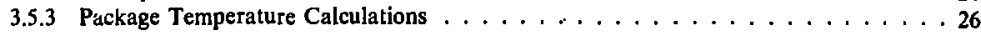

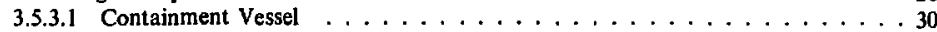

3.5.3.2 Storage Vessel . . . . . . . . . . . . . . . . . . . . . . . . . . . . . . . . .

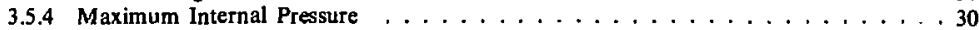

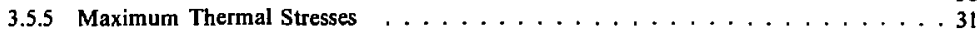

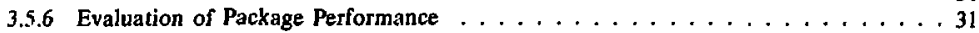

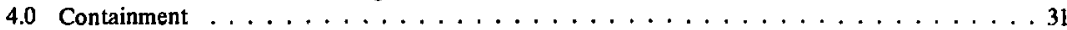

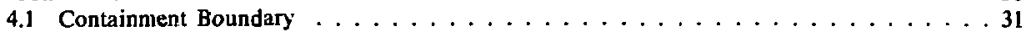

4.1 .1 Containment Vessel . . . . . . . . . . . . . . . . 31

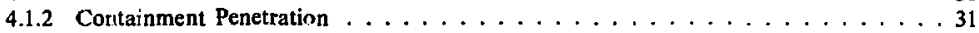

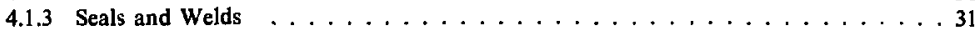

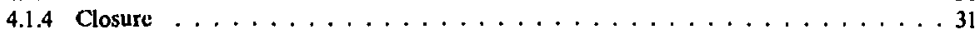

4.2 Requirements for Normal Conditions of Transport . . . . . . . . . . . 31

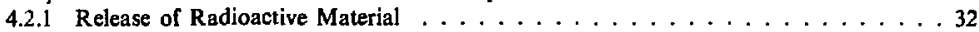

4.2.1.1 Permeation through Stainless Steel . . . . . . . . . . . . 32

4.2 .1 .2 Permeation through Copper Gasket . . . . . . . . . . . . 32

4.2.1.3 Total Release for Normal Transport . . . . . . . . . . . . . 32

4.2 .2 Pressurization of Containment Vessel ... . . . . . . . . . . . 33

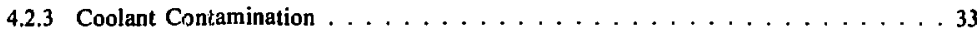

4.2 .4 Coolant Loss . . . . . . . . . . . . . . . . . . . . 33

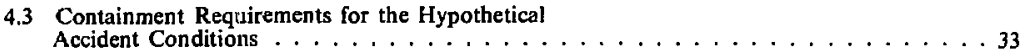

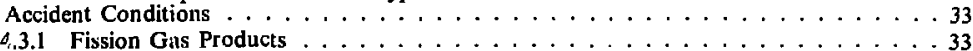

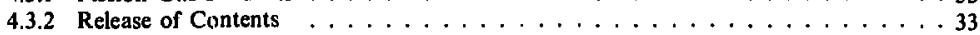

4.3.2.1 Permeation through Stainless Steel . . . . . . . . . . . . 33

4.3.2.2 Permmation through Copper Gasket . . . . . . . . . . . . . . . 33

4.3.2.3 Total Release for Accident Conditions . . . . . . . . . . . . 33

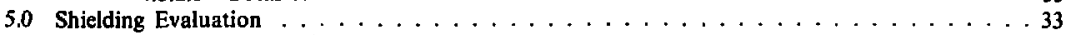

5.1 Discussion and Resilts . . . . . . . . . . . . . . . . . . . 34

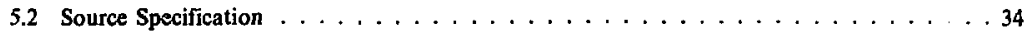

5.3 Model Specification . . . . . . . . . . . . . . . . . . . 34

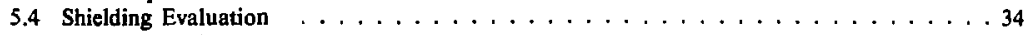

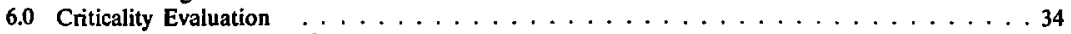

6.1 Discussion and Results . . . . . . . . . . . . . . . . . 34

6.2 Package Fuel Loading . . . . . . . . . . . . . . . . . . . 34

6.3 Model Specification . . . . . . . . . . . . . . . . . . . . . 34

6.4 Criticality Calculations and Experiments . . . . . . . . . . . . . . 34 


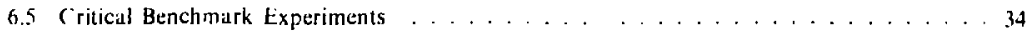

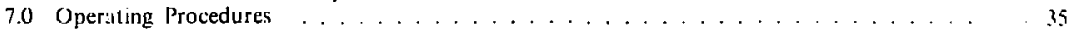

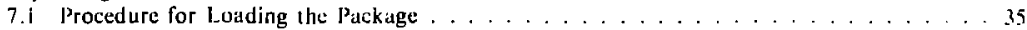

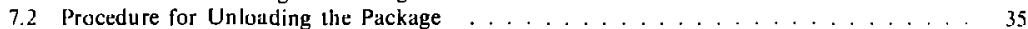

7.3 Preparation of an Empty Package for Transport . . . . . . . . . . . . . . . 35

8.0 Acceptance Tests and Maintenance Program . . . . . . . . . . . . . . . . . 35

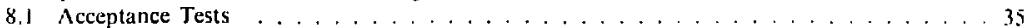

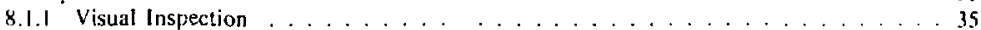

8.1 .2 Structural and Pressure Tests . . . . . . . . . . . . . . . . 35

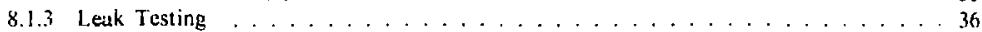

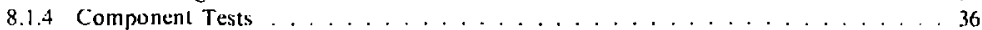

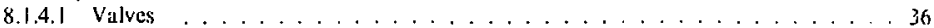

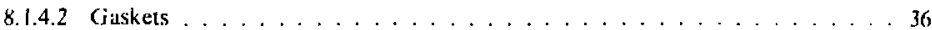

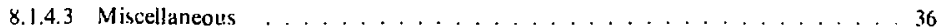

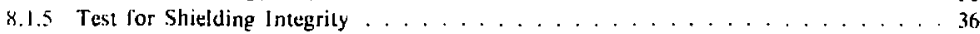

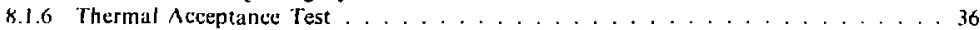

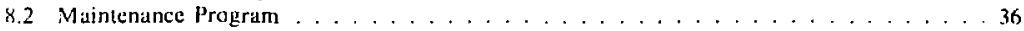

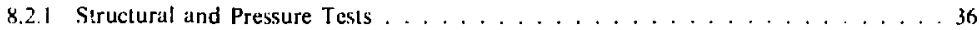

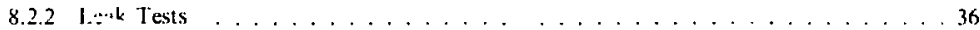

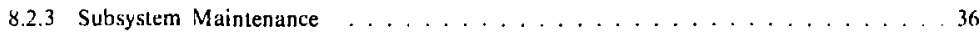

8.2.4 Valves. Rupture Disks, and Gaskets on 36

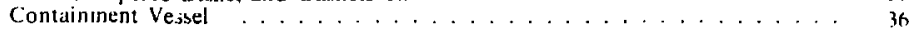

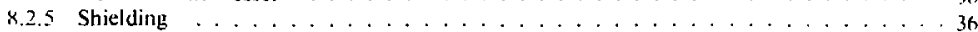

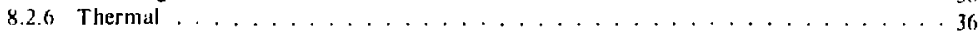

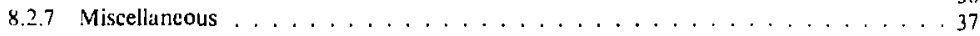

9.0 Ouallty s.surance Requirements f . . . . . . . . . . . . . . . . . . . . . . 37

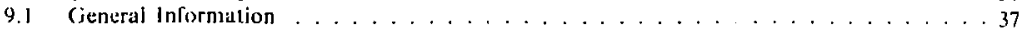

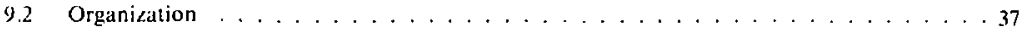

9.3 Quality Assurance Program . . . . . . . . . . . . . . . . . . . 37

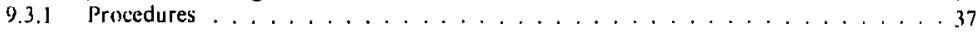

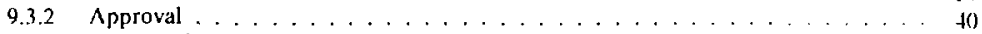

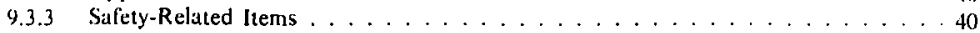

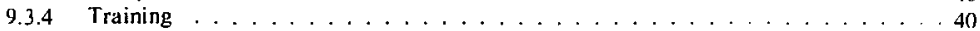

9.4 Design Review . . . . . . . . . . . . . . . . . . . . . . . . . . . . 40

9.5 Procurement Document Control . . . . . . . . . . . . . . . . . 40

9.6 Instructions, Procedures, and Drawings . . . . . . . . . . . . . . . . 40

9.7 Document Conirol . . . . . . . . . . . . . . . . . . . . . . . 40

9.8 Control of Purchased Material, Equipment, Parts, and

9.9 Identification and Control of Materials. Parts, and

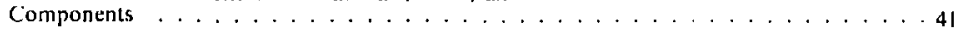

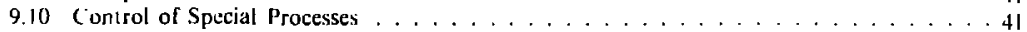

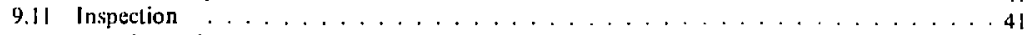

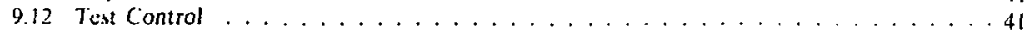

9.12.1 Preoperational Test Program . . . . . . . . . . . . . . . . 41

9.12.2 Acceptance Tests and Maintenance Program . . . . . . . . . . . . . . 41

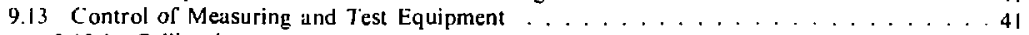

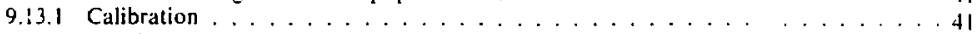

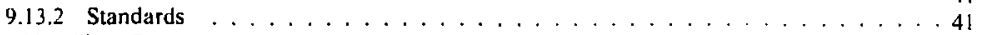

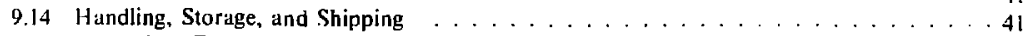

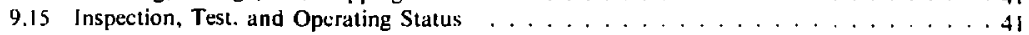

9.16 Nonconforming Material, Parts, or Components . . . . . . . . . . . . . . 42

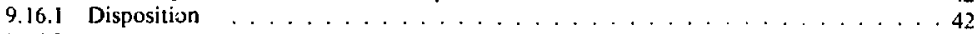

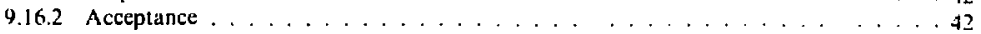

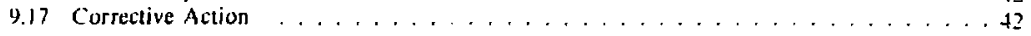


9.18 Quality Assurance Records . . . . . . . . . . . . . . . . . . 42

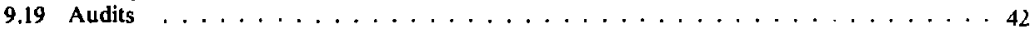

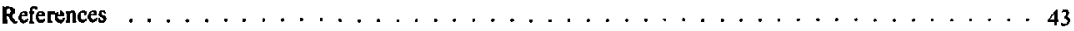

Appendix A: Engineering Notes . . . . . . . . . . . . . . . . . . . . . . . 44

END 77-16, UC-609 Shipping Container, Fabrication Specifications . . . . . . . . . . . 45

END 77-18, UC-609 Shipping Container, Pressure Test Report . . . . . . . . . . . . . . . . . 50

END 77-19, UC-609 Shipping Container, Assembly Fabricaticn Record . . . . . . . . . . . 5l

END 77-20, UC-609 Shipping Container, Component Inspection Form . . . . . . . . . . . 52

END 77-21, UC-609 Shipping Container, Packing and Test Procedure . . . . . . . . . . . 53

END 77-22, UC-609 Shipping Container, Packing Check List . . . . . . . . . . . . . . . 59

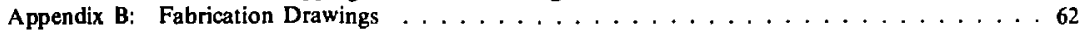

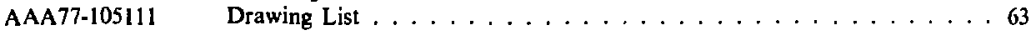

AA $76-1097 ? 1$

AAA $75-113967$

Model UC-609 Shipping Container .... . . . . . . . . . . . . . 64

AAA $75-113083$

Containment Vessel, Leak Test Assembly .............. 65

AAA77-102165

AAA $77-112930$

Vessel Assembly . . . . . . . . . . . . . . . . . . 66

Cover Assemibly . . . . . . . . . . . . . . . . . 67

AAA77-104161

Vessel Carrier Assembly . . . . . . . . . . . . . . . . . . 68

AAA77-104165

Insulation Cover Assembly . . . . . . . . . . . . . . . . . . . 69

AAA77-104163

Drum Assembly . . . . . . . . . . . . . . . 70

Insulation, Body ...................... 71 


\title{
SAFETY ANALYSIS REPOR'T ON MODEL UC-609 SHIPPING PACKAGE
}

\begin{abstract}
This Safety Analysis Report for Packaging demonstrates that model UC-609 shipping package can safely transport tritium in any of its forms. The report describes the package and its contents. It also evaiuates the package when subjected to the transport conditions specified in the Code of Federal Regulations, Title 10, Part 71. Finally, it discusses compliance with these regulations.
\end{abstract}

\subsection{INTRODUCTION}

\subsection{General Information}

The model UC- 609 shipping package will be usid to provide containment and offer impact and thermal resistance for shipments containing tritium during transpert under both normal and accident conditions.

Any tritium to be shipped will be placed in an appropriate storage vessel. That vessel will be placed within a stainless steel containment vessel, and the containment vessel placed within an insulated steal druin.

Each pack age will contain either a type-B quantity or a large quantity of tritium in any form, as defined in the Code of Federal Regulations, Title 10, Part 71 (10 CFR 71). All shipments will comply with the appropriate sections of these regulations. No exemptions are claimed.

The following points constitute the design basis of the UC-609 shipping packaze:

- The containment vessel is considered to be the primary containment boundary and will contain the tritium when the package is exposed to the normal or hypothetical accident conditions specified in 10 CFR 71 .

- Tritium will never be loaded directly into the containment vessel but will be put into a storage vessel.

- For design and analysis purposes the sturage vessel will receive no credit for tritium containment.

- Although the storage vessels receive no credit for containment, they are to be designed, certified, and tested to provide the maximum assurance of containment under all shipping conditions.

\subsection{Package Description}

\subsubsection{Packagi:ag}

The total package weighs $500 \mathrm{lb}$. The external dimensions are $25 \mathrm{in}$. in diameter $\times 55 \mathrm{in}$. high (see Fig. 1). Fabrication drawings of this package are presented in Appendix $A$. The major components, i.e., drum, insulation, and containment vessel, are described in the following paragraphs.

The drum is fabricated from 16-gauge earbon steel to the dimensions of 24.0 -in. i.d. $\times 52.5$-in. irside height per military standard MS 27683. Two l-in-diam holes near the center of the drum lid prevent package rupture from internal pressure during an accidental fire. These holes are sealed veathertight by inserting molded plastic plugs. Eight 3/16-in.-thick stainless brackets secure the cover to the Arum with $3 / 8$-in.-diam stainless steel bolts (see Fig. 2).

The insulation that cradles the containment vessel within the drum is Celotex laminated military packing board (a product of the Celotex Corp.) per military specification MIL-F-26862. The insulation is fabricated into disks and annular pieces of varying thickness. When the insulation pieces are installed in the drum, an internal cavity 18 in. in diameter and 44 in. long is formed. For ease in handling, the pieces of Celotex that must be removed to gain access to the containment vessel are glued into an assembly. Laminated into that assembly is a 1/2-in.thick disk of plywood that will prevent the ring on the containment vessel cover from penetrating the Celotex if the package is dropped on the top end. It is necessary to prevent this pentration because of 


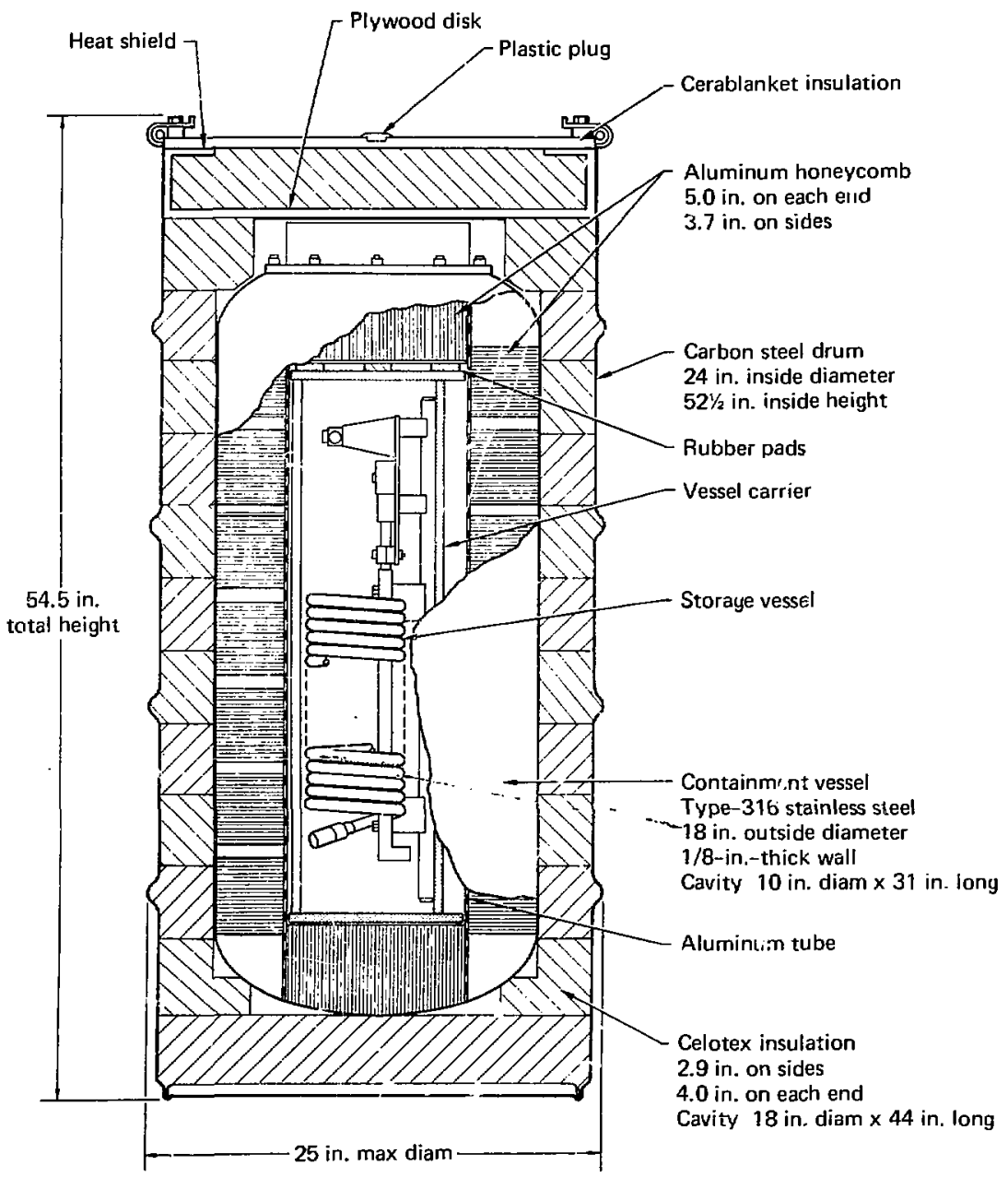

Fig. 1. Model (!C-609 shipping prackage.

possible damage to the valves and gauge on the cover. A sheet metal heat shield covers the top edge of the Celotex cover. The function of this part is to protect the Celotex from burning if a gap arcurs between the drum and its cover as a result of an accidental drop. 


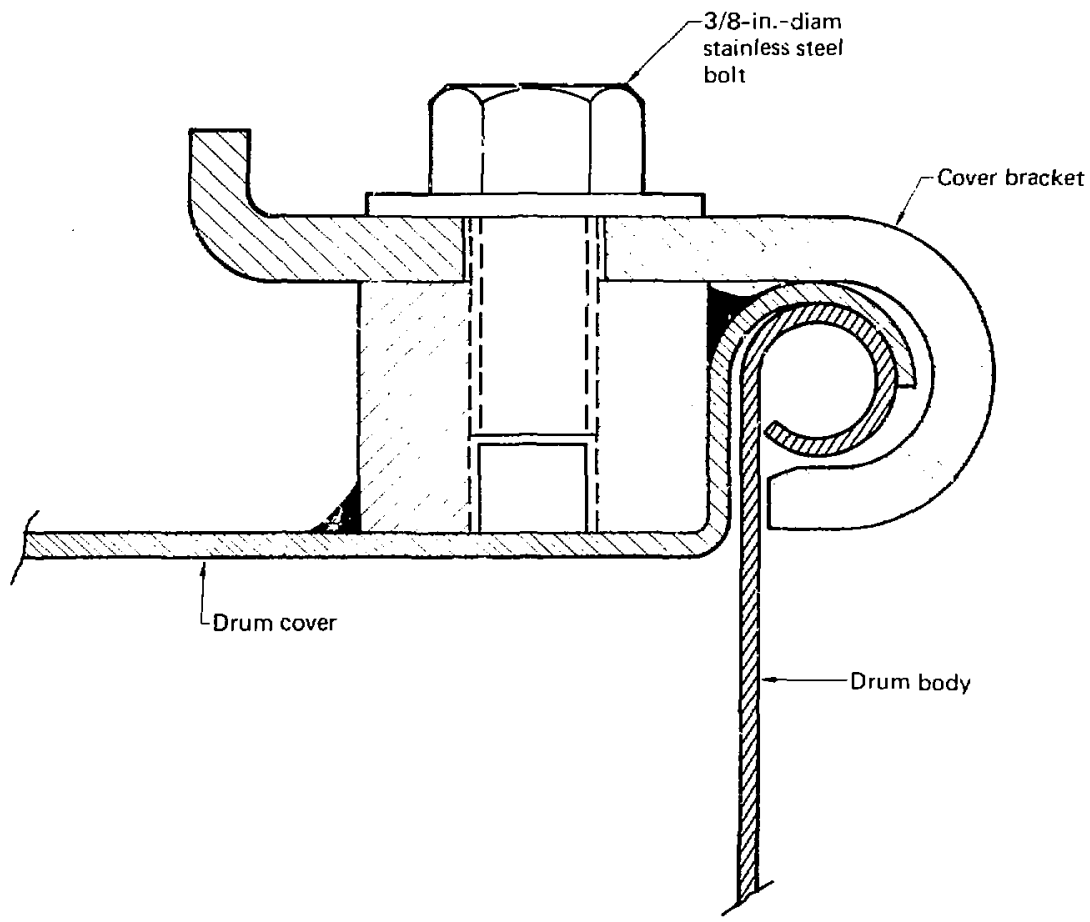

Fig. 2. Detail of drum coner hrdeket.

A disk of $1 / 2$-in.-thick Cerablanket (a porous refractory fiber irsulation produced by the Joins-Manville Corp.) is placed between the Celotex and the drum cover. This refractory fiber insulation performs the following functions:

- Protects the Celotex frori direct exposure to flame,

- Allows venting of the internal pressure.

- Limits the inflow of air to the drum to prevent the Celotex from smoldering after exposure to fire.

- Prevents separation of the Celolex by filling the gap between the drum cover and the Celotex.

The eontainment vessel consists of two parts, the body and the cover. Bnth are 1/8-in.-thick type-316 sta.niess steel. The body of the vessel is made by tungsten-inert-gas welding American Socieiy of Mechanical Engineurs elliptical heads to each end of a rolled and welded tube. The head on the top end of the sontainer body has a flange welded into it. The mating tlange is part of the welded cover assembly. The primary seal between the body and cover is made when opposed knife edges on the mating flanges are forced into an annealed, oxygen-free, high-cc nductivity copper gasket by the torquing oi eight $3 / 8$-in. alloy steel bolts. A Viton O-ring backs up the primary seal and allows a leak check of the primary seal with a mass spectrometer leak detector (see Fig. 3). 


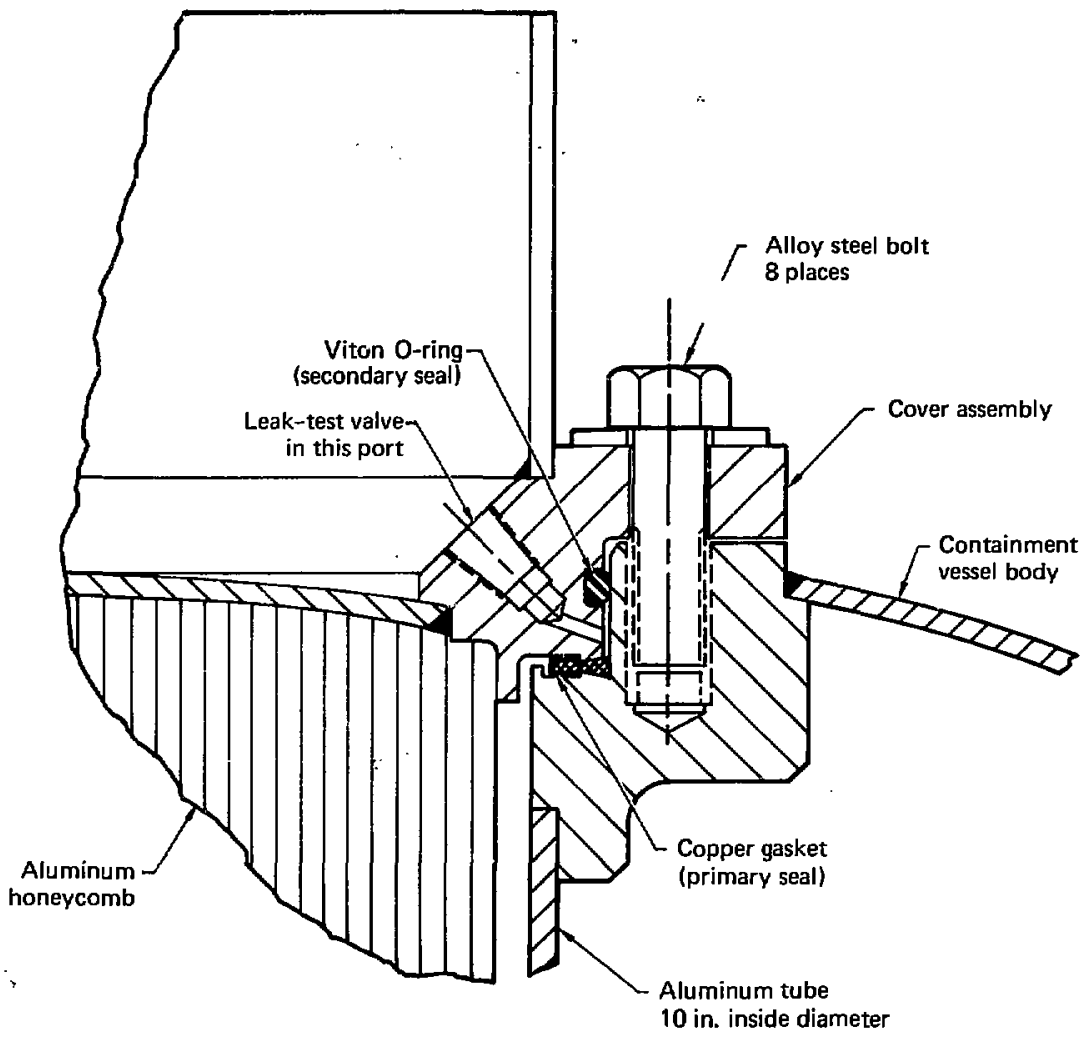

Fig. 3. Detail of containment vessel cover-to-body seal.

The cover asse: :ıbly has two penetrations. One is a 1/8-in. national pipe tapered-thread female pipe port that connects to the small volume between the primary and secondary seals. $A$ valve designated the leak-test valve is screwed into the port. The second port is in the center of the cover and connects to the main container volume. A manifold containing a 200-psi gauge and a valve is welded into this port. Both valves, the manifold, and the gauge components exposed to the container gas are type-316 stainless steel. The connections on both the valves are $1 / 4$ in. tube, $37^{\circ}$ male flare fittings (see Fig. 4).

Aluminum honeycomb (Hexcel Corp. designation AL-1/4-5052-0015P-3.4), 3.7 in. thick on the sides and 5 in. thick on the ends, lines the containment vessel. This honeycomb will prevent the storage vessel from impacting against the coutainraent vessel shell if the package is accidentally dropped. The maximum force that can be transmitted through the honeycomb is its crush strength, which is $150 \mathrm{psi}$. A 10-in.-i.d. aluminum tibe protects the inner surface of the honeycomb. The cavity forned within the containment vessel is $1 \tilde{u}$ in. in diameter $\times 31$ in. long (see Fig. 5). 


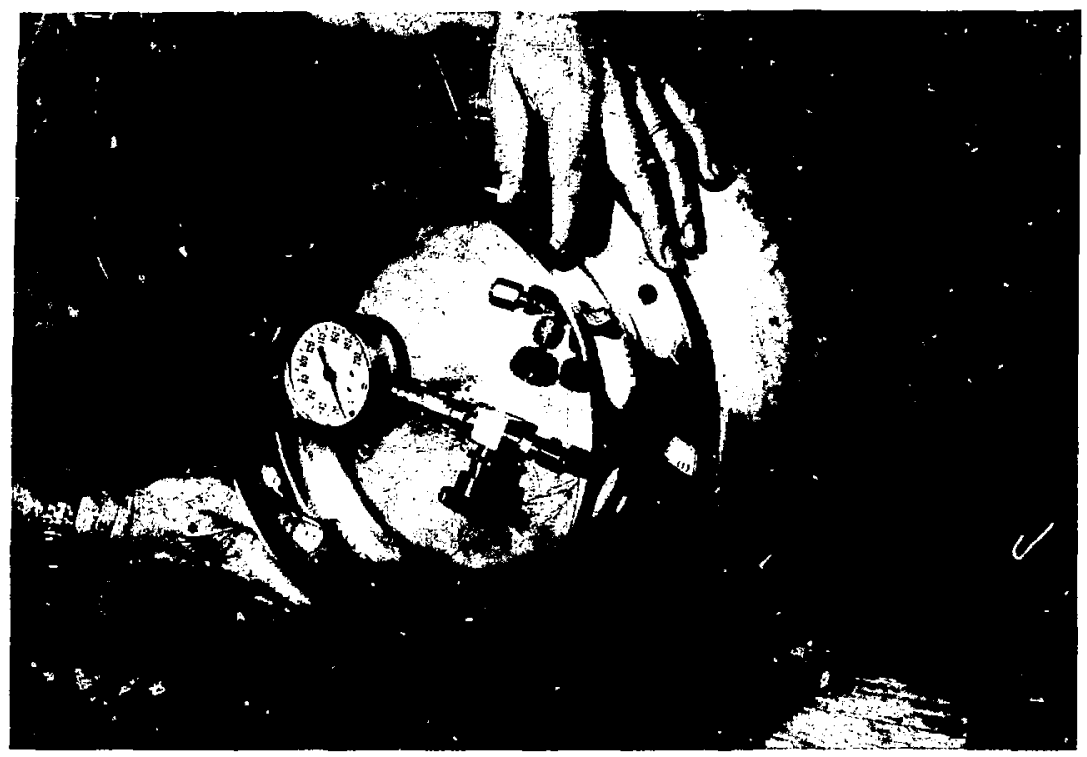

Fig. 4. Contalnment vessel cover assembly.

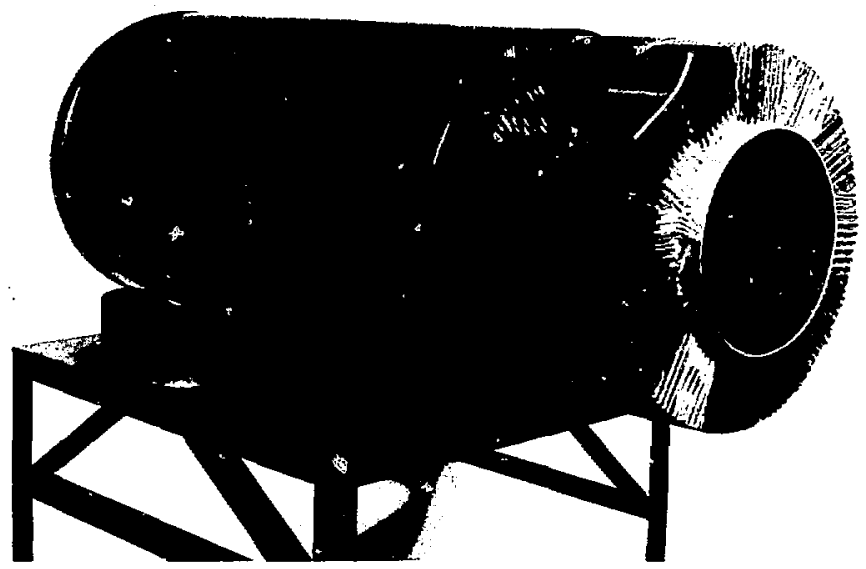

Fig. 5. Honeycomb tube assembly in containment vesset. 
The vessel carrier is basically a mounting, handling, and locating fixture for the storage vessel (see Fig. 6), but the major function in the package design is to distribute any forces transmitted by the storage vessel norer the entire area of the end pieces of the honeycomb. The vessel carrier may be redesigned in the future to accommodate storage vessel configurations not yet anticipated. The following restrictions must be observed in any redesign:

- Load-distributing aluminum (6061-T6) plates $1 / 2$ in. or thicker are required between the storage vessel and the end pieces of honeycomb.

- The total weight of the storage vessel plus the vessel carrier cannot exceed $120 \mathrm{lb}$.

- If materials less dense than aluminum are used for the vessel carrier, the total volume of the components to be installed in the containment vessel must be considered (see Sec. 1.2.3).

The vessel carrier is held in position by a close fit with the aluminum tube described previously. A gap in the long axis prevents interference due to tolerance buildup. Lightly compressed rubber pads fill the gap. This method of positioning provides both axial and traverse support and restricts the movement of the vessel carrier during transport.

\subsubsection{Operating Features}

The operational features of this packaging are described in Ch. 7.0, Operating Procedures.

\subsubsection{Contents of Packaging}

The radioactive contents of this package will be tritium in any of its forms. The following restrictions apply to the use of the container:

Maximum total gas contents

30 mole

Maximum tritium co:stents

25 mole

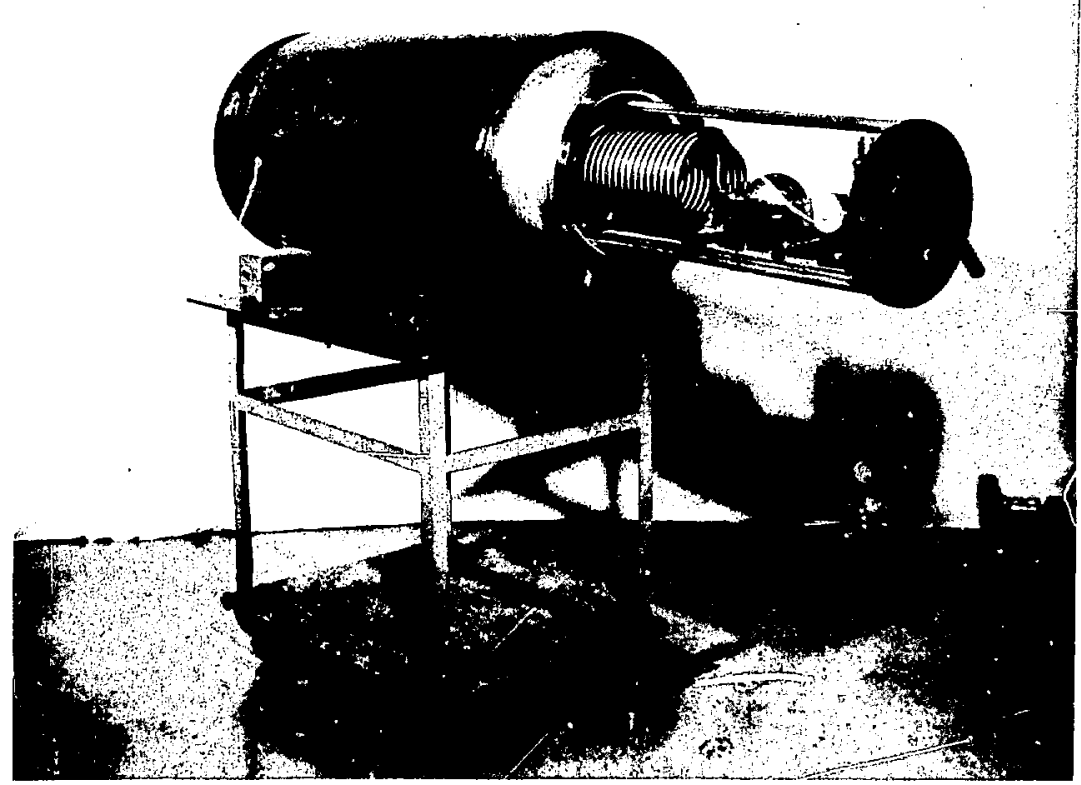

Fig. 6. Typical storage vessel mounted on vessel carrier. 
A maximum weight of $120 \mathrm{lb}$ will limit the combined volume of the storage vessel and vessel carrier to 20 litres if the materials of construction are at least as dense as aluminum $\left(0.098 \mathrm{lb} /\right.$ in. $\left.{ }^{3}\right)$. If materials less dense than aluminum are used, ejther the maximum tolal volume of the vessel and the carrier or the maximum total gits contents must be reduced. New linits may be calculated using the following equation:

$$
N^{\prime}=34.48-0.224 \mathrm{~V}_{\mathrm{T}} \text {. }
$$

where

$\therefore=$ maximum number of moles of material.

$v_{1}=$ total volume of vessel and carrier.

\subsection{STRUCTURAL EVALUATION}

\subsection{Structural Design}

\subsubsection{Struetural Members}

The principal structural members of the model UC-609 shifping package are the stainless steel containment vessel lined with impact-absorbing hontycomb, the Celolex insulation, and the carbon stcel drum.

The containment vesse] has a removible cover that is held in place by eight alloy steel bolts. These bolts. when tightened. force knifc edges on the mating flanges into a copper gasket, providing the primary closure seal. $A$ secondary seal is provided by an O-ring.

Two valves penetrate the cover. The first, called the fill valse, is part of a gauge manifold that is welded into the cuver. This valve is used to pressurize or evacuate the container and to monitor the vessel contents. The second, called the leak-lest valve, is serewed into a port that connects to the volume between the primary ar,d secondary seals. By connecing a mass spectrometer to this valve and pressurizing the container through the fill valve, it is possible to make s very sensitive leak check of the primary sea!.

The aluminum honeycomb that lines the interior of the containment vessel prevents the storage vessel from impacting against the vessel walls. A $1 / 8$ in.-thick aluminum tube protects the honeycomb strface and acts as a load distribution member in the radiai direction. Aluminum disks $1 / 2-i n$. thick act as load distribulion members in the longitudinal direction.

The Celotex not only insulates but centralizes the containment vessel within the steel drum that forms the outer surface of the package. The drum cover is held on by eight special brackets secured by $3 ; 8$-in.-diam stianless steel bolts.

\subsubsection{Design C riteria}

The load eriteria for the containment vessel are:

Maximum internal pressure

110 psig

Maxinum external pressure

25 psig

Maximum combined pressure load

260 psig

The calculated maximum pressure that could occur during a normal shipment is 103 psig (see Sec. 3.4.4). The 110-psig pressure is used for conservatism.

An accidentil drop of the package may result in localized crushing of the honeycomb that lines the containment vessel. If that occurs, the 150-psi crush streng:h of the honeycomb will be added to the 110-psig internal gas pressure.

The maximuru stress in the containment vessel shell is $25 \%$ of the minimum material tensile strength. This is the value specified in the ASME Boiler and Pressure Vessel Code. 'Appendix P. p. 365.

The maximum stress in the bolts used to secure the cover to the containment vessel is $60 \%$ of the minimum tensile strength. The Sturtevant Torque Manual. ${ }^{2}$ p. 41 , recommends a fastener tension between 60 and $70 \%$ of the minimum tensile strength. 


\subsection{Weights and Center of Gravity}

Weights, in pounds, of the component parts of the model UC- 609 package are:

Storage vessel plus vessel carrier

120 maximum

Celotex

110

Containment vessel

170

Drum

100

Total

500 maximum

The center of gravity of the package, assuming that the storage vessel is located centrally on the vessel carrier, is on the centerline of the drum and within 2 in. of the center of the long axis of the drum.

\subsection{Mechanical Properties of Materials}

The ASME Boiler and Pressure Vessel Code, Table UHA-23, pp. 182-183, specifies that the minimum yieid strength of type-316 stainless steel is $30,000 \mathrm{psi}$, the minimisii ultimate tensile strength is $70,000 \mathrm{psi}$, and the maximum design stress at temperatures between 93 and $149^{\circ} \mathrm{C}$ (200 and $300^{\circ} \mathrm{F}$ ) is 14,600 psi.

The crush strength of the aluminum honeycomb is $150 \mathrm{psi}^{3}$

The specified minimum tensile strength for the cover retaining bolts is 170,000 psi.

\subsection{General Standards tor All Packages}

\subsubsection{Chencical and Galvanic Reactions}

There is no reaction between the packaging and contents. However, some tritium can permeate through the wall of the containment vessel (see Ch. 4.0, Containnient). Also there will be no significant reaction between any of the parts of the packaging. The following materials are used in the package construction:

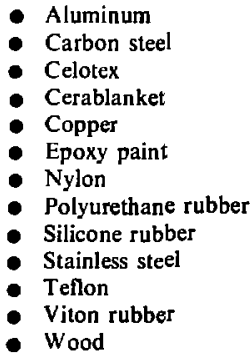

\subsubsection{Positive Clusure}

The closure system has two distinct levels, neither of which can be inadvertently opened.

The drum cover is fastened to the drum with eight brackets, each held in place by one bolt. Two of these bolts are secured with tamper seals.

The containment vessel cover is secured with eight bolts that may be secured with tamper seals if required for in-plant control. The two valves on the cover and the caps on their fittings also have provisions for tamper seals.

\subsubsection{Lifting Devices}

Not applicable. There are no lifting devices on the drum.

\subsubsection{Tie-Dewn Devices}

Not applicable. There are no tie-down devices on the drum. 


\subsection{Standards for Type-B and Large-Quantity Packaging}

\subsubsection{Load Resistance}

A drum identical to the one used on this package is used on he JP $157 \mathrm{~S}$ shipping package. ${ }^{4}$ For qualification of that package, bags of lead shot totaling $2400 \mathrm{lb}$ were stacked uniformly inside an empty drum along one side. After the lid was installed, the drum was carefully laid on its side and brought to rest with only the rim at each extreme end in contact with supporting timbers. No deformation or damage resulted.

That 2400 - lb test was only 100 lo less than would be required for the model UC-609 package [ $5 \times$ the weight of UC $-609(500 \mathrm{lb})=2500 \mathrm{lb}]$. In actual use the drum is stiffened considerably by being filled with Celotex and could certainly support an additional $100 \mathrm{lb}$ without damage.

\subsubsection{Extemal Pressure}

External pressure will affect only the stainless steel containment vessel, because it is the only sealed volume in the package. The weakest part of that vessel from an external pressure is the cylindrical shell between the two tind heads. The method for calculating the maximum allowable working pressure is outlined in the ASME Boiler and Pressure Vessel Code, paragraph UG-28, p.15:

$$
\begin{aligned}
D_{0} & =\text { outside diam of cylindrical shell }=18.0 \mathrm{in} . \\
\mathrm{L} & =\text { thickness of cylindrical shell }=0.125 \mathrm{in} . \\
\mathrm{L} & =\text { design length of cylindrical section } \\
& =\text { distance between head bend lines }+1 / 3 \text { of the depth of each head } \\
& =35+2[1 / 3(4.5)]=38 . \text { To be conservative, use } \mathrm{L}=40 .
\end{aligned}
$$

To find Factor B for temperatures up to $204^{\circ} \mathrm{C}\left(400^{\circ} \mathrm{F}\right)$, use values for $\mathrm{L} / \mathrm{D}_{0}$ and $\mathrm{D}_{0} / \mathrm{t}$ in Fig. UHA-28.2 of the Pressure Vessel Code, p. 303.

$$
\begin{aligned}
& \frac{\mathrm{L}}{\mathrm{D}_{0}}=\frac{40}{18}=2.22, \\
& \frac{\mathrm{D}_{0}}{\mathrm{~L}}=\frac{18}{0.125}=144 .
\end{aligned}
$$

After finding that Factor $\mathrm{B}=4500$, calculate the maximum allowable external pressure $(\mathrm{Pa})$ up to $204^{\circ} \mathrm{C}$ :

$$
\mathrm{Pa}=\frac{\mathrm{B}}{\mathrm{D}_{0} / \mathrm{t}}=\frac{4500}{144}=31.25 \mathrm{psi}
$$

\subsection{Normal Conditions of Transport}

\subsubsection{Heat}

2.6.1.1 Summary of Pressures and Temperatures. The maximum temperature of the containment vessel during normal transport is $76^{\circ} \mathrm{C}$ (see Sec. 3.4.2).

The maximum pressure in the containment vessel during normal transport is 103 psig (see Sec. 3.4.4).

2.6.1.2 Differential Thermal Expansion. Hypothetical accident tests did not cause any damage attributable to differential thermal expansion (see Sec. 2.7.3.2). Conditions of normal transport are much less severe. Thus, no problems will be encountered during normal transport or actual transport conditions.

2.6.1.3 Stress Calculations. Calculations of the stresses and maximum working pressure of the cylindrical body and the formed heads of the containment vessel were made using methods specified in the ASME Boiler and Pressure Vessel Code. For conservatism we used an internal pressure of 110 psig rather than the actual pressure of 103 psig. 


\subsection{Cylindrical Section.}

$$
P=\frac{\text { SEt }}{R+0.6 t} \quad \text { (Ref. 1, paragraph UG4, p. 14) }
$$

where

$\mathbf{P}=$ pressure $=110 \mathrm{psig}$,

$E=$ joint efficiency (Ref. 1, Table UW-12, p. 74, butt joint fully rudiographed $)=100 \%$,

$\mathbf{S}=$ stress,

$\mathrm{t}=$ shell thickness $=0.125$ in.,

$\mathrm{R}=$ inside radius $=8.875 \mathrm{in}$.

Solving for stress.

$$
S=\frac{P(R+0.6 t)}{E t}=\frac{110[8.875+0.6(0.125)]}{1.0(0.125)}=7876 \text { psi. }
$$

\subsection{Formed Ellipsoidal Heads.}

$$
P=\frac{2 S t}{K D_{0}-2 t(K-0.1)} \quad \text { (Ref. 1, paragraph UA4, pp. 226-228) }
$$

where

$$
\begin{aligned}
D_{0} & =\text { outside diameter }=18.0 \mathrm{in} . \\
t & =\text { shell thickness }=0.125 \mathrm{in.}, \\
\mathrm{S} & =\text { stress, } \\
\mathrm{K} & =\text { ellipsoidal head iactor for head with }(\mathrm{D} / 2 \mathrm{~h}=2)(\text { Ref. 1. Table UA } 4.1, \mathrm{p} .228), \\
\mathrm{K} & =1.0, \\
\mathbf{P} & =\text { pressure }=110 \mathrm{psig},
\end{aligned}
$$

Solving for stress,

$$
\mathrm{S}=\frac{\mathrm{P}\left[\mathrm{K}\left(\mathrm{D}_{0}\right)-2 \mathrm{t}(\mathrm{K}-0.1)\right]}{2 \mathrm{t}}=\frac{110[1(18.0)-2(0.125)}{2(0.125)} \underline{(1-0.1)]}=7821 \mathrm{psi}
$$

2.6.1.3.3 Cover Bolts. The cover-to-vessel joint is assumed to be rigid. That is, we assume little or no spring effect from the copper gasket. This is a reasonable assumption, since the gasket is very thin and is plastically yielded when the joint is tightened. Therefore, any elastic recovery of the gasket will be very small relative to the bolts.

With a properly tightened rigid joint, internal pressure effects on the bolts can be eliminated and the stresses on the bolts limited to the amount caused by initial tightening. ${ }^{2}$ To achieve this condition, the total tension in the eight bolts must be greater than the total pressure force on the cover.

The force (F) on the cover due to internal pressure is calculated as follows: 


$$
\mathrm{F}=\frac{\pi}{4}\left(\mathrm{D}^{2}\right) \mathrm{P}
$$

where

$$
\begin{aligned}
& D=\text { diam at gasket seal }=10.5 \mathrm{in} . \\
& P=\text { internal pressure }=110 \mathrm{psig} . \\
& F=\frac{\pi}{4}(10.5)^{2}(110)=9524 \mathrm{lb} .
\end{aligned}
$$

The initial tension (L) in the bolts from torquing can be calculated as follows:

$$
\mathrm{L}=\frac{\mathrm{T}}{0.2(\mathrm{D})} \quad \text { (Ref. 5, p. 34), }
$$

where

$$
\begin{aligned}
& D=\text { bolt diam }=0.375 \mathrm{in} . \\
& T=\text { torqut }=45(12) \text { in.-lb } \\
& L=\frac{45(12)}{0.2(0.375)}=7200 \mathrm{lb} \text { per bolt } .
\end{aligned}
$$

The total force on the cover from the eight bolts is $57,600 \mathrm{lb}$, which is much greater than the pressure force of $9524 \mathrm{lb}$.

The stress (S) on the bolts from initial tightening is:

$$
S=\frac{L}{A},
$$

where

$$
\begin{aligned}
& L=\text { initial tension }=7200 \mathrm{lb}, \\
& A=\text { tensile stress area at root of thread (Ref. } 5)=0.0878 \text { in. }{ }^{2} \\
& S=\frac{7200}{0.0878}=82,000 \mathrm{psi} .
\end{aligned}
$$

2.6.1.3.4 Flanges. A finite element analysis of the liange assembly was made. ${ }^{6}$ At an internal pressure of 110 psig, the maximum stress was 13,000 psi.

To verify the adequacy of the flange design, one of the prototype containers was hydraulically pressurized to failure with the following result:

- At 425 psia the primary (copper gasket) seal began to leak. The secondary (O-1 ing) seal held.

- At 650 psia the flange had deformed to the point that the O-ring blew out, releasing the pressure. None of the bolts failed. Although all were slightly bent from the deformation of the flange: they were easily unscrewed and removed.

2.6.1.4 Comparison with Allowable Stresses. The most highly stressed area in the $316 \mathrm{~s}$ :ainless steel containment vessel is the flanges. The 13,000-psi stress calculated for that area is approximately $90 \%$ of the maximum allowable stress of 14,600 psi per the ASME Pressure Vessel Code (see Sec. 2.6.1.3).

The maximum bolt stress uras calculated at 82,000 psi. The Sturtevant Torque Manual (p. 41) recommends a maximul. stress of $60 \%$ of the tensile strength, or $0.60 \times 170,000=102,000$ psi. The 82.000-psi stress is approximately $80 \%$ of that value.

\subsubsection{Cold}

The effectiveness of the packaging material is not significantly impaired by a temperature of $-40^{\circ} \mathrm{C}$. The tensile strength and ductility of the materials do not change significantly at $-40^{\circ} \mathrm{C}$. In fact, the tensile strength of the type-316 stainless steel used for the containment vessel increases without a loss in ductility. 


\subsection{Pressure}

Reduction of the external pressure to 7.4 psia $(0.5 \mathrm{~atm})$ would give a maximum differential pressure across the containment vessel wall of $110.0+7.4=117.4 \mathrm{psig}$. Each vessel is tested at $200 \mathrm{psig}$ and therefore would not be damaged at a pressure of 118 psig.

\subsubsection{Vibration}

A vibration test on one prototype package simulated transportation by common carrier as secured cargo. ${ }^{7}$ The package was vibrated in the upright position in a sweep from 5 to 200 to $5 \mathrm{~Hz}, 12 \mathrm{~min}$ up and 12 min down, for a total of $84 \mathrm{~min}$. The acceleration level was $1.5 \mathrm{~g}$.

The tightness of all fastenings was checked before and after the test. No changes were found. The primary seal was tested hefore and after the test at 120 psig. No leakage was found on a mass spectrometer with a sensitivity in the $10^{-9}$ atm- $-\mathrm{cm}^{3} / \mathrm{s} /$ div range.

\subsubsection{Water Spray}

The closed steel drum with the vent holes sealed by plastic plugs is impervious to water spray and is not significantly affected.

\subsubsection{Free Drop}

The requirements of the free-drop condition for normal transport are less severe than those for the freedrop condition of the hypothetical accident to which the prototype shipping package was actually subjected. In fact, one package was dropped twice from $30 \mathrm{ft}$ with no resulting damage to the containment vessel. The results of these impact tests provide the basis for the conclusion that the package complies with the free-drop requirements for normal transport.

\subsubsection{Cn ...er Drop}

Since this pack age is constructed primarily of metal, not wood or fiberboard, and because it weighs more than $110 \mathrm{lb}$, this test is not applicable.

\subsubsection{Penetration}

The required penetration test was performed on the JP $157 \mathrm{~S}$ package, which uses the same drum and Celotex insulation as is used for the model UC-609 shipping package (Ref. 4, pp. 1-8). In those tests, maximum deflection to the drum surface was less than $1 / 4$ in. with no damage to the Celotex insulation.

\subsubsection{Compression}

A drum identical to the one used on this package is used on the JP 157S shipping package (Ref. 4, pp. 18). To qualify that package, an empty drum was loaded to $2400 \mathrm{lb}$, and no visible damage or deformation occurred. That $2400-1 \mathrm{~b}$ test was only $100 \mathrm{lb}$ less than would be required for the model UC-609 package [ $\times$ the weight of UC-609 $(500 \mathrm{lb})=2500 \mathrm{lb}$ ]. In actual use the drum is completely filled with Celotex and could certainly support $100 \mathrm{lb}$ more than an empty drum without daniage.

\subsection{Hypthetical Accident Conditions}

Records of tests made to verify adequacy of the design when subjected to the hypthetical accident conditions are contained in Engineering Note END 78-004 (UC-609 test recouds).

\subsubsection{Free Drop}

In the process of developing a satisfactory method of securing the drum cover, a total of seven $30-\mathrm{ft}$ free drops were made on the two prototype containment vessels. The impact surface was a 1-in.-thick steel plate resting on an asphalt roadway for the first three drops and a 6-in.-thick steel plate resting on concrete for the last four. Five drops impacted the package on the edge of the drum cover with the center of gravity directly above the impact point (see Fig. 7). One drop impacted on the long axis of the drum. In all but one instance, the drum and any damaged Celotex were seplaced before making another drop. In the one exception, one package was dropped on the cover and then on the side of the drum with no repair or replacement between drops. 


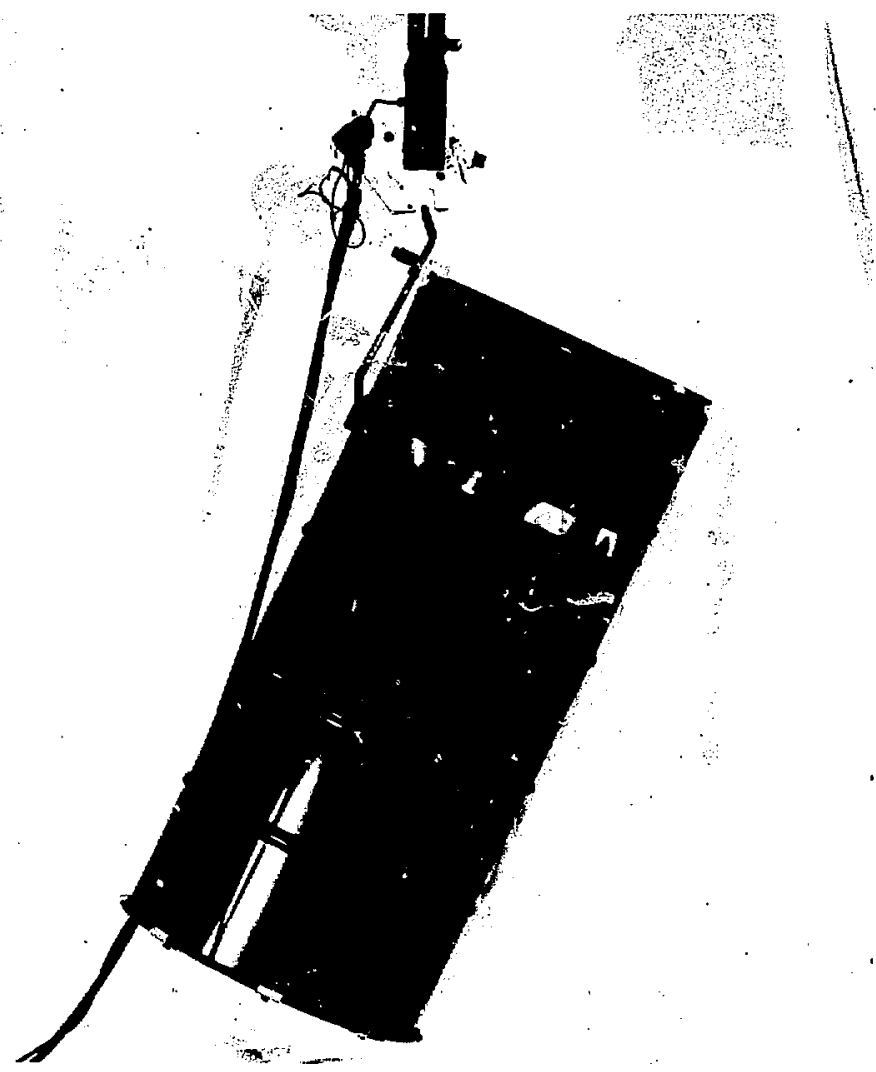

Fig. 7. Orientation of package on free drop.

A 100-lb weight (a steel bar 5 in. diam $\times 18$ in. long) was used to simulate the heaviest storage vessel allowed for the package. On three drops this $100-\mathrm{lb}$ weight was loose within the containment vessel cavity. On the other drops the weight was securely attached to the vessel carrier.

The last drop was onto the edge of the drum cover with the final drum closure system in use. On this last drop the corner was crushed ahout 3 in., but no opening occurred and no significant loss of insulating capacity resulted (see Figs. 8-12).

None of the drops resulted in damage to the containment vessels that impaired leak tightness. The greatest effect on the containment vessel was caused by the horizontal drop impacting on the long axis of the drum. This flattened the containment vessel to a maximum depth of $1 \mathrm{in}$. along one side. There was no loss of insulation thickness.

The copper gasket-to-flange seal was tested before and after each drop with the container pressurized to 120 psia with helium. No leakage was detectable on a mass spectrometer with a sensitivity in the $10^{-9}$ atm$\mathrm{cm}^{3} / \mathrm{s} /$ div range. All drops were made with the container at approximately 20 psia. 


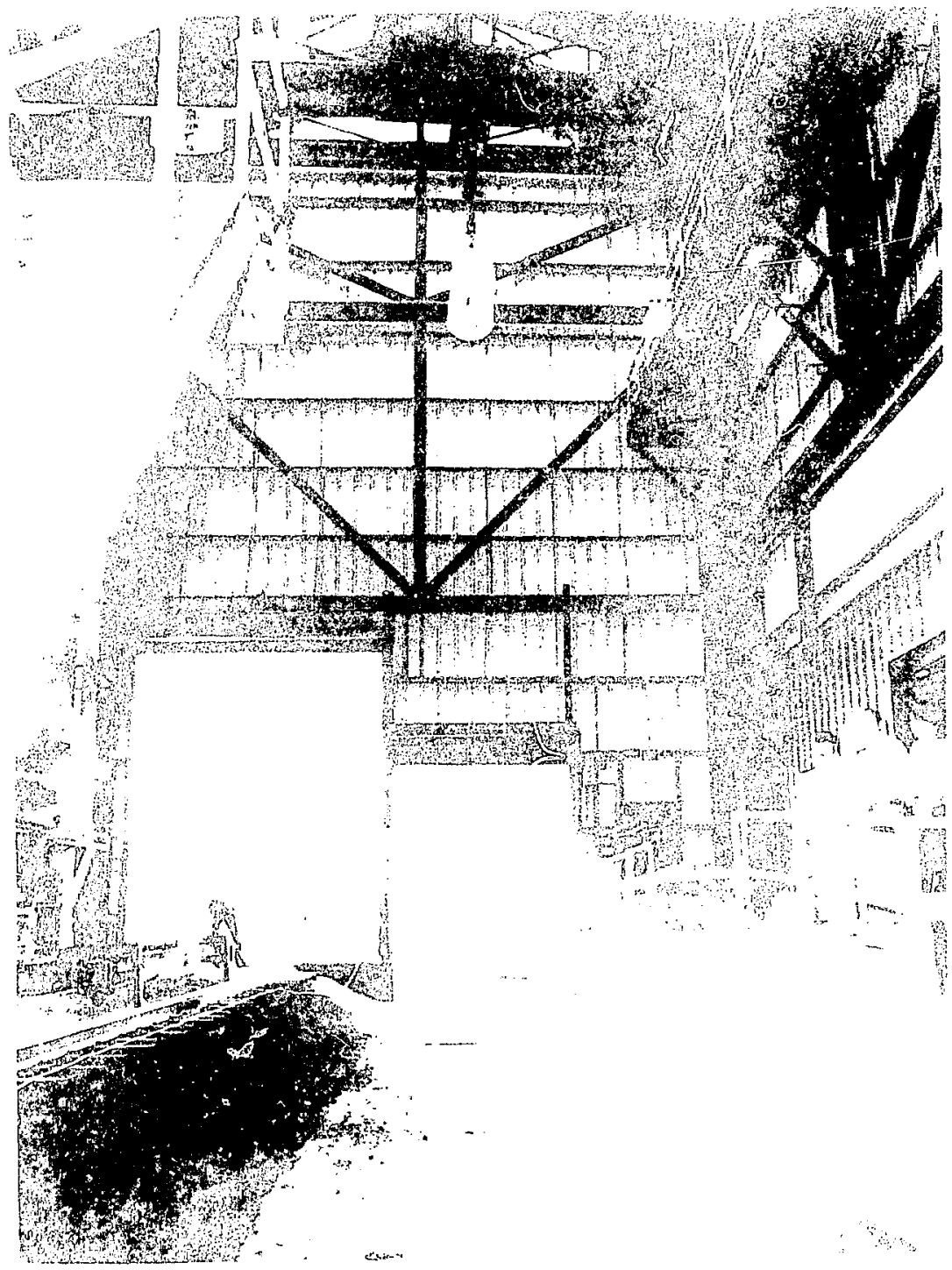



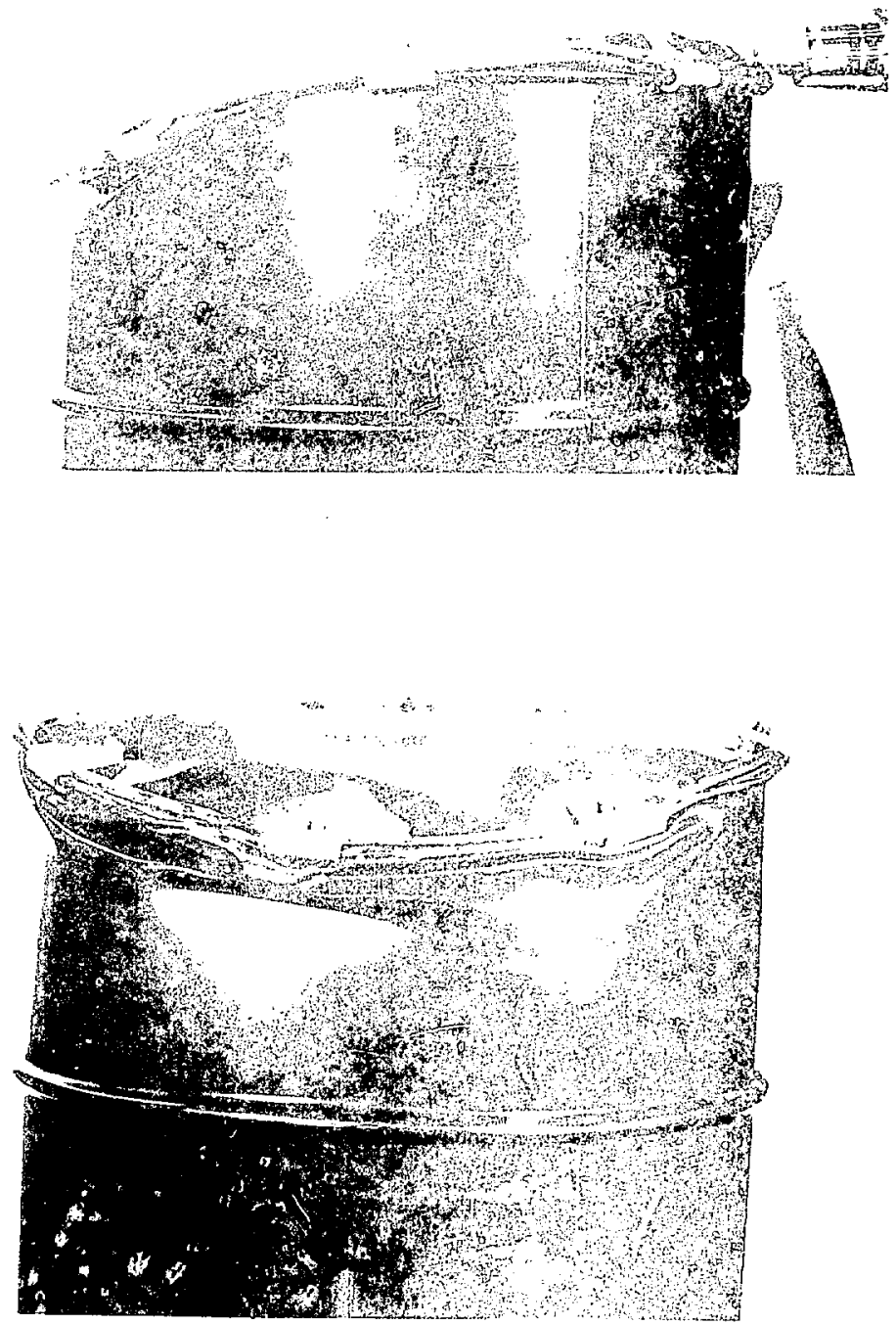

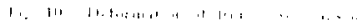



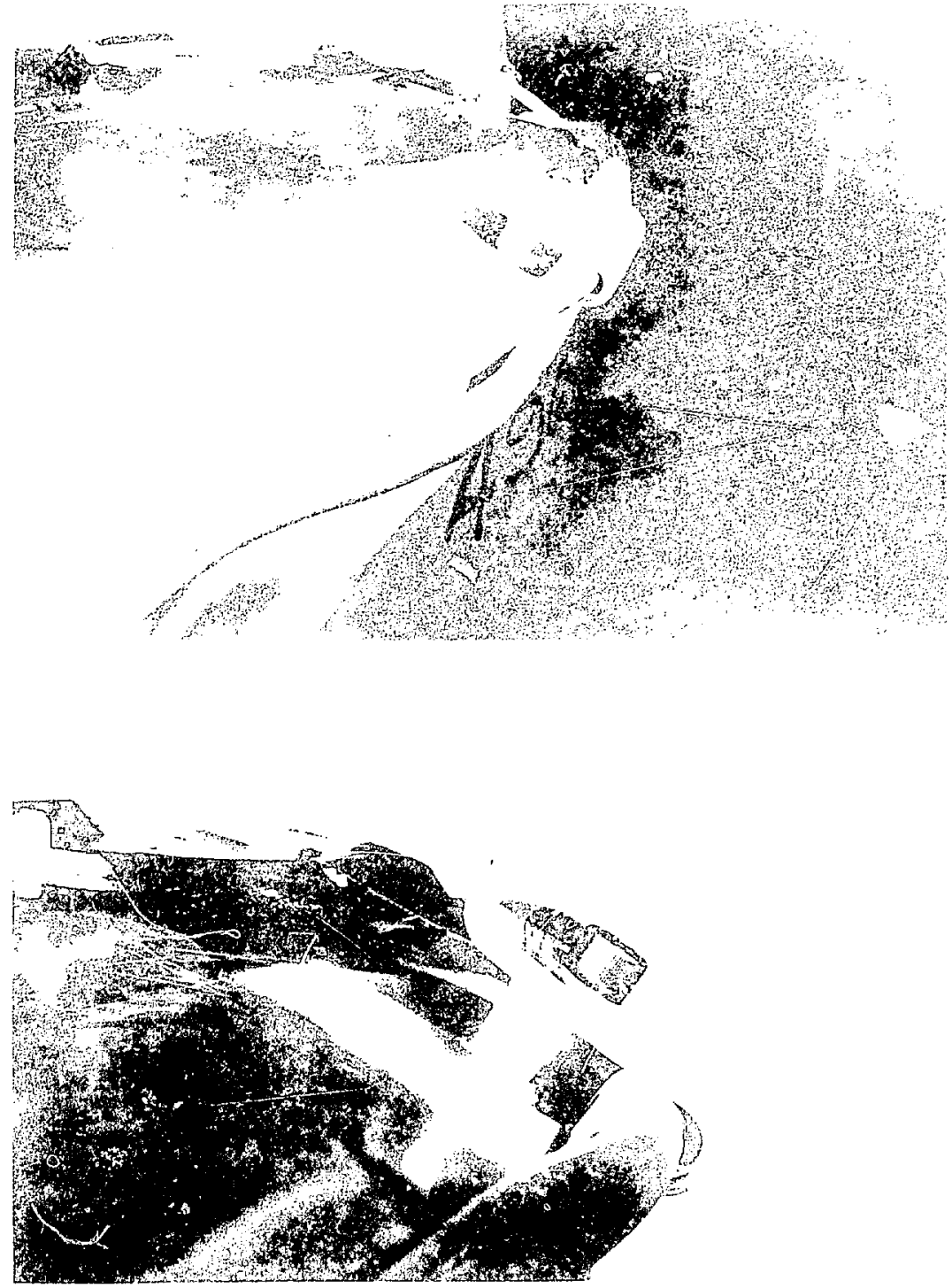

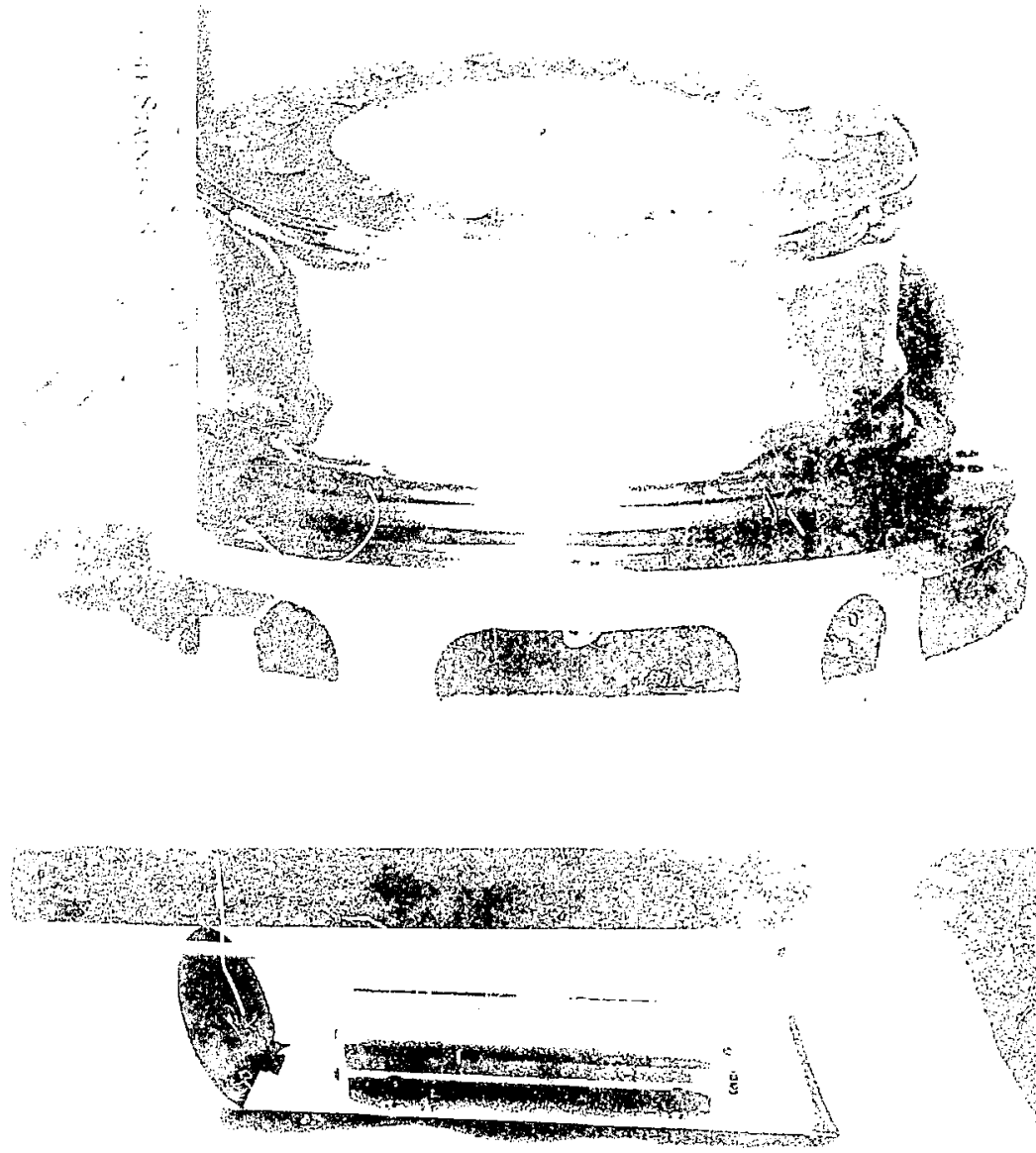


\subsubsection{Puncture}

The pack age used for the final drop test was dropped 40 in. onto a 6-in.-diam s!eel post 10 in. high. The side of the drum was indented no more than 1 ir. (see Figs. 15 and 16).

\subsubsection{Thermal}

\subsubsection{Summary of Pressures and Temperatures.}

Assumed maximum ambient temperature before fire

$38^{\circ} \mathrm{C}$

Maximum containment vessel temperature

$141^{\circ} \mathrm{C}$ (See Sec. 3.5.3.1.1)

Maximum storage vesse temperature

$170^{\circ} \mathrm{C}$ (See Sec, 3.5.3.1.2)

Maximum containment vessel pressure

125 psig (See Sec. 3.5.4.)

2.7.3.2 Differeutial Thermal Expansion. The furnace test (see Sec. 3.5.1) did not cause any damage that could be attributed to differential thermal expansion. There is no rigid structural coupling of materials having dissimilar expansion rates or important temperature gradients.

The clearances, the temperature differentials involved, and the thermal expansion coefficient of the materials will minimize the effects of thermal expansion.

2.7.3.3 Stress Calculations. The effective internal pressure of the containment vessel may be temporarily increased to $260 \mathrm{psig}$ as a result of a free drop. This would happen only if the honejuivinb lining were crushed. At the location where crushing occurs, the 150-psi crush strength would be added to the I10-psig norma! conditions pressure. Subjecting the package to the fire enivornment would increase the containment vessel temperature to $141^{\circ} \mathrm{C}$ and thereby increase the internal pressure to $125 \mathrm{psig}$ (see Sec. 3.5.4).

The greatest stress on the containment vessel occurs on the flanges (see Sec. 2.6.1.3.4). At 260 psig the calculated maximum stress is $30,600 \mathrm{psi}^{6}$

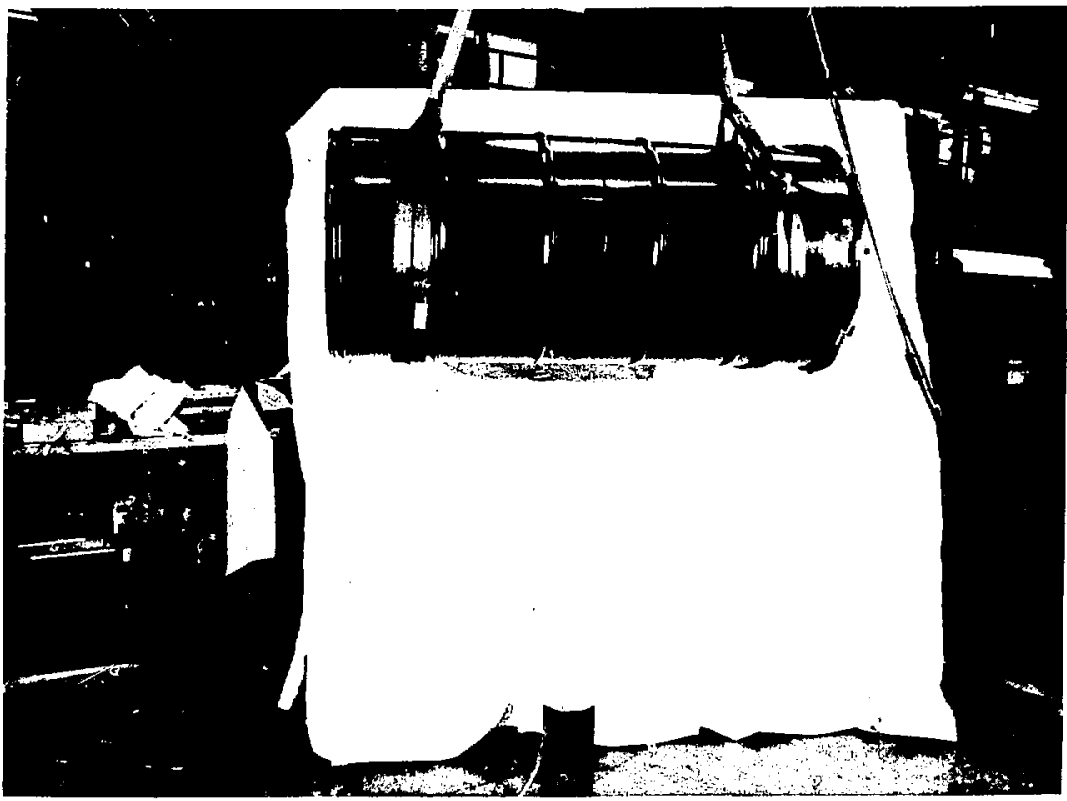

Fig. 15. Package orientation for 40-in. drop onto 6-in.-diam bar. 


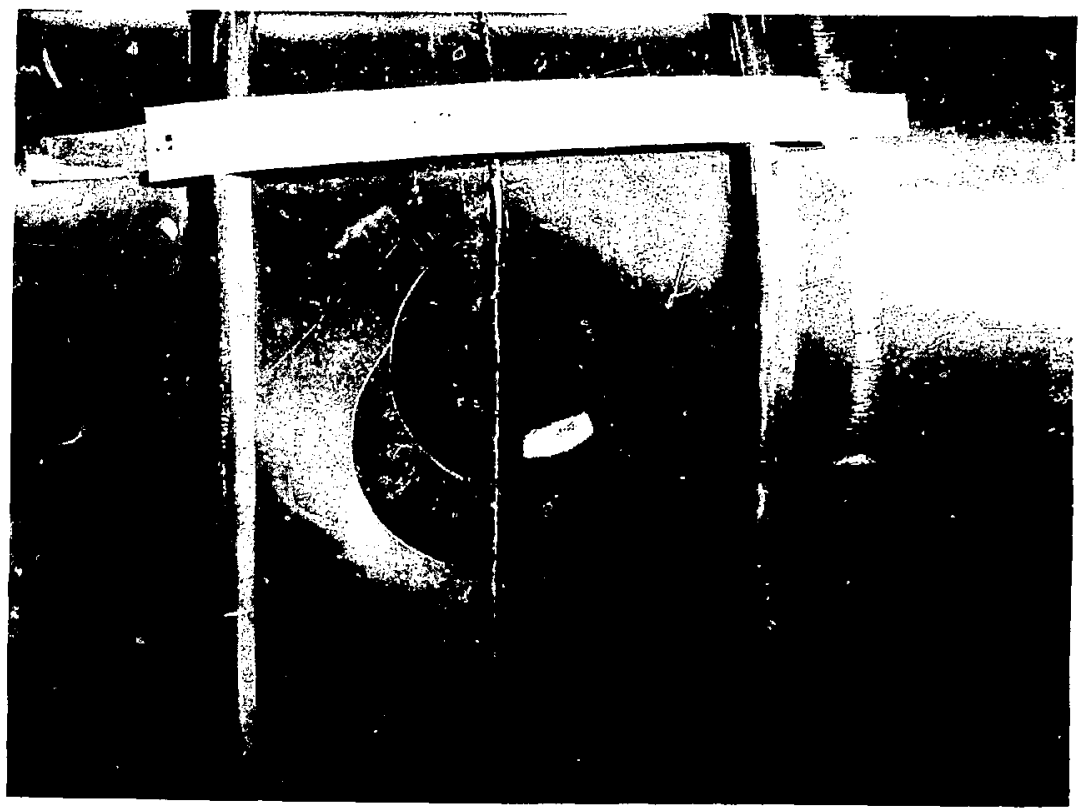

Fig. 16. Impact point for penetration test.

The force on the cover, calculated as in Sec. 2.6.1.3.3, a1 $260 \mathrm{psig}$ is $22,513 \mathrm{lb}$. The total initial bolt tension of $57,600 \mathrm{lb}$ (see Sec. 2.6.1.3.3) is much greater than the 22,513-lb force on the head. Therefore, increasing the containment vessel pressure to 260 psi will not increase the bolt stress.

2.7.3.4 Comparison with Allowable Stresses. The calculated maximum stress of 30,600 psi on the containment vessel flanges is slightly greater than the specified minimum yield of 30,000 psi that is listed in the Pressure Vessel Code (Table UHA-23, p. 182). A more meaningful number is that the 260-psig pressure is $61 \%$ of the 425-psia pressure that was required to cause the primary seal to leak (see Sec. 2.6.1.3.4).

\subsubsection{Water Immersion}

Not applicable. There is no fissionable material in this package.

\subsubsection{Summary of Damage}

A complete package was dropped on a flat surface and on a piston. Then it was heated in a furnace in the manner prescribed in Appendix B of 10 CFR 71. The appearance of the package after the drops is shown in Figs. 8-11. The package was not significantly damaged from these tests. The Celotex insulation was in good condition after the furnace test, as shown in Fig. 13. The temperatire rise in the test was low enough that the tritium permeation and leakage are less than the 10-Ci release linit (see Sec. 4.3).

\subsection{Special Form}

Not applicable. No special form is claimed. 


\subsection{Fuel Rods}

Not applicable. There are no fuel rods in the shipment.

\subsection{THERMAL EVALUATION}

\subsection{Discussion}

The significant thermal design feature of the UC- 609 package is the Celotex insulated shipping drum. A minimum of 2.88 in. of Celotex insulation completely surrounds the containment vessel (primary containment boundary). This thickness of Celotcx adequately protects the package contents during both normal transport and hypothetical accident conditions. Similar packaging, the JPI57S, ${ }^{4}$ has been used for numerous shipments over a period of several years without adverse effects due to heat.

The maximum decay heat load is $48 \mathrm{~W}$. The minimum heat load is zero. Significant results of the thermal analysis follow in Secs, 3.1.1 and 3.1.2.

\subsubsection{Normal Transport Conditions}

Ambient air temperature

$54.4^{\circ} \mathrm{C}$

Maximum containment vessel temperature

$76.0^{\circ} \mathrm{C}$

Maximum storag ${ }^{*}$ vessel temperature

$106.0^{\circ} \mathrm{C}^{*}$

Containment vessel pressure

103 psig

\subsubsection{Hypothetical Accident Conditions}

Assumed maximum ambient temperature before accident

Meusured containment vessel temperature rise during furnace test

$79^{\circ} \mathrm{C}$

Measured temperature difference between ambient air and containment vessel

Measured temperature difference between containment vessel and storage vessel

$29^{\circ} \mathrm{C}$

Calculated containment vessel temperature after hypothetical fire

Calculated storage vessel temperature after hypothetical fire

$170^{\circ} \mathrm{C}^{*}$

Containment vessel pressure

\footnotetext{
"The anelysis of the UC- 609 package is based an the hypothetical escape of tritium from the gorage vessel into the containment vessel. If that occurred, the temperature of the two tritium remains with,n the storage vessel and are included as information only.
} 


\subsection{Summary of Thermal Properties of Materials}

The thermal properties of Celotex and stainless steel are summarized in Table 1 .

Table 1. Summary of thermal properties of materials.

\begin{tabular}{|c|c|c|c|c|c|c|}
\hline \multirow[b]{3}{*}{ Material } & \multirow{3}{*}{$\begin{array}{l}\text { Density, } \\
\mathbf{g} / \mathrm{cm}^{\mathbf{3}}\end{array}$} & \multirow{3}{*}{$\begin{array}{c}\text { Specific heat } \\
\mathrm{cal} / \mathrm{g}\end{array}$} & \multicolumn{4}{|c|}{ Thermal conductivity, cal $/ \mathrm{s}-\mathrm{cm}^{2}-{ }^{\circ} \mathrm{C}$} \\
\hline & & & \multicolumn{4}{|c|}{$\begin{array}{c}\text { Temperature } \\
\end{array}$} \\
\hline & & & $30^{\circ} \mathrm{C}$ & $49.9^{\circ} \mathrm{C}$ & $100^{\circ} \mathrm{C}$ & $150^{\circ} \mathrm{C}$ \\
\hline Celotex ${ }^{8,9}$ & 0.25 & 0.3 & $1.78 \times 10^{-4}$ & $1.89 \times 10^{-4}$ & $2.03 \times 10^{-4}$ & $1.59 \times 10^{-4}$ \\
\hline Stainless steel & 8.0 & 0.12 & \multicolumn{4}{|c|}{0.04 at all temperatures } \\
\hline
\end{tabular}

Heat transfer coefficients and emissivity values ${ }^{10}$ used in the thermal calculations for heat transfer to or from the external surfaces are:

\begin{tabular}{|c|c|c|}
\hline & $\begin{array}{l}\text { Free convection, } \\
\mathrm{cal}^{2} / \mathrm{s}-\mathrm{cm}^{2}-^{\circ} \mathrm{C}\end{array}$ & Emissivity \\
\hline Top (end) surface & $8.000 \times 10^{-5}$ & 0.8 \\
\hline Cylindrical surface & $7.000 \times 10^{-5}$ & 0.8 \\
\hline
\end{tabular}

\subsection{Technical Specification of Components}

Celotex is fiberboard made from sugar cane fibers bonded with organic glue per MIL.F-26862. It is stable to $120^{\circ} \mathrm{C}$.

Cerablanket is a loosely spun alumina-silica refractory material $1 / 2 \mathrm{in}$. thick with a density of $4 \mathrm{lb} / \mathrm{ft}^{3}$. It is stable to $1260^{\circ} \mathrm{C}$.

\subsection{Thermal Evaluation for Normal Conditions of Transport}

\subsubsection{Thermal Model}

3.4.1.1 Analytical Model '!. In making the thermal analysis of the UC-609 package, we assumed that the container was resting on an insulated surface in a vertical position. In this position the solar input on the horizontal top surface depends only on the relative angle between the sun rays and vertical. ${ }^{12}$ This angle varies during the day, but the solar input never goes to zero during the daylight hours. The solar input on the vertical sides depends additionally on the orientation of the surface with respect to the east-west plane. For a specific vertical surface element this angle varies during the day, and the solar input can act ually be zero during daylight. The azimuth angle of the sun, which varies with the time of day, location on the earth, time of the year, and solar declination, also affects the solar flux. ${ }^{13}$ We obtained appropriate relationships between the various angles and the time of day for a position at $30^{\circ}$ north latitude from May to August. We combined these with the vertical cylinder geometry and wrote a small computer code ${ }^{13}$ to evaluate the solar flux incident on the exterior surfaces. At sea level, at the location specified above, the normal solar flux at noon on a clear day (attenuated by the atmosphere) is approximately $356 \mathrm{BTU} / \mathrm{h} / \mathrm{ft}^{2}, 12 \mathrm{We}$ obtained calculations for a specified zone structure of the sides and top from sunrise to sunset. We then used this information as the solar heat input for the thermal model of the structure. The daily total integrated solar flux on the package surface is shown in Fig. 17

We assumed that the sky was clear during daylight and that a cloud cover existed at night. This assumption maximizes the radiation input during the day and minimizes the radiation loss at night. 


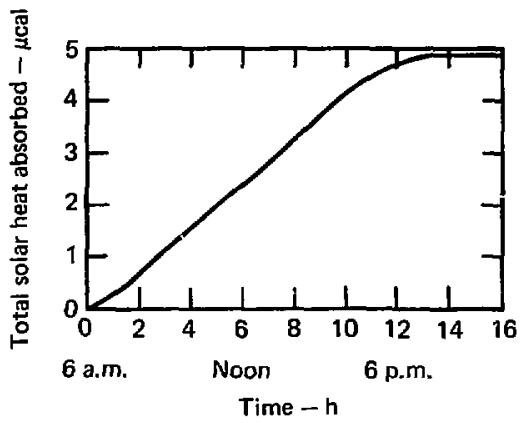

Summary of daily accumulated solar heat

$\begin{array}{lll}\text { Top surface (end) } & \begin{array}{l}3.3 \mathrm{Mcal} \\ \text { Cylindrical walls }\end{array} & \begin{array}{l}1.6 \mathrm{Mcal} \\$\cline { 2 - 2 }\end{array}\end{array}

Fig. 17. Daily solar heat accumblation for entire package.

The air temperature input to the model varied sinusoidally between a maximum of $54.4^{\circ} \mathrm{C}\left(130^{\circ} \mathrm{F}\right)$ and a minimum of $26.7^{\circ} \mathrm{C}\left(80^{\circ} \mathrm{F}\right)$ over repeating $24 \mathrm{~h}$ cycles. The maximum temperature occurred $3 \mathrm{~h}$ after solar noon.

To properly input the solar radiation flux, we used a three-dimensional themal model from the outer surface through the Celotex insulation. We used a two-dimensional thermal model to simulate the inner portion (containment vessel to storage vessel) of the package. Using a two-dimensional model inside the Celotex causes the radial gradients at the inner surface of the Celotex to smooth out to an average uniform temperature in the stainless steel $\because$ vll of the containment vessel. This is reasonable, especially when the aluminum honeycomb that backs up the stainless is considered. The integrated thermal model is shown in Fig. 18. We used a free convection coefficient and a radiation coefficient (see Sec. 3.2) to connect the exposed outer surface of the thermal model to the cycling boundary. (Note: The surface emissivity value used represents that of new, oxide-free, light-color paint.)

There are two major areas of thermal resistance between the outer surface of the package and the internal storage vessel. The dominating thermal resistance is in the Celotex insulation material between the outer steel drum and the containment vessel. In this closed-end cylindrical part, the thermal resistance between the outer surface and the containment vessel depends almost completely on the thermal conductivity coefficient of the Celotex. The thermal resistance of the thin outer metal wall (steel drum) is negligible compared to the thick Celotex and was not used in the thermal model. We made the Celotex thickness in the thermal model equal to the space between the outer drum and the containment vessel. This compensates for any air-gap resistances at the interfaces. The other area of major thermal resistance is between the containment vessel and the storage vessel. The heat path between these two vessels is such a complicated network of conduction, convection, and radiation that the thermal coefficients for the path cannot be reliably calculated. However, using temperature data from an experiment with constant boundary conditions and selected internal-heat-generation rates (see Sec. 3.4.1.2), we determined an equivalent convection coefficient. We used this value to calculate the storage vessel temperature for the condition in which the tritium remains within that vessel.

We used the TRUMP ${ }^{14}$ computer program for the thermal calculations. This Lawrence Livermore Laboratory (LLL)-developed code has been thoroughly checked out and has been used for a number of years at LLL and at other agencies throughout the U.S. and abroad. Figures 19-2l show the results of the computer calculations. 


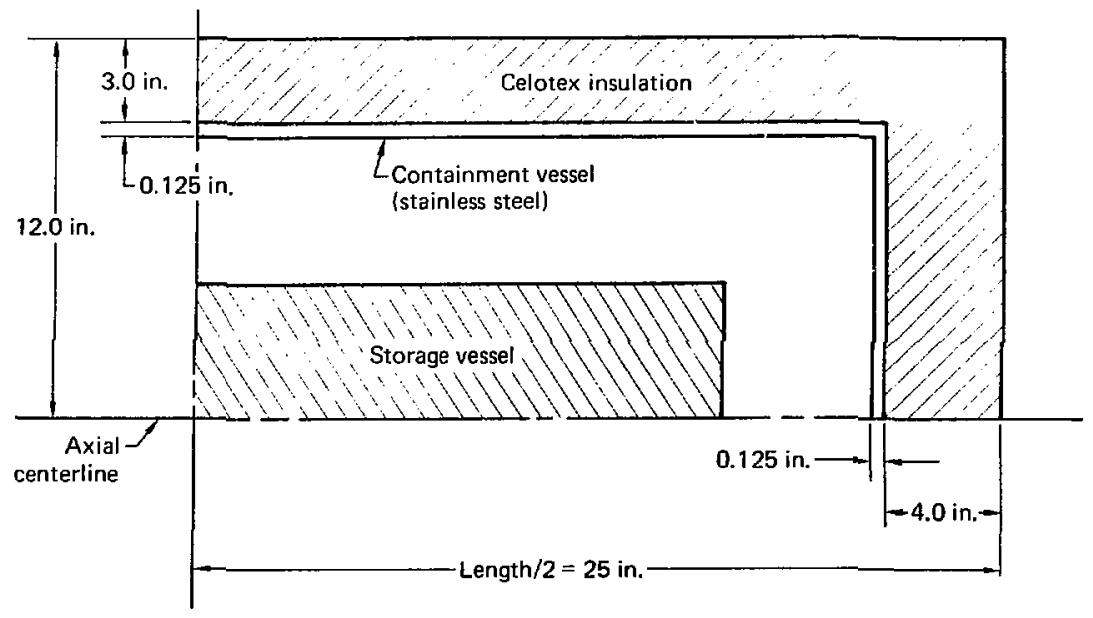

17ig. 18. 'Thermat model for I' ('-609 package.

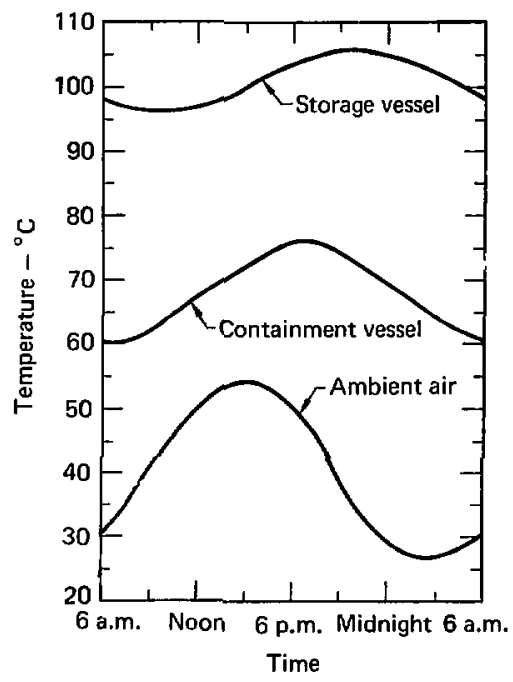

Fig. 19. Duily temperature response of $\mathrm{CCC}-609$ packgge containing $46-W$ heat logd alter exposure to disert environment for three cunsteutive days.

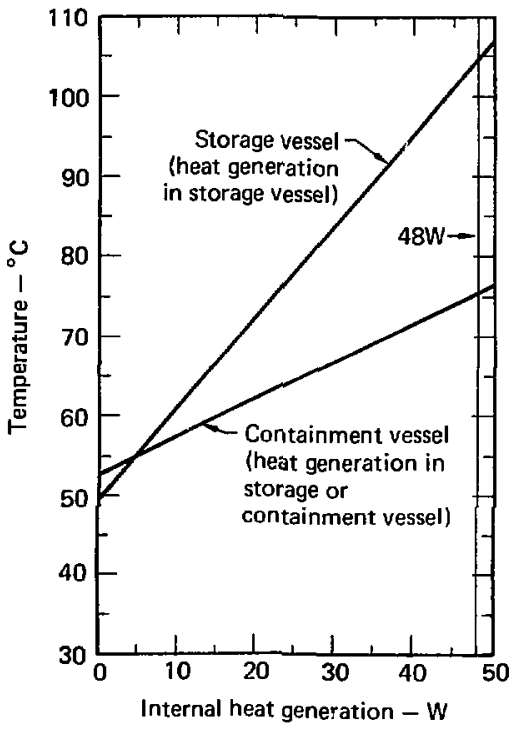

Fig. 20. Vesial temperatures after L'C-609 package has heten thposed to desert enviranment for three consecutive duss. 


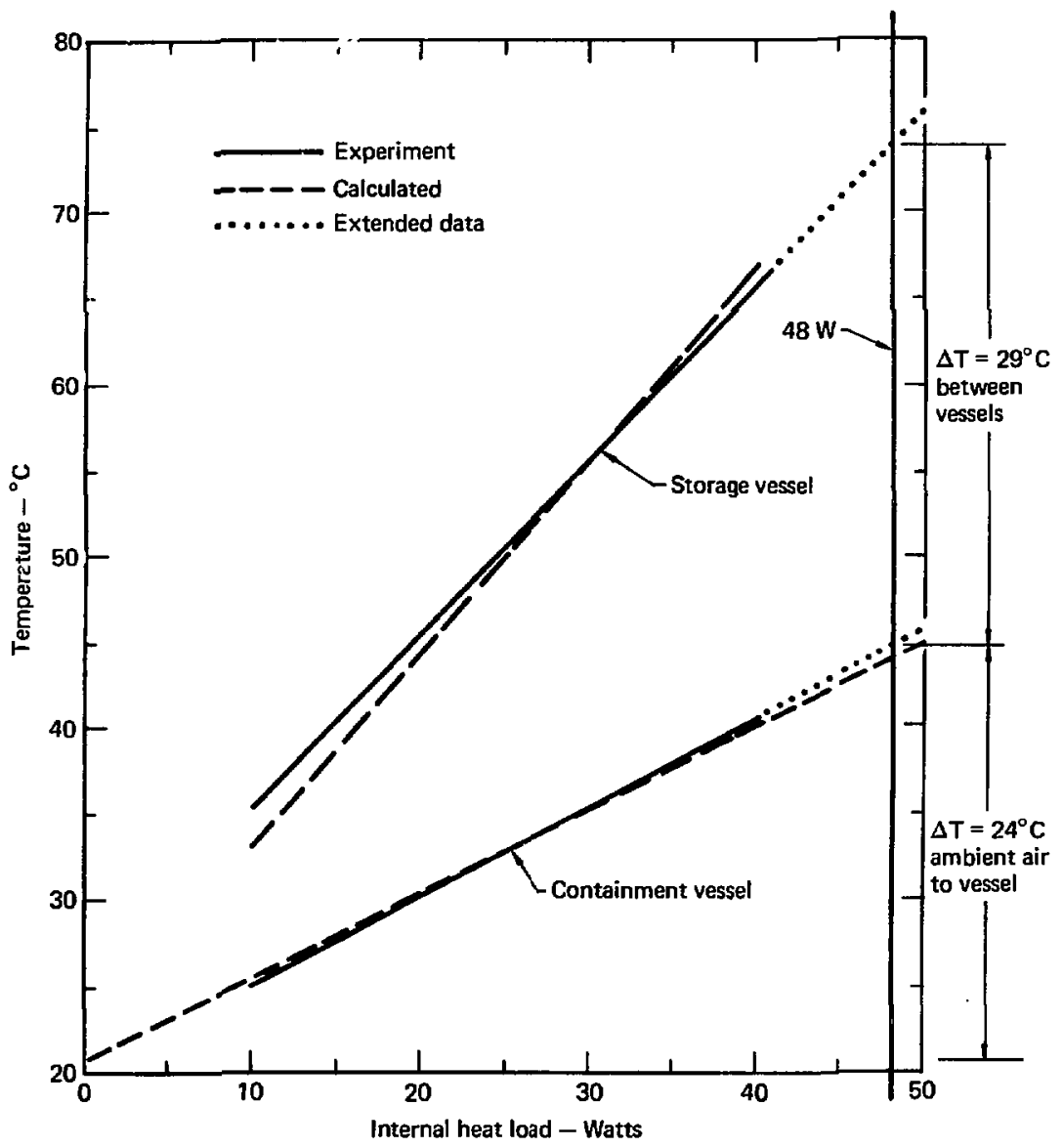

Fig. 21. Model UC-609 stesdy-state tempentures with constant $21^{\circ} \mathrm{C}$ boundary condition.

Figure 19 is the daily temperature fluctuation for both the containment and storage vessels with a $48-W$ heat load. The temperature cycles shown are calculated after three consecutive days in the sun and will repeat daily as long as the boundary conditions remain the same. The storage vessel curve is only for the case in which the tritium remains within that vessel and is included as information only.

Figure 20 shows the maximum daily temperatures for both vessels for internal heat loads from 0 to $50 \mathrm{~W}$. As in Fig. 19, the maximum temperatures are achieved only after three consecutive days in the sun. 
3.4.1.2 Test Model. We tested a prototype package identical to that described in Sec. 1.2.1 to determine the temperature distribution through the package at steady-state conditions under several internal heat loads with constant boundary conditions. The test was run as follows.

We attached a storage vessel containing a resistance wire to the vessel carrier. We installed the storage vessel in the containment vessel, which was in turn put in a Celotex-insulated drum. The volume inside the containment vessel was then filled with helium to 15 psia. We put the assembled package in a temperaturecon:rolled room and applied electrical energy to the resistance wire. Thermocouples recorded the temperatures at numerous points throughout the package. Figure 21 compares the results of the test with computer calculations. The good agreement between the test data and the calculations shows that the thermal model is good and that the values used for conductivity through the Celotex and for convection between the two vessels are accurate.

\subsubsection{Maximum Temperatures}

Figure 19 shows that the maximum temperatures for normal transport condition are $76.0^{\circ} \mathrm{C}$ for the containment vessel with a $48-\mathrm{W}$ heat load and $106^{\circ} \mathrm{C}$ for the storage vessel with the same heat load in the storage vessel.

\subsubsection{Minimum Temperatures}

The UC- 609 package contains no materials harmfully affected by' a temperature of $-40^{\circ} \mathrm{C}$.

\subsubsection{Maximum Internal Pressure}

Maximum initial gas contents of storage vessel

30 moles*

Measured volume of containment vessel

154 litres

Maximum initial pressure in containment vessel

1 atm at $0^{\circ} \mathrm{C}$

Maximum temperature of containment vessel

$76^{\circ} \mathrm{C}(349 \mathrm{~K})$

Calculated volume of $120-\mathrm{lb}$ aluminum

(storage vessel + vessel carrier)

20.0 litres

If all the material in the storage vessel leaks into the containment vessel, the maximum pressure is calculated as follows:

$$
\begin{aligned}
& P_{\text {fin al }}=P_{\text {initial }}+\frac{\text { Number of moles } X \text { yolume of } 1 \text { mole at standard temperature and pressure }}{\text { Volume of container }- \text { volume of contents }} \\
& =1 \mathrm{~atm}+\frac{31.4 \text { moles } \times 22.4 \text { litres } / \text { mole }}{154 \text { litres }-\frac{20 \text { litres }}{20}} \\
& =6.25 \mathrm{~atm} \text { at } 0^{\circ} \mathrm{C}(273 \mathrm{~K}) \text {. } \\
& P \text { at } 76^{\circ} \mathrm{C}=6.25 \times \frac{349}{273}=8 \text { atm } \cong 118 \text { psia }=103 \text { psig. }
\end{aligned}
$$

\subsubsection{Maximum Thermal Stress}

The temperature differentials throughout the package are relatively small and will cause no significant thermal stresses. There is no rigid constraint among the steel, aluminum, and other packaging elements.

\footnotetext{
"Some of the tritium will decuy into helium-3 within one year, thereby increasing the original 30 moles of muterial to 31.4 moles.
} 


\subsubsection{Evalustion of Package Performance}

The package will not be affected by full sunlight and a temperature of $54^{\circ} \mathrm{C}$. because the naximum temperature of the containment vessel will not exceed $76^{\circ} \mathrm{C}$. It is well under the $120^{\circ} \mathrm{C}$ teniperature that affects the Celotex and well within the temperature capabilities of the other package components. The minimum temperature of $-40^{\circ} \mathrm{C}$ will produce no detrimental effects on the packagc. The containment materials are of the type that increase in strength and setain ductility at low temperature.

An internal pressure of 103 psig or an external pressure of 25 psig xill not damage the containment vessel (see Secs. 2.5.2 and 2.6.1.4). Vibration and water spray will not affect the package (see Secs. 2.6.4 and 2.6.5).

Free drops and penetration will have no significant effect on the package (see Secs. 2.6.7 and 2.6.8). The compression test will produce no damage to the package (see Sec. 2.6.9).

\subsection{Hypothetical Thermal Accident Evaluation}

\subsubsection{Thermal Model}

3.5.1.1 Analytical Model. The maximum temperatures achieved during the fite are based entirely an experimental results.

3.5.1.2 Test Model. The model used for both the drop and thermal tests was identical to the packaging described in Sec. 1.2.1. A complete package was dropped on a flat unyielding surface and on a piston, then heated in a heat-treating furnace in the manner prescribed in Appendix B of 10 CFR 71 . The furnace was heated to $1475^{\circ} \mathrm{F}\left(802^{\circ} \mathrm{C}\right)$. The package was inserted for $30 \mathrm{~min}$, then removed and allowed to cool (Fig. 22).

The maximum temperatures that various points inside and outside the containment vessel reached were determined by the conditions of Tempilabels (manufactured by Tempil Corp. of New York, NY). The Tempilabels have indicator spots that permanently change color at specific temperatures. The color change occurs within $1 \%$ of the indicated temperature. Figure 23 shows Tempilabel installation inside containment vcssel.

The puckage tested contained no radioactive materials. The containment vessel was pressurized to approximately 20 psia during both the drops and fire tests.

A separate test was performed to determine the effectiveness of the flange-to-copper-gasket seal when subjected to both pressure and temperatures. The cover and top end of one of the prototype containment vessels were heated to $121^{\circ} \mathrm{C}$ and pressurized internally with helium to $150 \mathrm{psig}$. The maximum leakage across the seal was $3.0 \times 10^{-9} \mathrm{~atm}-\mathrm{cm}^{3} / \mathrm{s}$. The leak rate increased slowly with temperature and decreased to below the sensitivity of the mass spectrometer $\left(5 \times 10^{-11} \mathrm{~atm} \cdot \mathrm{cm}^{3} / \mathrm{s} / \mathrm{div}\right)$ as the package cooled.

\subsubsection{Package Conditions and Environment}

The condition of the package during disassembly after the drops and fire tests is shown in Figs. 24-27. The 100-lb weight, which simulated the storage vessel, crushed the end piece of honeycomb slightly, dented the aluminum tube, and deformed the vessel carrier (sec Figs. 25 and 26). The containment vessel shell was undamaged by any of the six drops. Before and after each drop the containment vessel was pressurized to 120 psia and the metal-to-metal seal leak-tested with a mass spectrometer leak detector. No leakage was observed on a leak detector with sensitivity in the $10^{-9} \mathrm{~atm}-\mathrm{cm}^{3} / \mathrm{s} / \mathrm{div}$ range.

The drop test did not significantly damage the Celotex and therefore was not detrimental to the container during the furnace test. Note in Figs. 24 and 27 the good (uncharred) Celotex adjacent to the containnent vessel.

\subsubsection{Package Temperature Calculations}

Based on Tempilabel data, the maximum temperature reached by the UC-609 containment vessel in the furnace test was as follows, with no cecay heat load:

Outer wall of vessel ( 5 places):

Aluminum ube lining vessel $(2$ places):

greater than $90^{\circ} \mathrm{C}$. less than $104^{\circ} \mathrm{C}$ :

Mock storage vessel (1 place): greater than $71^{\circ} \mathrm{C}$, less than $77^{\circ} \mathrm{C}$ : less than $66^{\circ} \mathrm{C}$.

Note: The Tempilabel sensors change color at specific temperatures. The "greater than" temperatures are the highest value that changed color, and the "less than" temperatures are the next higher sensur that did not change. 


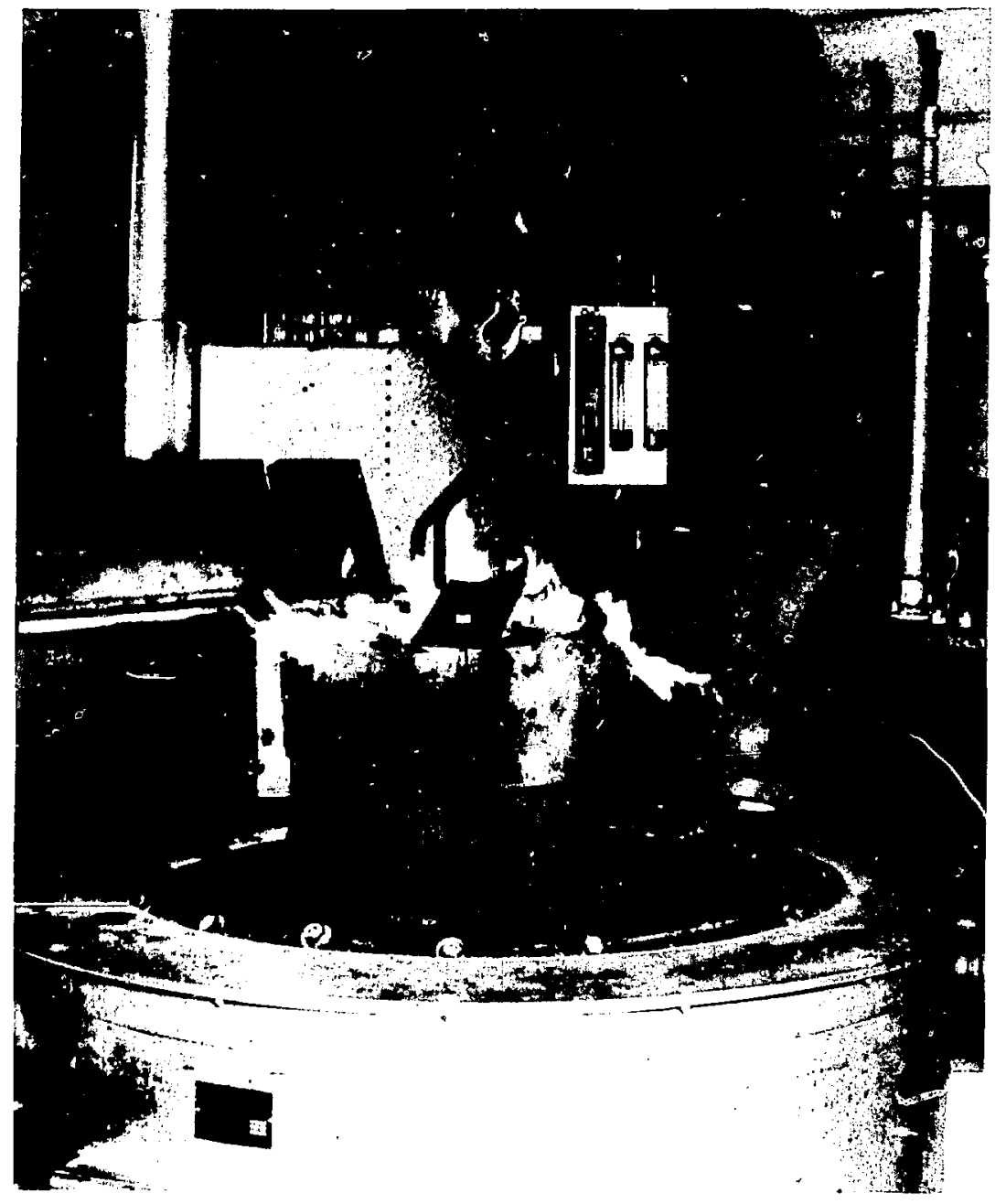

Fig. 22. Package being semored from furngee after 30-min fire test. 


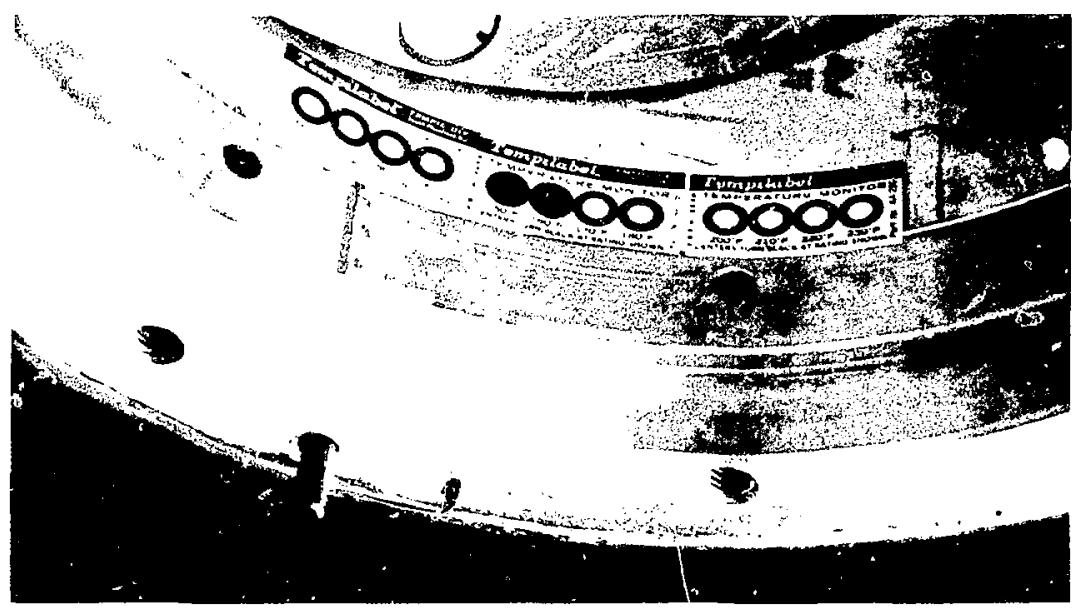

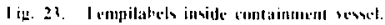

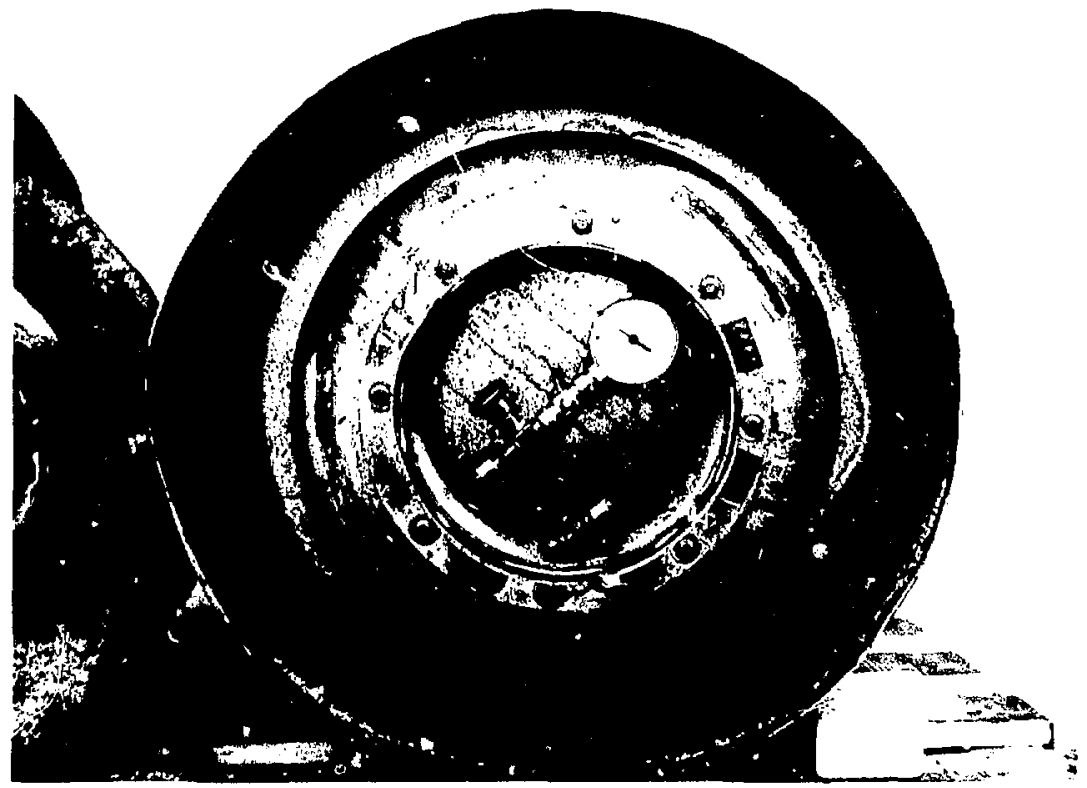

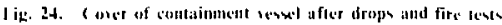




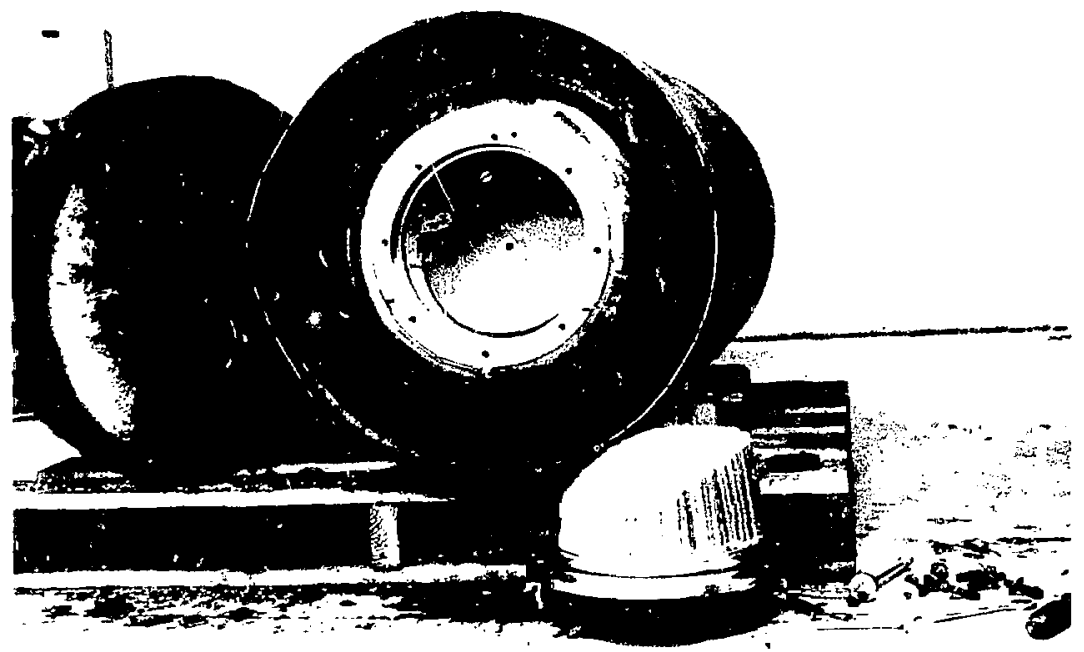

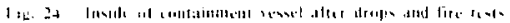

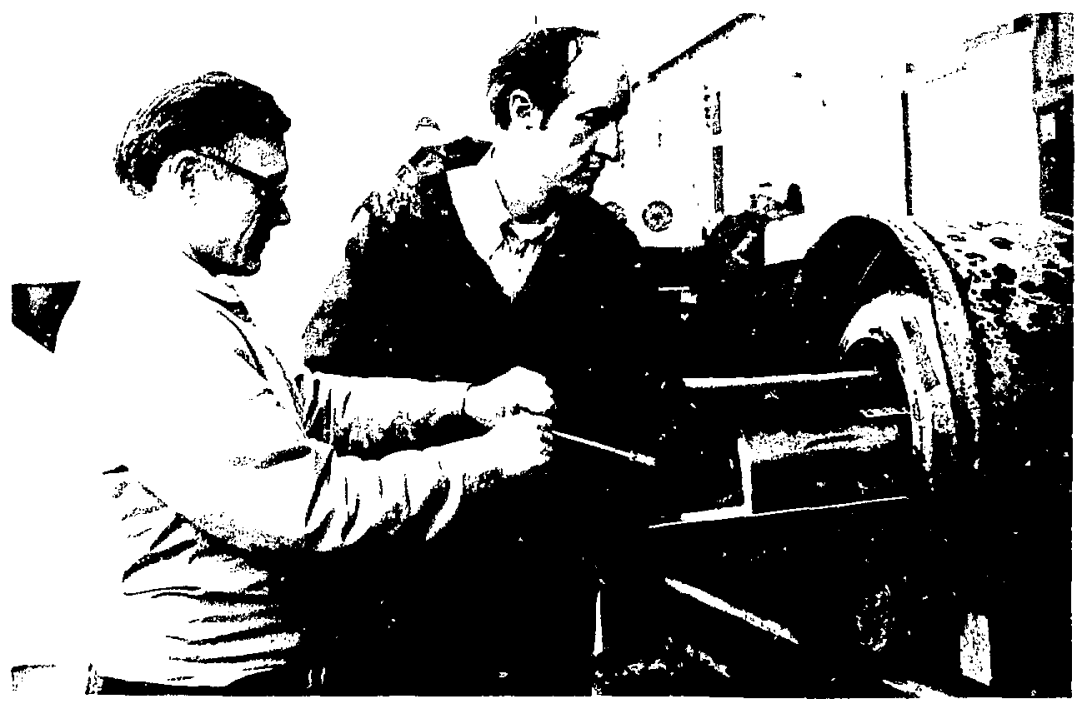

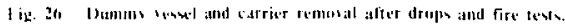




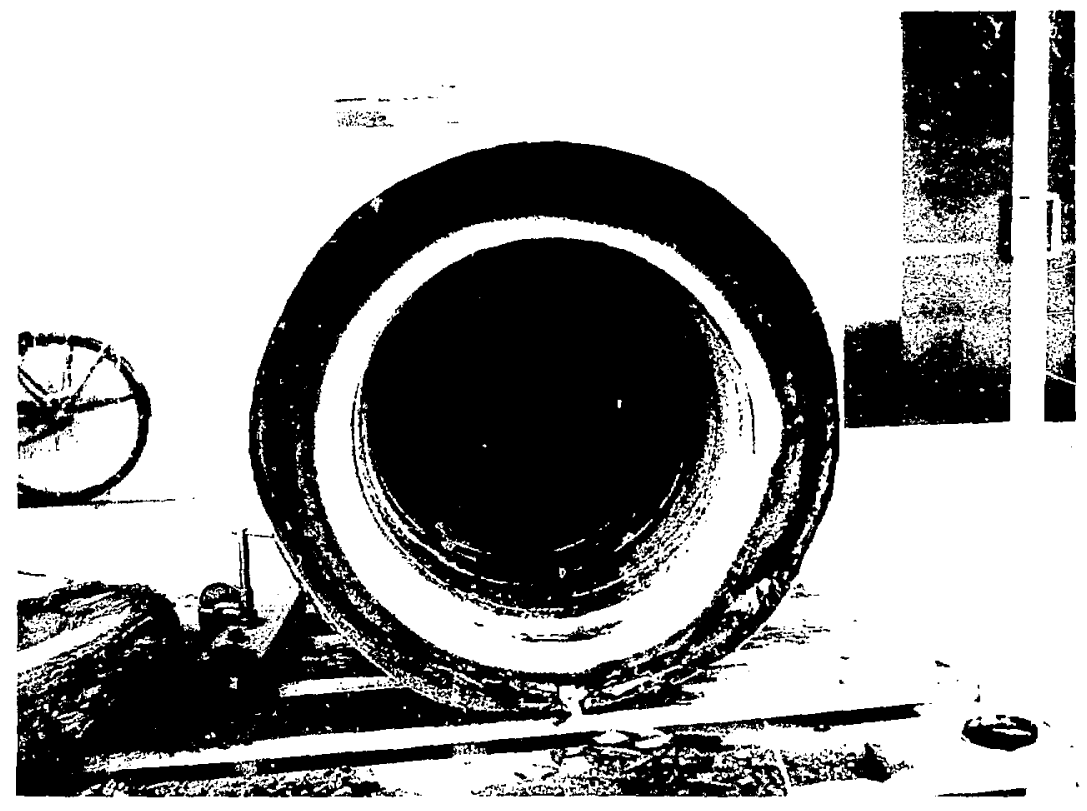

Fig. 27. Insuliation conditisn atter draps and fire tests.

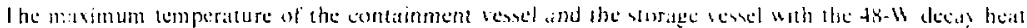
lorad and he cidculated an follons:

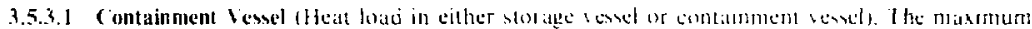
lemperature of the contatmment rensel is a sum of the following:

Asaumed muximum ambient temperature belore fire

$3 x^{\circ}($

Measured conlainment vestel temperature rise durme fire $\left(104^{\circ} \mathrm{C}-25^{\circ} \mathrm{C}\right)$

$79 \%$

Nedsured temperature diflerence between ambient

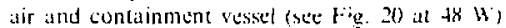

Maximum emperature of containment vessel

$$
\frac{34^{\circ} \mathrm{C}}{1+1^{\circ} \mathrm{C}}
$$

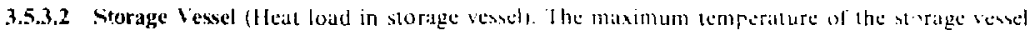
with the heal load in that vessel is the sum ol the maxim um iemperature of the containment vesucl, deicrmined abo'e. plus the measured lemperature difference between the emtainment and storage vessels.

M iximum containnem vessel icmperature

$1+1^{\circ} \mathrm{C}$

Temperause difference between containment vessel and $i l o$ dge vessel (Fig. 20 at $4 \times W$ ')

Mixi:num temperature of storage vesset

$$
-\frac{29^{\circ} \mathrm{C}}{170^{\circ} \mathrm{C}}
$$

\subsubsection{Maximum Itdernal Pressure}

From Sec. 3.4.4, the maxinum pressure within the contailument vessel with 30 moles of gas at $0^{\circ} \mathrm{C}$ is 6.25 alm. 


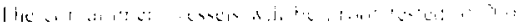

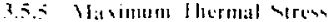

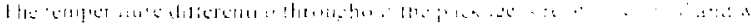

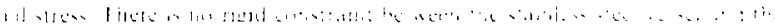

1.is $1:$

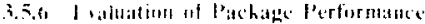

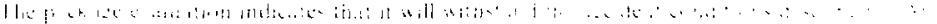

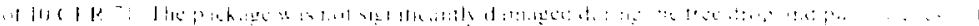

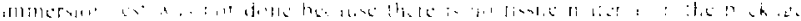

la

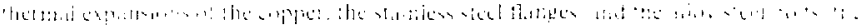

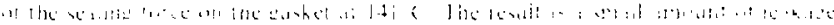

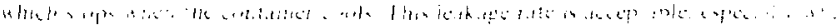

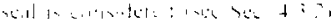

\section{$4.110 \times 111 \backslash 11) 1$}

\section{1 i ontainment Boundars}

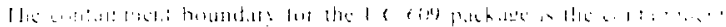

\subsection{1 ( antaimunent lessel}

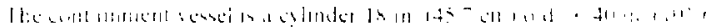

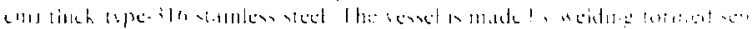

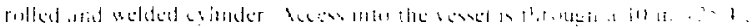

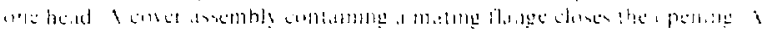

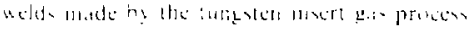

\subsection{2 ( IIItainment V'enetration}

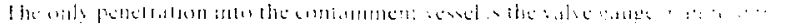
warubl:

\subsection{3 heals and 31 uld}

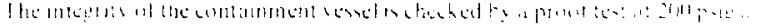

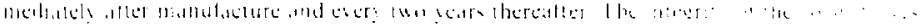

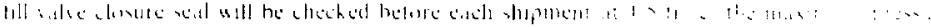

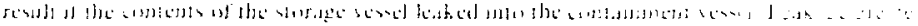

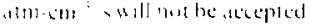

\subsection{4 ( lovure}

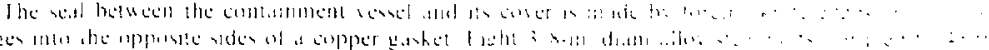

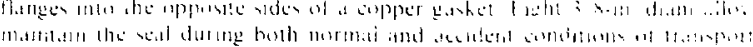

\subsection{Requirements for Vornal Conditions of Transport}

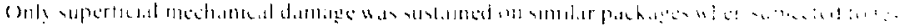

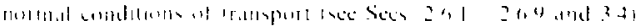




\subsubsection{Release of Radioactive Material}

Gaseous tritium permeates the material of construction at rates dependent upon pressure, temperature, concentration, and other factors. Therefore, the requirement in 10 CFR 71.35 (a) (i) that there be no release from the containment vessel during normal conditions of transport is considered to be satisfied by complians * with International Atomic Encrgy Agency (IAEA) regulations, paragraph 230 (a). This regulation restricts the loss of contents to no more than Factor $A_{2} \times 10^{-6} / \mathrm{h} .{ }^{15}$ Factor $A_{2}$ for tritium equals $1000 \mathrm{Ci}$ (Ref. 15, Table VIII), and the permissible release is

$$
\left(1000 \times 10^{-6} \mathrm{Ci} / \mathrm{h}\right) \times\left(\frac{1}{3600 \mathrm{~s} / \mathrm{h}}\right) \times\left(\frac{1}{2.57 \mathrm{Ci} / \mathrm{cm}^{3}}\right)=1.08 \times 10^{-7} \mathrm{~cm}^{3} / \mathrm{s}
$$

4.2.1.1 Permeation through Stainless Steel. Steady-state permeation through the containment vessel wall is assumed to have been reached when

$$
\left(\frac{\mathrm{D}}{\mathrm{L}^{2}}\right)=0.45 \quad(\text { Ref. 16) }
$$

where

$$
\begin{aligned}
& t=\text { time in } \mathrm{s}, \\
& \mathrm{L}=\text { thickness of diffusion barrier }=0.317 \mathrm{~cm}(0.125 \mathrm{in.}), \\
& \left.D=\text { diffusion rate in } \mathrm{cm}^{2} / \mathrm{s}=4.7 \times 10^{-3} \mathrm{e}^{-(12900 / \mathrm{RT})} \text { (Ref. } \mathrm{L} 7\right), \\
& \mathrm{R}=1.987 \mathrm{cal} / \mathrm{mole} \mathrm{K}, \\
& \left.\mathrm{T}=\text { temperature }=349 \mathrm{~K} .\left(76^{\circ} \mathrm{C}\right) \text { (see Sec. } 3.1 .1\right) .
\end{aligned}
$$

The above relationship shows that the time to reach steady state is $10^{4}$ days. Since the time for nornal transport is considered to last not more than 30 days, the nonsteady-state situation applies. The tlowrate through the container wall for very short times can be calculated asing the following equation:

$$
\ln F=\ln \left[2 C_{1}\left(\frac{D}{\pi t}\right)^{1 / 2}\right]-\frac{L^{2}}{4 D t} \quad(\operatorname{Ref} .16),
$$

where

$$
\begin{aligned}
& C_{1}=\text { surface concentration }=C \sqrt{\mathrm{P}} \text { atm }-\mathrm{cm}^{3} / \mathrm{cm}^{3} \text { (Ref. 17), } \\
& \mathrm{C}=! .28 \mathrm{e}^{-(1400 / \mathrm{RT})} \mathrm{atm}-\mathrm{crn}^{3} / \mathrm{atm}^{1 / 2}-\mathrm{cm}^{3} \\
& P=\text { internal pressure }=8.0 \mathrm{~atm}, 118.0 \text { psia (see Sec. } 3.4 .4 \text { ), } \\
& T=349 K \text { (see Sec. 3.1.1), } \\
& \mathrm{D}=\text { diffusion rate in } \mathrm{cm}^{2} / \mathrm{s}=4.7 \times 10^{-3} \mathrm{e}^{-(12900 / \mathrm{RT})} \text {, } \\
& \mathrm{R}=1.987 \mathrm{cal} / \text { mole } \mathrm{K} \text {, } \\
& \mathrm{L}=\text { thickness }=0.317 \mathrm{~cm} \text {, } \\
& \mathrm{F}=\text { flowrate, atm-cm }{ }^{3} \text { of tritium }\left(\mathrm{T}_{2}\right) / \mathrm{s} / \mathrm{cm}^{2} \text {. }
\end{aligned}
$$

Using a containr : nt vessel area of $1.8 \times 10^{4} \mathrm{~cm}^{2}$ (a right circular cylinder 18 in. diam $\times 40$ in. long), the flow through the vessel wall at 30 days is less than $10^{-100} \mathrm{~atm}-\mathrm{cm}^{3} \mathrm{~T}_{2} / \mathrm{s}$, which is far below the allowable 1.08 $\times 10^{-7} \mathrm{~atm}-\mathrm{cm}^{3} \mathrm{~T}_{2} / \mathrm{s}$. Therefore, there is no problem with permeation through the contairisent vessel walls during normal transport.

4.2.1.3 Permeation through Copper Gasket. Because permeation of tritium through copper is less than through stainless steel, and the area for permeation through copper is so much smaller, the diffusion through the gasket is too small to have an effect.

4.2.1.3 Total Release for Normal Transpart. The total release during transport is the sum of permeation through the stainless steel and the copper gasket plus any leakage.

Permeation through stainless steel $<1 \times 10^{-100} \mathrm{~atm}-\mathrm{cm}^{3} \mathrm{~T}_{2} / \mathrm{s}$

Permeation through copper gasket $<<\mathrm{I} \times 10^{-100} \mathrm{~atm}-\mathrm{cm}^{3} \mathrm{~T}_{2} / \mathrm{s}$

Leakage past gasket (see Sec. 7.1 ) $<1 \times 10^{-8} \mathrm{~atm}-\mathrm{cm}^{3} \mathrm{~T}_{2} / \mathrm{s}$

Leakage from total vessel (see Sec. 8.1.3) $<1 \times 10^{-8} \mathrm{~atm}-\mathrm{cm}^{3} \mathrm{~T}_{2} / \mathrm{s}$ 
The total release from all the above is less than $2 \times 10^{-8} \mathrm{~atm}-\mathrm{cm}^{3} \mathrm{~T}_{2} / \mathrm{s}$, which is less than the allowable $1.08 \times 10^{-7} \mathrm{~atm}-\mathrm{cm}^{3} \mathrm{~T}_{2} / \mathrm{s}$; therefore, the normal transport mode is acceptable.

\subsubsection{Pressurization of Containment Vessel}

Although tritiun decay produces two volumes of helium for each volume of tritium lost, the increase in pressure is negligible because of the short duration of a shipment ( 30 days or less).

The gases within the containment vessel cannot ignite or explode because no oxygen is present. The container volume is pumped out and backfilled with helium before each shipment.

\subsubsection{Coolant Contamination}

There is no coolant in the UC-609 package.

\subsubsection{Coolant Loss}

Not applicable.

\subsection{Containment Requirements for the Hypothetical Accident Conditions}

The performance of the package during the hypothetical accident tests is given in Secs. 2.7.1 - 2.7.5. The results indicate that the package can withstand the mechanical abuse and fire that these tests comprise.

\subsubsection{Fission Gas Products}

Not applicable. There are no fission gas products in this package.

\subsubsection{Release of Contents}

For purpose of analysis the accident conditions $141^{\circ} \mathrm{C}$ and $9.10 \mathrm{~atm}$ (see Secs. 3.5.3.1 and 3.5.4) are considered to exist for $12 \mathrm{~h}$. (This is conses vative hecause the regulations permit artificial cooling of the package after $3 \mathrm{~h}$.) During and as a result of the hypothetical accident conditions, the regulations $[10 \mathrm{CFR} 71.36$ (a) (2). ii] specify a maximum release of $10 \mathrm{Ci}$ for Group IV radionuclides. No leak rates are specified for tu itium in Group VII; however, tritium is also a Group IV material, so the Group IV leak rate is used.) The release rate required to lose $10 \mathrm{Ci}$ in $12 \mathrm{~h}$ is $9 \times 10^{-5} \mathrm{~atm}-\mathrm{cm}^{3} \mathrm{~T}_{2} / \mathrm{s}$.

4.3.2.1 Permeation through Stainless Steel. The time required to reach steady-state permeation through the containment vessel wall at a temperature of $141^{\circ} \mathrm{C}$ was found to be approximately 700 days. Since the time of concern is much shorter, we must do a short-time calculation as in Sec. 4.2.1.1. The flowrate then becomes less than $1.8 \times 10^{-96} \mathrm{~atm}-\mathrm{cm}^{3} \mathrm{~T}_{2} / \mathrm{s}$ after $12 \mathrm{~h}$ at $141^{\circ} \mathrm{C}$.

4.3.2.2 Permeation through Copper Gasket. The permeation through the copper gasket is less than through the steel, so it is negligible in this case.

4.3.2.3 Total Release for Accident Conditions. For the accident condition, total release is the sum of all permeation and leaks.

Permeation through stainless steel $<1 \times 10^{-95} \mathrm{~atm}-\mathrm{cm}^{3} \mathrm{~T}_{2} / \mathrm{s}$

Permeation through copper gasket $<<1 \times 10^{-95} \mathrm{~atm}-\mathrm{cm}^{3} \mathrm{~T}_{2} / \mathrm{s}$

Leakage past gasket (see Sec. 7.1$)<I \times 10^{-8} \mathrm{~atm}-\mathrm{cm}^{3} \mathrm{r}_{2} / \mathrm{s}$

Leakage total vessel (see Sec. 8.13) $<1 \times 10^{-8} \mathrm{~atm}-\mathrm{cm}^{3} \mathrm{~T}_{2} / \mathrm{s}$

The total release from alt of the above is less than $2 \times 10^{-8} \mathrm{~atm}-\mathrm{cm}^{3} \mathrm{~T}_{2} / \mathrm{s}$, which is much less than the 9 $\times 10^{-5} \mathrm{~atm}-\mathrm{cm}^{3} \mathrm{~T}_{2} / \mathrm{s}$ that is allowable. Therefore, the containment vessel meets the requirements for the assumed accident conditions.

\subsection{SHIELDING EVALUATION}

It is unnecessary to evaluate shielding for this package, since the radioactive material (tritium) is a weak beta emitter and gives off no penetrating radiation, and the resultant bremsstrahlung radiation is insignificant. 


\subsection{Discussion and Results}

Not applicable.

\subsection{Source Specification}

Not applicabie.

\subsection{Model Specification}

Not applicable.

\subsection{Shielding Evaluation}

Not applicable.

\subsection{CRITICALITY EVALUATION}

The radioactive material (tritium) in this package is not fissile. Therefore, nuclear criticality safety is of no concern in the shipment of this package.

\subsection{Discussion and Results}

Not applicable.

\subsection{Package Fuel Loading}

Not applicable.

\subsection{Model Specification}

Not applicable.

\subsection{Criticality Calculations and Experiments}

Not applicable.

\subsection{Critical Benchmark Experiments}

Not applicable. 


\subsection{OPERATING PROCEDURES}

\subsection{Procedure for Loading the Package}

The model UC-609 package is loaded per END 77-21. An empty contaimnent vessel is visually inspected for dimage with special attention to ussure that

- the internal cavity is clean and free of foreign material,

- the O-ring and metal gasket sealing surfaces are clean and undamaged,

- the valves and the gauge on the cuver are in good condition.

A tritium-loaded storage vessel with a leak rate of less than $1 \times 10^{-9} \mathrm{~atm}-\mathrm{cm}^{3} / \mathrm{s}$ is mounted on the vessel carrier. That assembly is put into the containment vessel, and the cover is installed with a new copper gasket.

The containment vessel is evacuated, then pressurized with helium through the fill valve to a minimum of $11 / 2$ times the pressure that would occur if the storage vessel vented into the containment vessel. (The maximum test pressure is 170 psia for a storage vessel containing 30 moles of gas.) A mass spectrometer leak detector is connected to the open leak-test valve, and the leak rate across the copper gasket is measured. To be acceptable, the leak rate must be less than $1 \times 10^{-8} \mathrm{~atm}-\mathrm{cm}^{3} / \mathrm{s}$. Upon completion of the test, the pressure is vented to atmospheric and both valves are closed and capped. The valve caps and cover bolts have provisions for lockwire. Tamper seals may be installed if required for in-plant control.

The shipping drum is opened and inspected for significant defects or damage. The sealed cuntainment vessel is then placed within the overpack, the insulation cover is installed. and the Cerablanket insulation is put in place. Finally the drum cover is installed. The cover is held on by eight special brackets, which are sccured by eight hults. Two of the cover retaining bolts are sealed with tamper seals. After attachment of the necessary labels, the sealed overpack is ready for shipment.

\subsection{Procedure for Unloading the Package}

After monitoring the exterior of the package for radioactivity, the seals on the lid retaining bolts are broken and the lid and insulation cover are removed. A sample of the gas within the container is monitored by metering through the fill valve. When the gas is ascertained to be "clean," the bolts can be removed and the cover lifted. Removal of the storage vessel from the carrier completes the unloading procedure.

\subsection{Preparation of an Empty Package for Transport}

No special procedures are required to prepare an emply model UC-609 package for transport. Any container that becomes radioactively contaminated will be removed from service.

\subsection{ACCEPTANCE TESTS AND MAINTENANCE PROGRAM}

\subsection{Acceptance Tests}

\subsubsection{Visual Inspection}

Upon receipt, the containment vessel will be inspected for bulges, dents, mars, or other obvious defects. The shipping packaging will be inspected for obvious damage such as cracks or voids in the insulation or damage to the drum. The acceptance criteria for the various components and assemblies that make up the package are specified on the applicable fabrication drawings. Noncomplying parts are to be rejected for rework or replacement.

\subsubsection{Structural and Pressure Tests}

Each containment vessel is to be proof tested at 200 psig with helium for a minimum of $4 \mathrm{~h}$ before its first use and every 2 years thereafter. Before each shipment, the container is proof tested at 1.5 times the maximum pressure possible during the shipment. 


\subsubsection{Leak Testing}

Each containment vessel will be leak tested with helium before its first usage at 150 psig. Maximum leakage allowable is less than $1 \times 10^{-8} \mathrm{~atm}-\mathrm{cm}^{3} / \mathrm{s}$.

Before each shipment, the primary seal will be leak tested at 1.5 times the maximum pressure that could occur during the shipment. Maximum leakage allowable is less than $1 \times 10^{-8} \mathrm{~atm}-\mathrm{cm}^{3} / \mathrm{s}$.

\subsubsection{Component Tests}

8.1.4.1 Valves. The valves on the containment vessel cover will be checked for leakage during shipping preparations (see Secs. 7.1 and 8.1.3).

To qualify the fill and leak-test valves for usage at temperature, three of each were pressurized to $105 \mathrm{psig}$ at $121^{\circ} \mathrm{C}$. No leakage was detected on a mass spectrometer with a sensitivity of $1.9 \times 10^{-11} \mathrm{~atm}-\mathrm{cm} / 3 / \mathrm{s} / \mathrm{div}$.

8.1.4.2 Gaskets. The primary and secondary cover seals will be tested prior to each use hy vacuum and pressure tests (see Secs. 7.1 and 8.1.3).

To qualify the primary and secondary seals at temperature, the following test was iun. The cover area of a prototype containment vessel was heated to $121^{\circ} \mathrm{C}$ and then pressurized to $150 \mathrm{psig}$. A maximum leakage of $3.1 \times 10^{-9} \mathrm{~atm}-\mathrm{cm}^{3} / \mathrm{s}$ was observed across the primary seal. This leak stopped as the temperature decreased. The secondary seal held the vacuum required for the use of a mass spectrometer. The above leakage can be tolerated (see Sec. 4.2.2).

8. 1.4.3 Miscellaneous. The bourdon tube gauge that is part of the fill valve manifold will be leak tested before each shipment in the same manner as the valves and gaskets. The high-temperature test of the gaskets described in Sec. 8.1.4.2 included the valves and the gauge that are on the containment vessel cover. No leakage from either the gauge or the valves was found.

\subsubsection{Test for Shielding Integrity}

Not applicable.

\subsubsection{Thermal Acceptance Test}

The thickness and condition of the Celotex insulation will be checked as the packages are recejved. No further testing is necessary, based on results found during development of this packaging. ${ }^{8}$

\subsection{Maintenance Program}

\subsubsection{Structural and Pressure Tests}

The containment vessels are to be pressure tested prior to each shipment (see Sec. 8.1.3). The pressure is measured on a Heise gauge, which is accurate to \pm 1 psi.

\subsubsection{Leak Tests}

The containment vessel will be leak tested at the same time it is pressure tested prior to each shipment. The sensitivity of the tests is the sensitivity of a mass spectrometer leak detector, typically between $1 \times 10^{-10}$ and $1 \times 10^{-9} \mathrm{~atm}-\mathrm{cm}^{3} / \mathrm{s}$.

\subsubsection{Subsystems Maintenance}

Not applicable. There are no subsystems requiring periodic maintenance.

\subsubsection{Valves, Rupture Disks, and Gaskets on Containment Vessel}

The valves will be tested before each usage and replaced as necessary. A new copper gasket is to be used for each shipment. The O-ring will be inspected before each use and replaced as necessary.

\subsubsection{Shielding}

Not applicable.

\subsubsection{Thermal}

The insulation and drum are to be inspected for moisture, voids, or cracks prior to loading the containment vessel into the package. Damaged items will not be used for shipment. 


\subsubsection{Miscellaneous}

The containment vessel is to be retested at 200 psig every two years.

\subsection{QUALITY ASSURANCE REQUIREMENTS}

\subsection{General Information}

The quality assurance functions for the UC-609 package are the inspection tests and certifications that are required during fabrication and over the entire life of the package (see Fig. 28).

The most insportant criterion that the package must meet if it is to operate safely and successfully is that the containment vessel be leaktight and structurally sound. That criterion is met as follows:

- The drawings require that the manfacturer provide certification of the materials used for structural components. That certification along with the dimensional inspection data is reviewed by the project engineer before the components can be used in assemblies. Reference: END 77-20, Components Inspection Form.

- Structural welds are made and inspected per the requirements of the ASME Pressure Vessel Code. The nondestructive test reports plus other assembly dat a is reviewed by the project engineer before a package is released for use. Reference: END 77-19, Assembly and Fabrication Record.

- Every completed containment vessel is pressure tested at 200 psig and leak tested at 150 psig before the first usage and every two years thereafter. Reference: END 77-914, Containment Vessel Safety Note.

- Before each shipment the copper gasket seal is leak tested at 1.5 times the maximum pressure that would occur if all the gas in the shipment were released into the containment vessel. Reference: END 77-21, Packing and Test Procedure.

A second important criterion for successful operation is that the package nol deteriorate with use. That criterion is achieved as follows:

- All structural parts that may come in contact with hydrogen during shipping are made from materials that are not affected by hydrogen (type-316 stainless steel and oxygen-free, high-conductivity copper).

- Before each shipment, the entire package is completely inspected and any damaged or nonconforming components are replaced. References: END 77-21, Packing and Test Procedure; END 77-22, Packing Check I.ist.

- Every two years the containment vessel is completely inspected and pressure tested by a group completely independent of the users.

The third important criterion for successful use is that the package must be used correctly and within the design linits that have been approved. This is accomplished by having all packing, testing. and maintenance operations performed according to written procedures with a check list that covers each step of the procedure. All operations ire performed by trained technicians. A qualified professional (engineer, chemist, health physicisl, etc.) inspects and approves all work.

\subsection{Organization}

Mechanical Engineering Department management is responsible for quality assurance of the UC-609 package at LLL. Quality assurance is an integral part of the design-fabrication-operational systerr in eich working engincering group at LLL. This system also includes an independent check at all organnizational levels.

Personnel in the various grotips shown on the organization chart (Fig. 29) have been trained and havi atquired expertise in their respective fields.

Fubrication, shipping, and testing operations are performed with approved procedures.

\subsection{Quality Assurance Program}

\section{$\because 3.1$ Procedures}

The fabrication and testing of the UC-609 shipping package is covered by a written procedure. Reference: END 77-16. Fubrication Specification. Quality assurarce is also incorporated into the operating and maintenance procedures. 


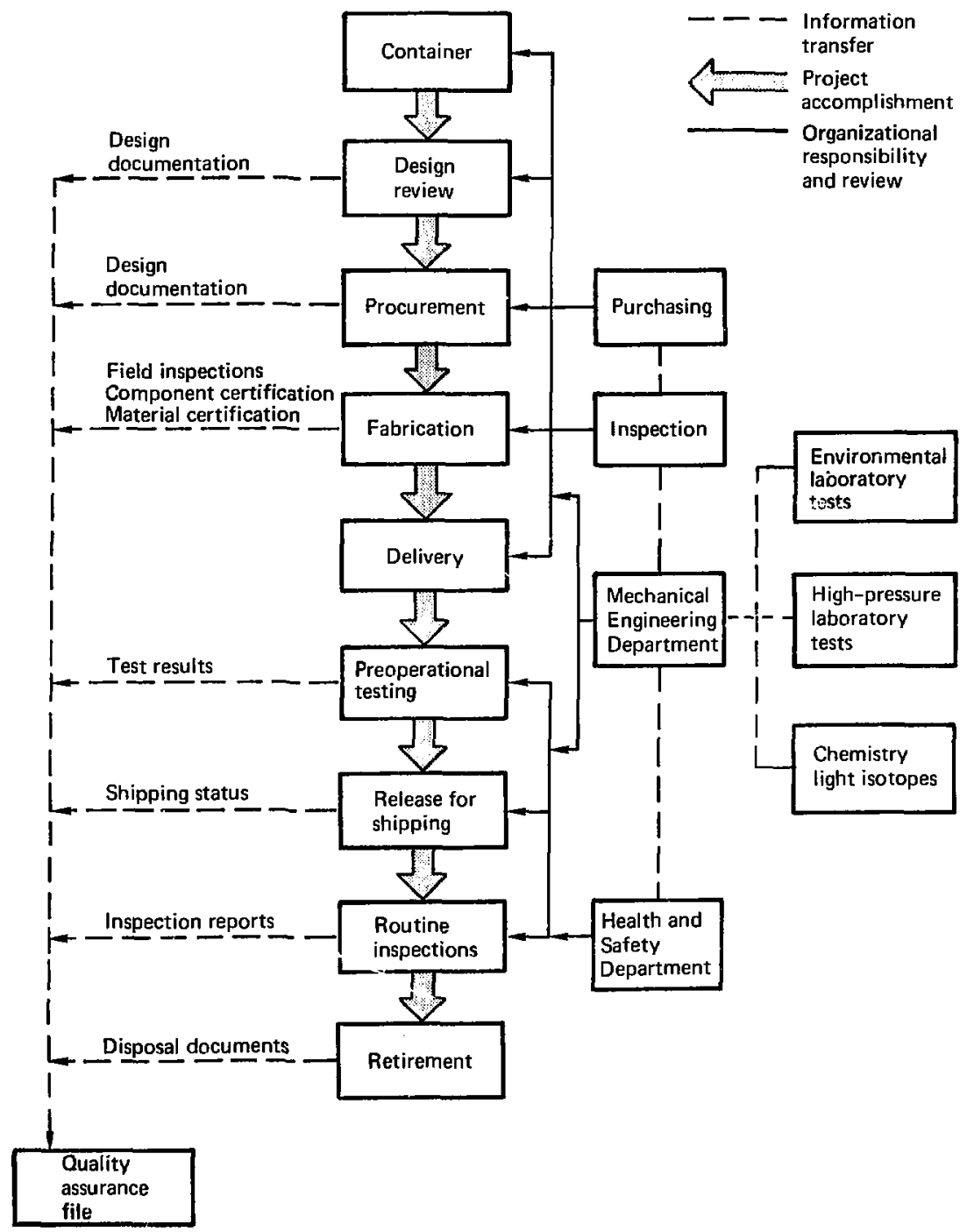

Fig. 28. Inspectlon tests and certificates requited by quality assurance program for UC'-609 package. 


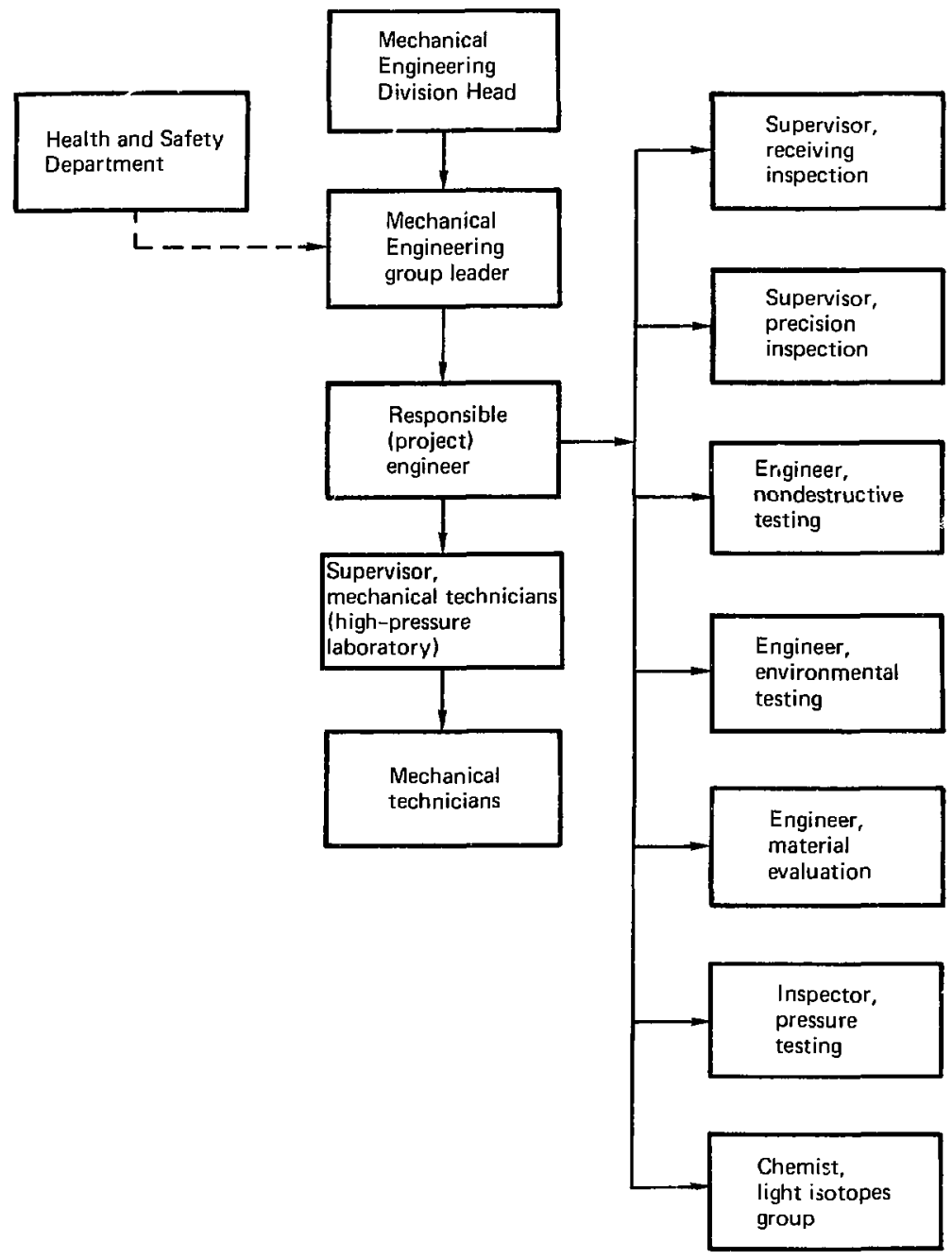

Fig. 29. Orgunisation chart for L.I.L. Mechanical Engineering Ilepartment. 


\subsubsection{Approvals}

Quality assurance functions are incorporated into the fabrication and operating procedures. The procedures are reviewed and approved by the engineering group leader.

\subsubsection{Safety-Related Items}

Safety-related or " $Q$ items" are the containment vessel, the insulation, and the shipping drums. The "non-Q item" is the storage vessel.

\subsubsection{Training}

The mechanical technicians that will perform the various operations inzolved in fabricating. testing, and shipping are trained by mechanical engineers using approved procedures.

\subsection{Design Review}

The UC-609 shipping package has been independently reviewed by the Separations and the Separations Technology Departments of the Savannah River Plant of E. 1. duPont de Nemours and Co.

\subsection{Procurement Document Control}

The component and assembly drawings are the procurement documents that specify the minimum acceptable quality.

\subsection{Instruction, Procedures, and Drawings}

All fabrication, testing, shipping, and maintenance are performed in accordance with written procedures. Activities that affect the quality of a shipment are certified on "use every time" procedures or certification sheets.

Refer to $\mathrm{Ch}$. 7.0, Operating Procedures, for specific information relating to procedures governing activities with this packaging.

\subsection{Document Control}

Onerating procedures and drawings are given an independent review by the engineuring group supervisor and by the technician group supervisor. The reviewers thoroughly understand that quality assurance is an integral part of the design, construction, and operations at LLL.

Documents to be controlled are LLL drawings and procedures. Drawing and procedure changes must be approved by the engineering group leader. It is his responsibility to verify that any proposed change will not violate the substance of the Safety Analysis Report on Packaging. The Mechanical Engineering Department records section maintains a file of the latest revisions. The master files reflect the latest revisions and is updated as soon as changes are released. Newly revised copies of documents are issued to the appropriate groups as soon as released.

\subsection{Control of Purchased Material, Equipment Parts, and Services}

The drawings require that fabricators provide mill test reports for the critical matcrials used. At LLL, dimensional inspections and radiographic examinations are made. Only after the above data have been reviewed and approved by the project engineer are the parts tagged and stored for use in a secure, limitedaccess storage area. The results of these inspections will be included in the quality assurance record file. 


\subsection{Identification and Control of Materials, Parts, and Components}

Verification of material and identification of parts for use on the UC-609 shipping package are discussed in Sec. 9.8.

\subsection{Control of Special Processes}

The welding on the containment vessel is controlled by visual and radiographic inspections. All welding must meet the requirements of the ASME Boiler and Pressure Vessel Code. Sec. VIII, paragraph UW-5I. Radiographic inspections will be made by LLL by qualified personnel in the nondestructive test section of Mechanical Engineering Department.

\subsection{Inspection}

Each lot of parts will be inspected and the inspection results reviewed before the parts are released for use. See Sec. 9.7.

\subsection{Test Control}

\subsubsection{Preoperational Test Program}

The only preoperational tests required for the UC-609 shipping package are the proof test and the leak test of the containment vessel. That testing will be accomplished using written test procedures that have been approved by engineering supervision. 1 he tests will be performed at LLL by high-pressure technicians and observed by a pressure inspector. The project engineer must review and certify that the test results meet the requirements before the container can be used.

\subsubsection{Acceptance Tests and Maintenance Program}

See Secs. 8.2.1 and 8.2.2 for discussion.

\subsection{Control of Measuring and Test Equipment}

\subsubsection{Calibration}

Standard helium leaks us $\checkmark+$ in calibrating mass spectrometer leak detectors are purchased from reputable manufacturers who certify the $k$ : $k$ rate of each unit.

\subsubsection{Standards}

The Heise gauges used to pressurize the containment vessel are periodically calibrated on dead-weight testers.

\subsection{Handling, Storage, and Shipping}

Written operating procedures in $\mathrm{Ch} .7$ cover the handling and storage of UC- $609 \mathrm{p}$ ?:kaging components.

Shipment of UC-609 packages will comply with U.S. Department of Energy and Department of Transportation requirements. On receipt, all packaging is visually inspected for obvious damage.

\subsection{Inspection, Test, and Operational Status}

The status of each UC-609 package is maintained by a procedure which outlines and records each required step in the preparation of a package for shipment. See Ch. 7.

A tag indicating that the containment vessel has been suocessfully proof tested and leak tested is attached by the pressure inspector. The packaging is not complex, and its status is determined per Ch. 7 and 8 . 


\subsection{Nonconforming Materials, Parts, or Components}

\subsubsection{Disposition}

Nonconforming packaging will be tagged, removed from service as soon as it is identified, and replaced with a spare. The nonconforming packaging, if repaired, will be repaired using an approved procedure and standard maintenance techniques.

\subsubsection{Acceptance}

Inspections of packaging at the vendor's shop or upon recejpt may result in rejection of material.

\subsection{Corrective Action}

Nonconforming packaging may be repaired by the vendor or by LLL, depending on the cost and payment allocations made between the purchasing department and the vendor. Repairs are to be made using approved procedures.

\subsection{Quality Assurance Records}

The records for the UC-609 containment package will be kept on permanent file at LLL.

\subsection{Audits}

LLL Materials Management will make annual audits to determine if the packaging is being used in an approved manner. 


\section{REFERENCES}

1. Americall Society of Mechanical Engineers. Bosiler and Pressure Vessed Code (American Society of Mechanicat I:ngineers, New York, 1974!, Sec. VIII. Div. 1.

2. I. A. Slurtevant. Torque Mamal (P. A. Sturtevant Co., Addison. IL), pp. 33-41.

3. Hechanical Properties of Hexcel Honeycomb Materials, Document No. TSB 120 (Hexcel Corporation. DLitjin. ( $\lambda$, 1974), p. 15.

4. A. A. Galles and P. G. MoCarthy. Safery Analysis Report - Packages, IPI57S Packages, Suvannah River Plant, Aiken, SC, Rept. DPSPWD 76-124-2 (title $\mathcal{U}$, report SRD) (1976), pp. i-3.

5. I1. A. Rothbart, Mechanical Design and Systems Handbook (McCiraw-Hill Book Co.. New York. 1964). Table 20.2. p. 20-7.

6. M. S. Burger, General Purpose Shipping Conlainer Stress Analysis, Lawrence Livermore Labnratory. Rept. FND 77-10 (1977).

7. Envirommental Test Methods, U.S. Department of Defense, Rept. MIL-STD-810C (Fifr. 514.2-7, p. 514.2.40: Tiable 514.2-VII, p. 514.2-39).

8. R. C. Lum, Thermal Conductivity of (elotex. Lawrence Livermore Laboratory, Job No. 2403k8 (1975).

9. D. Ornellas, private communication (1978).

10. J. P. Holman, Heat Transfer (McGraw-Hill Book Co., New York, 1968), 2nd ed., pp. 199.385.

11. G. C. Schaack and D. A. Schauer, Thermal Study of Tritium Transfer Container, Lawrence Livermore Laboratory, Rept. END 77-15 (1977).

12. F. Krith, Principles of Heas Transfer (International Tey book Co., Scranton. PA, 1962) pp. 217-226.

13. D. A. Schauer, FED - A Computer Program 10 Generate Geometric Iipia for the Heat Fransfer code TRUMP. Lawrence Livermore Laboratory, Rept. UCRL-50816, Rev. I (1973).

14. A. L. Edwards, TRUMP - A Computer Program for Transient and Steadj-State Temperature Distribuiion in Mulidimensional Systems, Lawrence Livermore Laboratory, Rept. UCRL-14754, Rev. 2(1969).

15. Internx iunal Atomic Energy Agency, Regulations for the Safe Transportation of Radioaclive Materials. Safety Series No. 6, Rev, ed. (1973).

16. J. Crank, Mathematics of Diffusion, 2nd ed, (Clarendon Press, Oxford, 1975), pp. 51-52.

17. M. R. Loutham and R. G. Derrick, Hydrogen Transporl in Austenitic Stainles.s Steel. Savannah River Plant, Aiken, SC, Rept. DP-MS-73-10 (1973). 


\section{APPENDIX A: ENGINEERING NOTES}




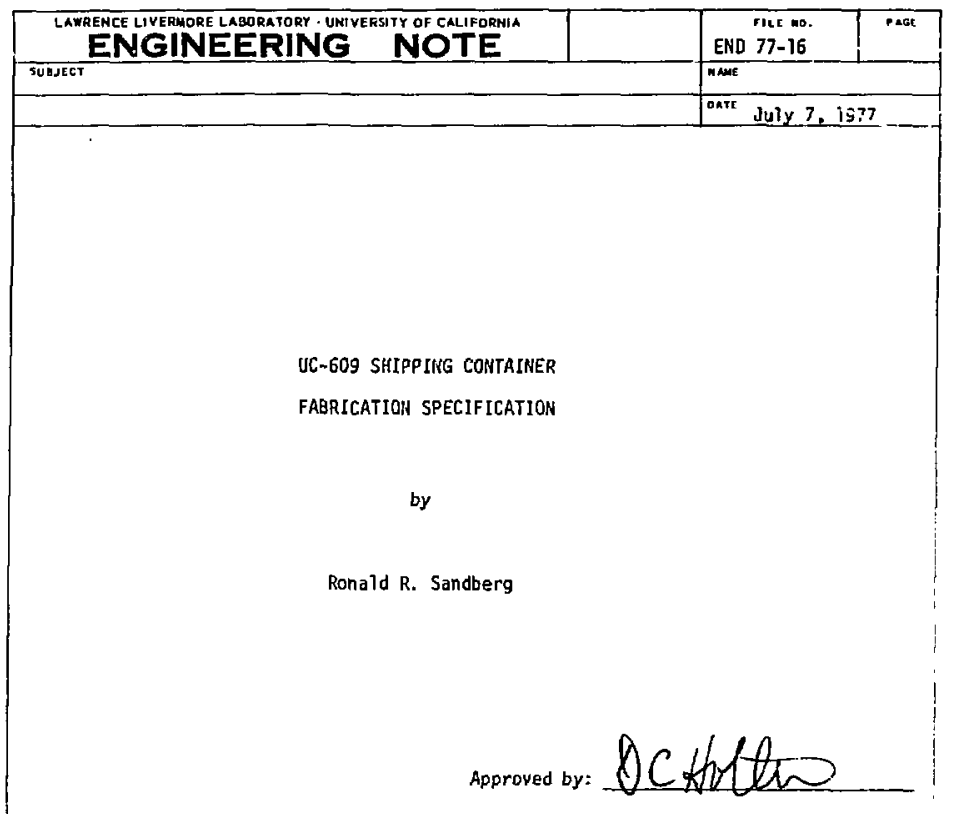

CL.376 (KEV.6/71)

45 


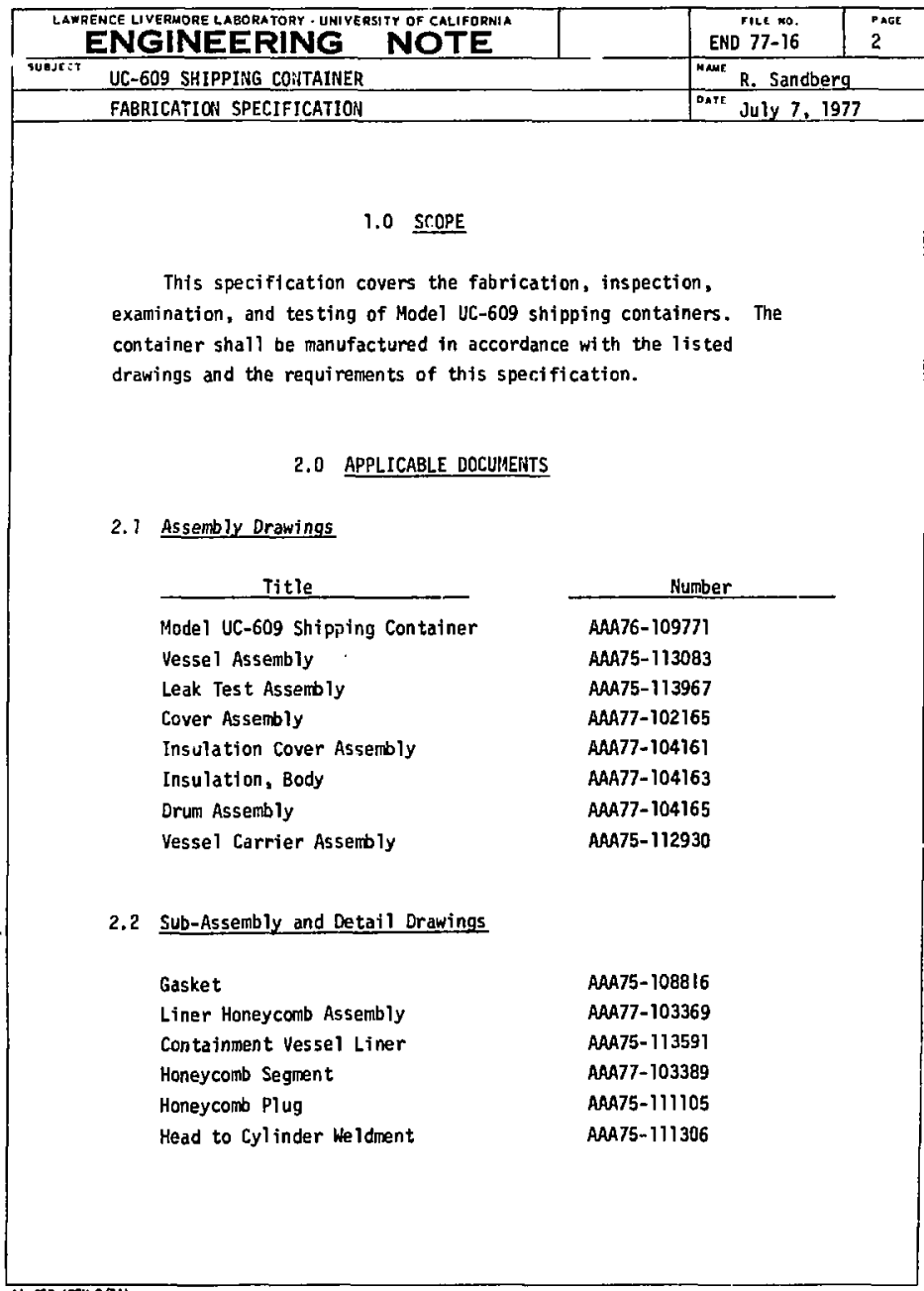

LL-200 (EEV. 6/71) 


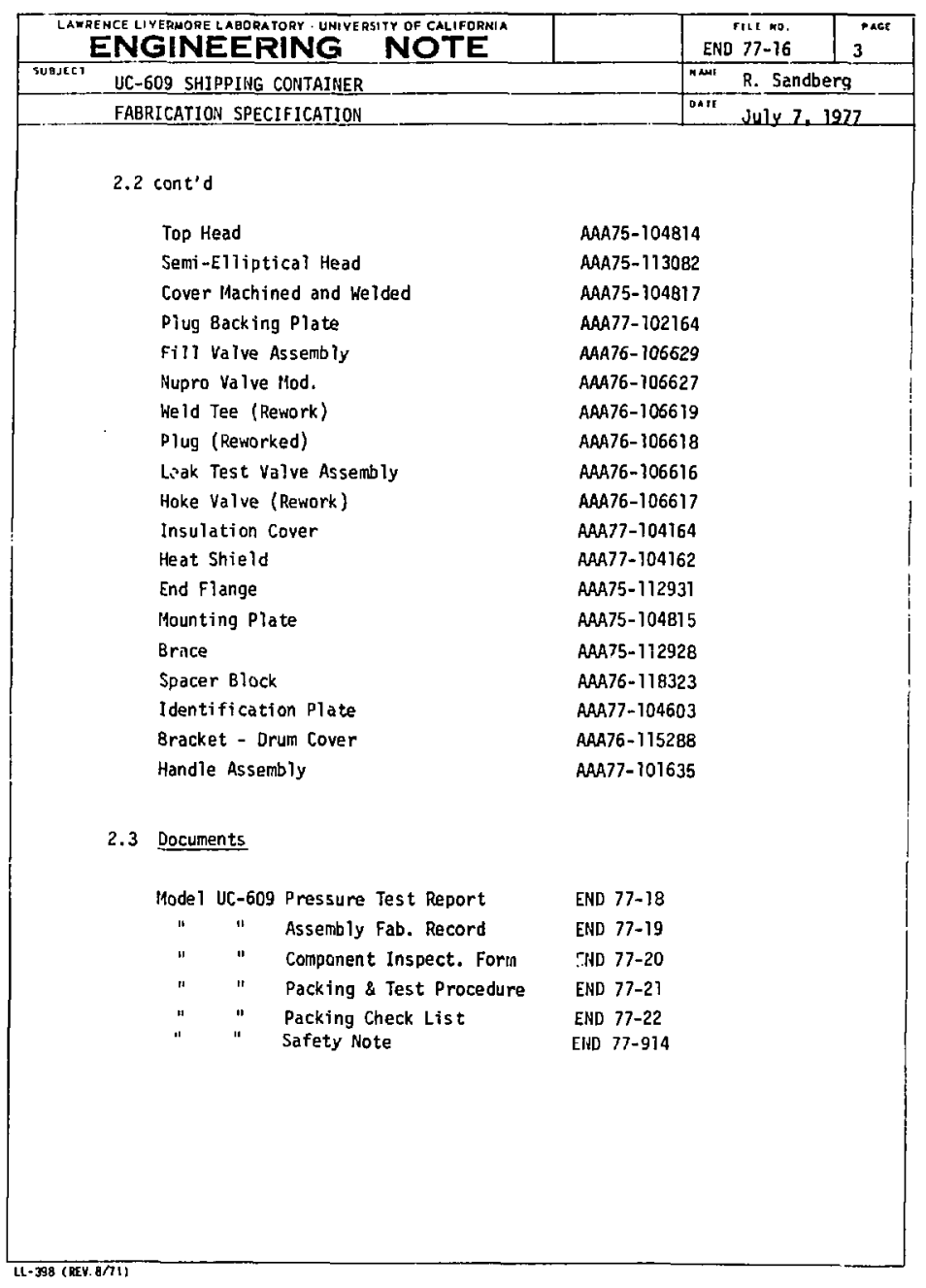




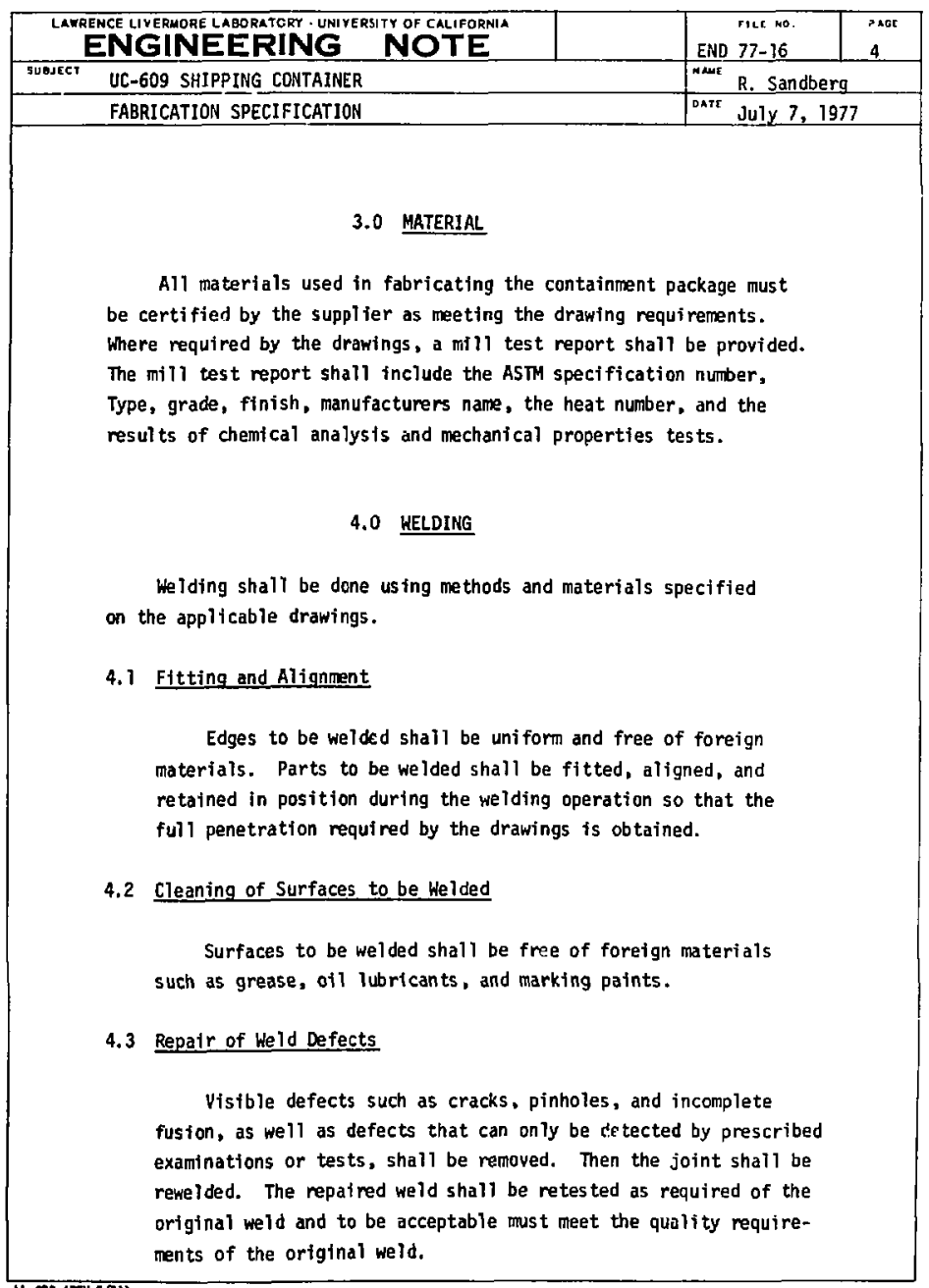




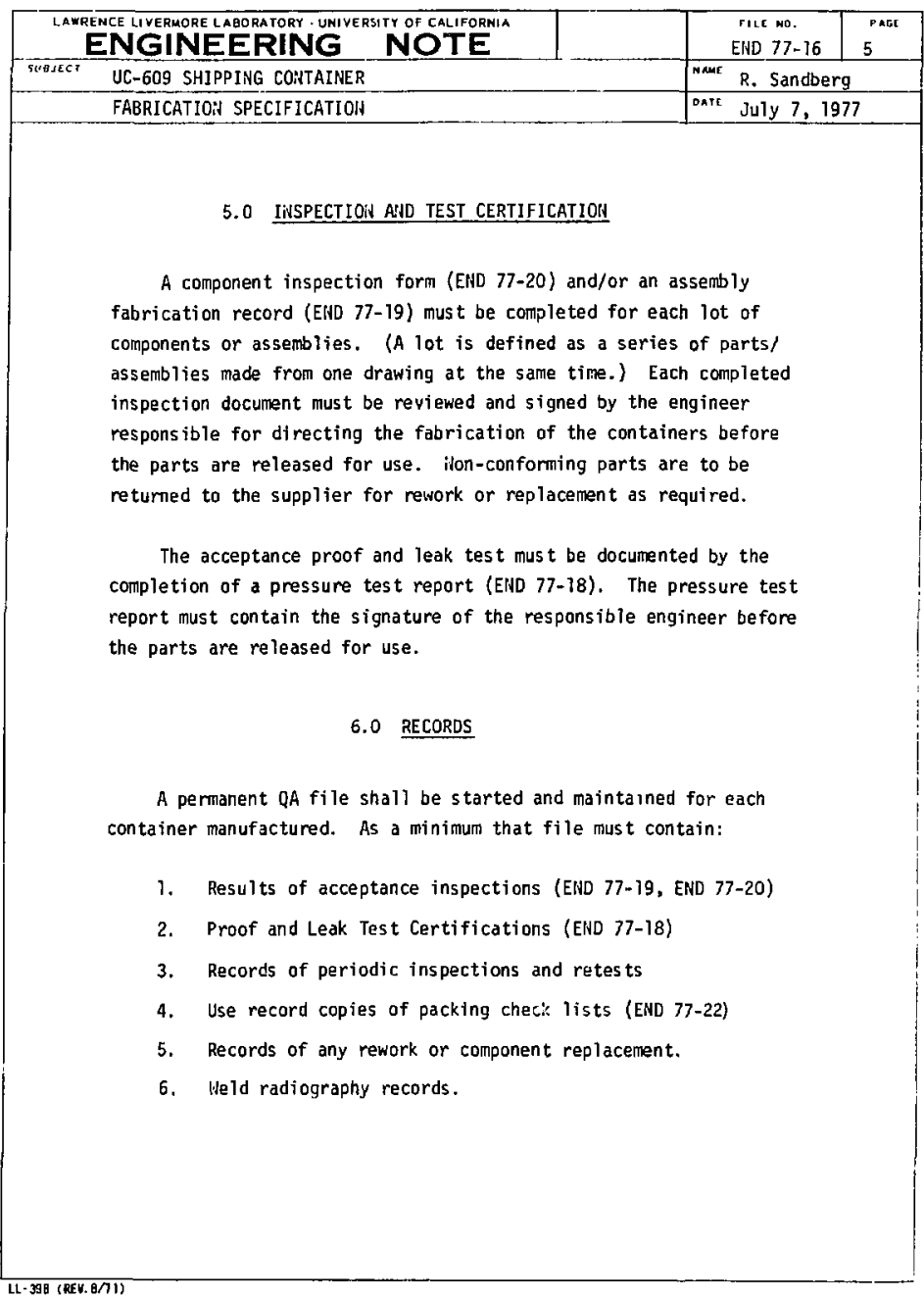




\begin{tabular}{|c|c|c|}
\hline TITLE: & $\begin{array}{l}\text { rile no. END } 77 \\
\end{array}$ & ${ }^{P A G R}$ \\
\hline MODEL UC-609 SHIPPING CONTAINER & $\begin{array}{r}\text { Wht Tré br } \\
\text { R. Sandberg }\end{array}$ & \\
\hline PRESSURE TEST REPORT & & \\
\hline
\end{tabular}

Reference: Drawing AAA75-113967, Safety Note END 77-914

Container Serial No.

1. Sensitivity of mass spectrometer:

atm cc/s/div. (hand probe)

atm cc/s/div. (integrated leak test)

Standard Leak No.

with a leak rate of

2. Proof pressure psig for hr

3. Leak test pressure psig

4. Leak rates:

Across Cu gasket $\mathrm{atm} \mathrm{cc} / \mathrm{s}$

External atm $c c / s$

(tota) must be less than $2 \times 10^{-8} \mathrm{~atm} \mathrm{cc} / \mathrm{s}$ )

Tested by Date

Inspector: Fressure tested label applied: Date

Approved for use Date 
MODEL UC-609 SHIPPING CONTAIRER

ASSEMBLY FABRICATION RECORD

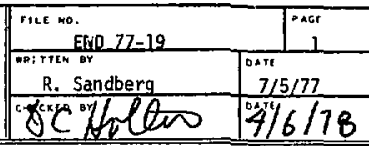

Assembly

Drawing No.

Lot No.

Size of Lot

List Serial Hos.

Supplier.

LLL P.O. No. $\cos t \$$ each

\begin{tabular}{|c|c|c|}
\hline 1 & $\begin{array}{l}\text { Component parts inspected and approved } \\
\text { for use (attach inspection forms END77-20) }\end{array}$ & \\
\hline 2 & $\begin{array}{l}\text { dimensional compliance } \\
\text { dimsemblies inspected for }\end{array}$ & \\
\hline 3 & $\begin{array}{l}\text { General comnents on workmanship and } \\
\text { quality of assenblies }\end{array}$ & \\
\hline 4 & $\begin{array}{l}\text { Acceptable assemblies tagged with LLL } \\
\text { P.C. No. and Lot No. }\end{array}$ \\
\hline
\end{tabular}

Inspection: Accepted Date

N.D. Tests Accepted Date

Date

Approved for use Date 


\begin{tabular}{|c|c|c|}
\hline TITLE & FHK *O. END 77-20 & $\int_{1}^{\text {Pace }}$ \\
\hline MODEL UC-609 SHIPPING COMIAINER & $\begin{array}{l}\text { WRIFTEM Er } \\
\text { R. Sandberg }\end{array}$ & OATE \\
\hline COMPONENT INSPECTION FORM & $\operatorname{cop} \times x \log 0$ & 2016 \\
\hline
\end{tabular}

Part Drawing No.

Lot No. Size of Lot

List Serial Nos.

Supplier

LLL P.0. No. $\cos t \$$ each

\begin{tabular}{|c|c|c|}
\hline 1 & SPEMCIFICATION & \\
\hline 2 & $\begin{array}{l}\text { Material - meets drawing requirements, } \\
\text { certification at tached }\end{array}$ & \\
\hline 3 & $\begin{array}{l}\text { compliance. Surmary attached. } \\
\text { General conments on workmanship and } \\
\text { quality of parts }\end{array}$ & \\
\hline 4 & $\begin{array}{l}\text { Acceptable parts tagged with LLL } \\
\text { P.O. No. and Lot No. }\end{array}$ & \\
\hline
\end{tabular}

t

Inspection: Accepted Date

N.D. Tests Accepted Date Date

Approved for use Date 


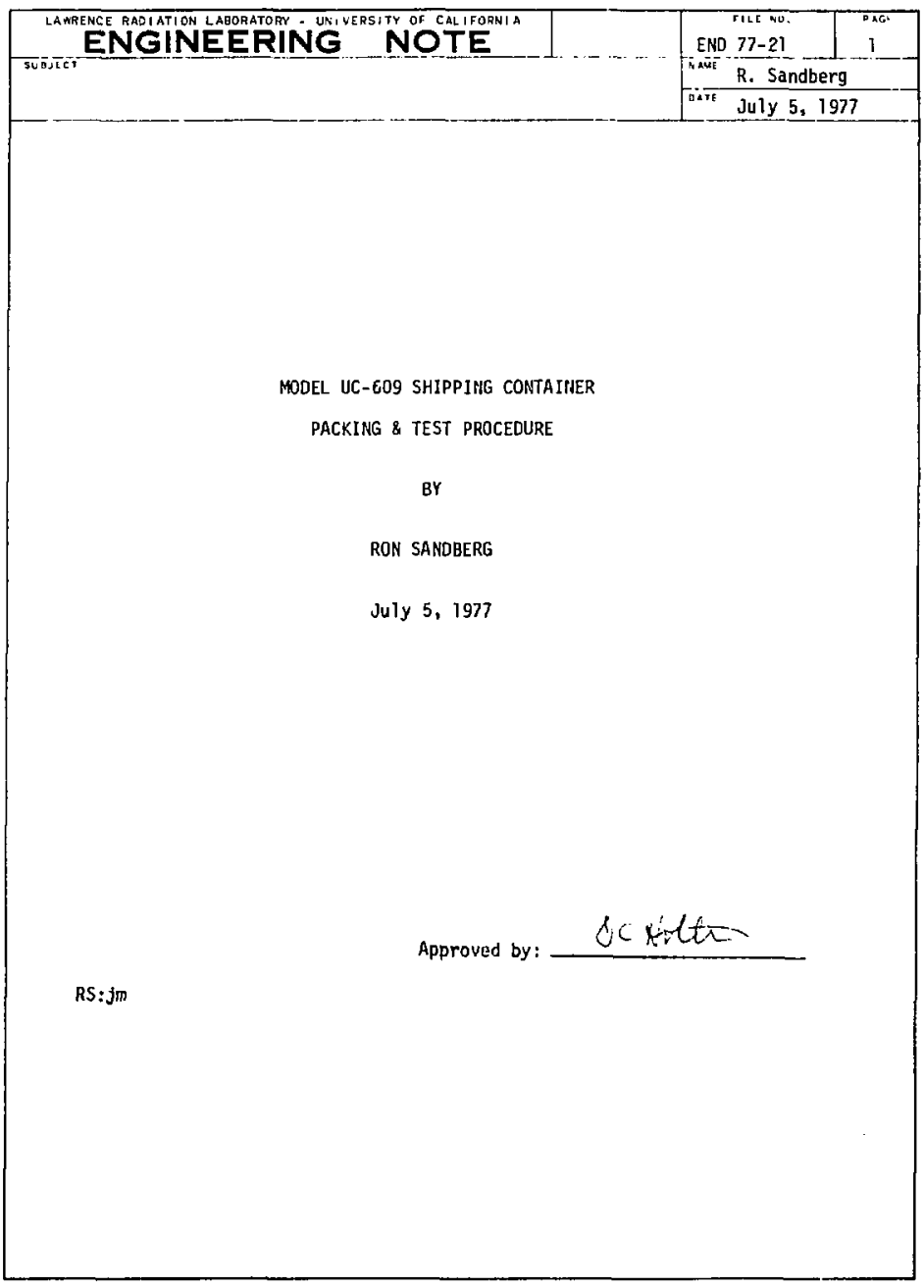

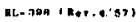




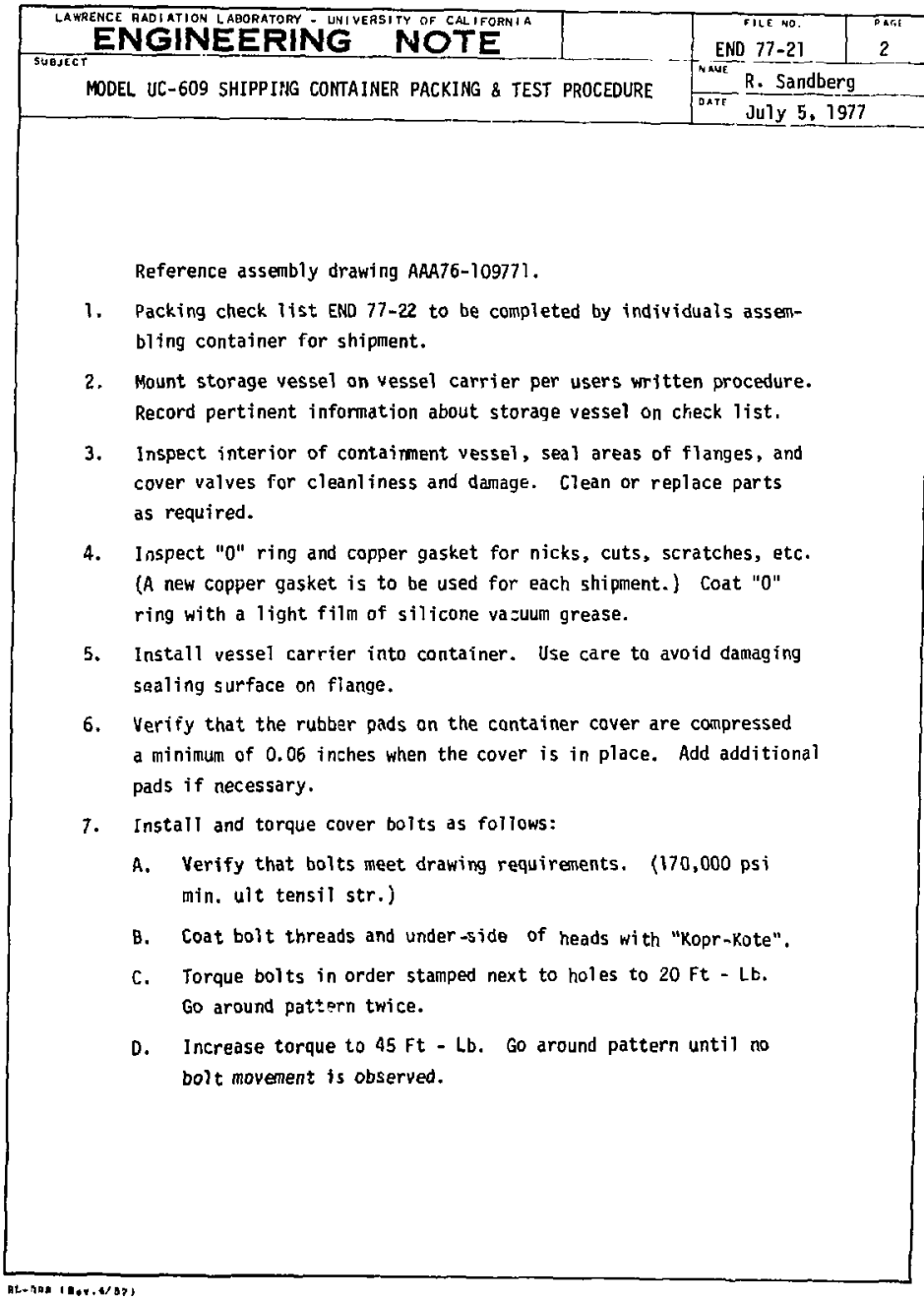

BL-Ane 10er.t/as 


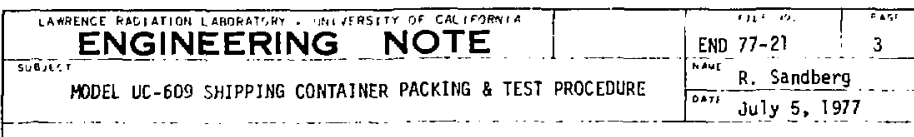

8. Leak test container as follows:

A. Evacuate the container volume (through the fill vaive) to less than 150 Torr ( 3 psia).

8. Pressurize through the fill valve with helium to the pressure determined from the tabli on page 5. Close the fill valve.

c. Detemine the sensitivity of a mass spectrometer leak detector with a standard leak.

D. Connect the leak detector to the open leak check valve and to the closed fill valve. Measure leakage across gasket and across fill valve seat.

E. Vent pressure to atmospheric.

F. Close both valves, and cap fittings.

9. If required for in plant control install tamper seals on cover bolts and on valves.

10. Inspect celotex insulation, drum, drum cover and drum covar brackets for damage. Replace parts as necessary. Remove any old shippi.tg labels.

11. Verify that plastic plugs are in place in drum cover.

12. Install container into insulating overpack. Use enough $\frac{2}{2}$ inch thick ceroblanket disks on top of the insulation cover so that approxinately 100 pounds force must be applied to the cover to engage the cover brackets.

13. Torque bolts securing drum cover to $20 \mathrm{ft} .-1 \mathrm{~b}$, and install tamper seals on two bolts $180^{\circ}$ apart.

14. Monitor package for contamination: nust be 1 ess than $150 \mathrm{~d} / \mathrm{m} / 100 \mathrm{~cm}^{2}$ beta-gamma. 


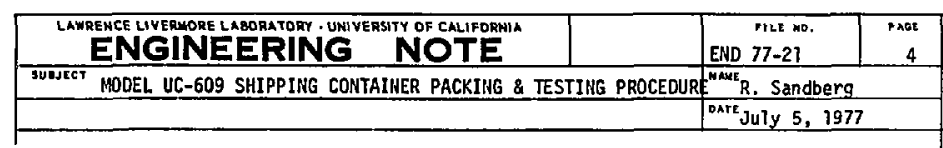

15. Install appropriate labels in conformance with DOT regulations. Also attach tag identifying shipment.

16. 


\begin{tabular}{|c|c|c|c|c|c|c|}
\hline \multicolumn{5}{|c|}{ 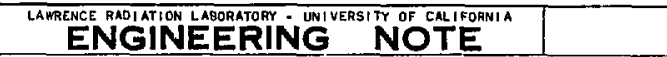 } & \multicolumn{2}{|c|}{ 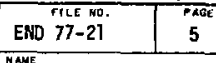 } \\
\hline \multicolumn{5}{|c|}{ MODEL UC-609 SHIPPING CONTAINER PACKING \& TESTING PROCEDURE } & \multicolumn{2}{|c|}{$\begin{array}{l}\text { NAME R. Sandberg } \\
\text { RATE July } 5,1977\end{array}$} \\
\hline \multirow{3}{*}{$\begin{array}{l}\text { Quantity } \\
\text { of gas } \\
\text { moles }(1)\end{array}$} & \multicolumn{5}{|c|}{$\begin{array}{l}\text { HOOEL UC-609 SHIPPIHG CONTAINER } \\
\text { BLE OF PRESSURES \& TEMP. FOR YARIOUS QUANTLTIES OF GAS }\end{array}$} & \\
\hline & \multirow{2}{*}{$\begin{array}{l}\text { Decay } \\
\text { heat load } \\
\text { watts }\end{array}$} & \multicolumn{2}{|c|}{$\begin{array}{c}\text { Contaiment yessel } \\
\text { Temp (2) }\end{array}$} & \multicolumn{2}{|c|}{ Pressure (psia) (3) } & \\
\hline & & ${ }^{\circ} \mathrm{C}$ & ${ }^{\circ} \mathrm{K}$ & Equil ibrium & Test $(4)$ & \\
\hline 2 & 3.8 & 54.8 & 327.8 & 23.5 & 35. . & \\
\hline 4 & 7.7 & 56.7 & 329.7 & 29.6 & 45 & \\
\hline 6 & 11.5 & 58.5 & 331.5 & 35.7 & 54 & \\
\hline 8 & 15.4 & 60.4 & 333.4 & 41.9 & 63 & \\
\hline 10 & 19.2 & 62.2 & 335.2 & 48.2 & 73 & \\
\hline 12 & 23.0 & 64.0 & 337.0 & 54.5 & 82 & \\
\hline 14 & 26.9 & 65.9 & 338.9 & 60.9 & 92 & \\
\hline 16 & 30.7 & 67.7 & 340.7 & 67.4 & 102 & \\
\hline 18 & 34.6 & 00.6 & 342.6 & 73.9 & ווו & \\
\hline 20 & 38.4 & 77.4 & 344.4 & 80.5 & 121 & \\
\hline 22 & 42.2 & 73.2 & 346.2 & 87.2 & 137 & \\
\hline 24 & 46.7 & 75.7 & 348.1 & 93.9 & 341 & \\
\hline 25 & 48.0 & 76.0 & 349.0 & 97.3 & 146 & \\
\hline 26 & 48.0 & 76.0 & 349.0 & 100.5 & 151 & \\
\hline 28 & 48.0 & 76.0 & 349.0 & 106.8 & 161 & \\
\hline 30 & 48.0 & 76.0 & 349.0 & 113 & 170 & \\
\hline
\end{tabular}




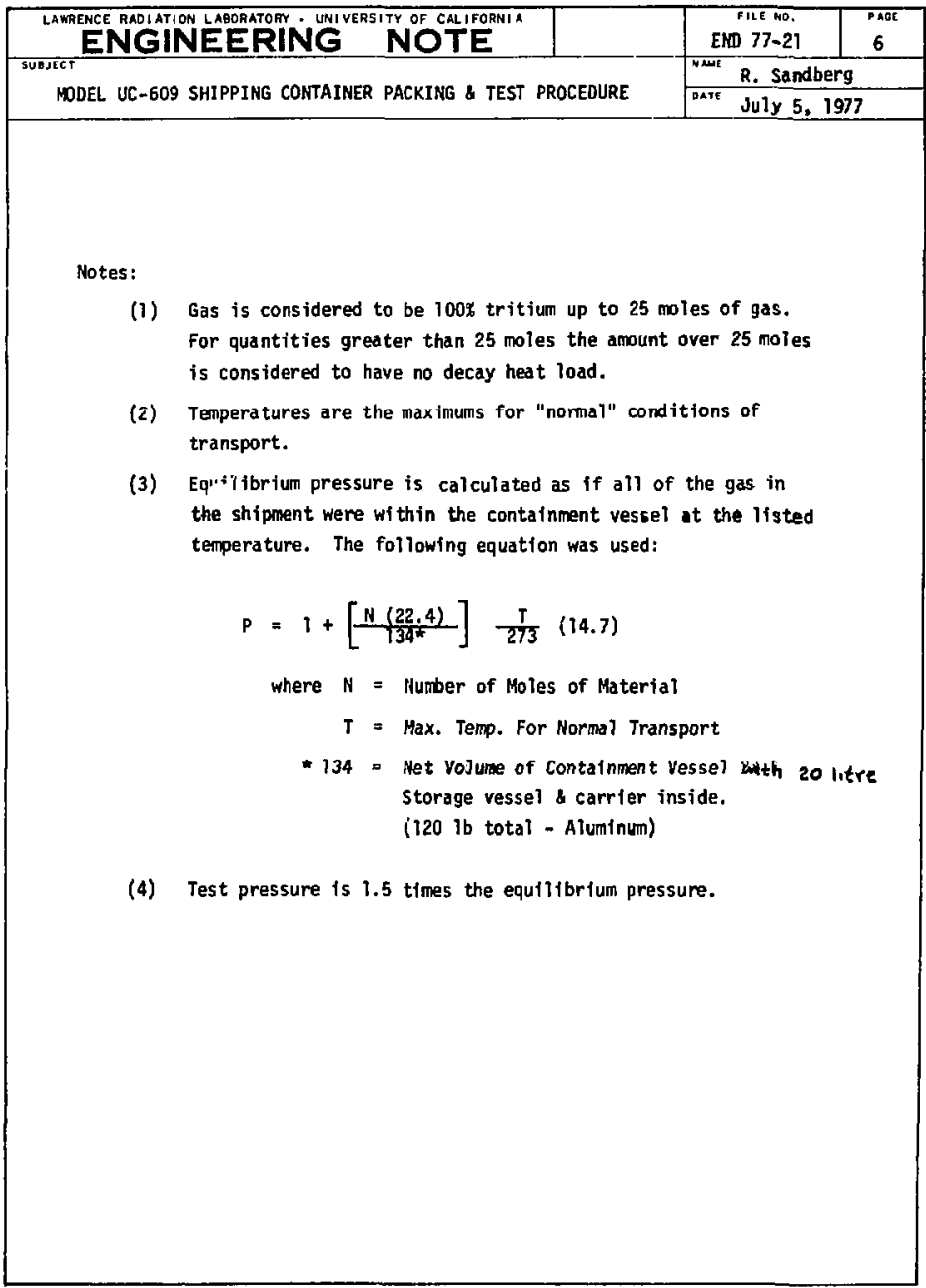

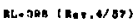




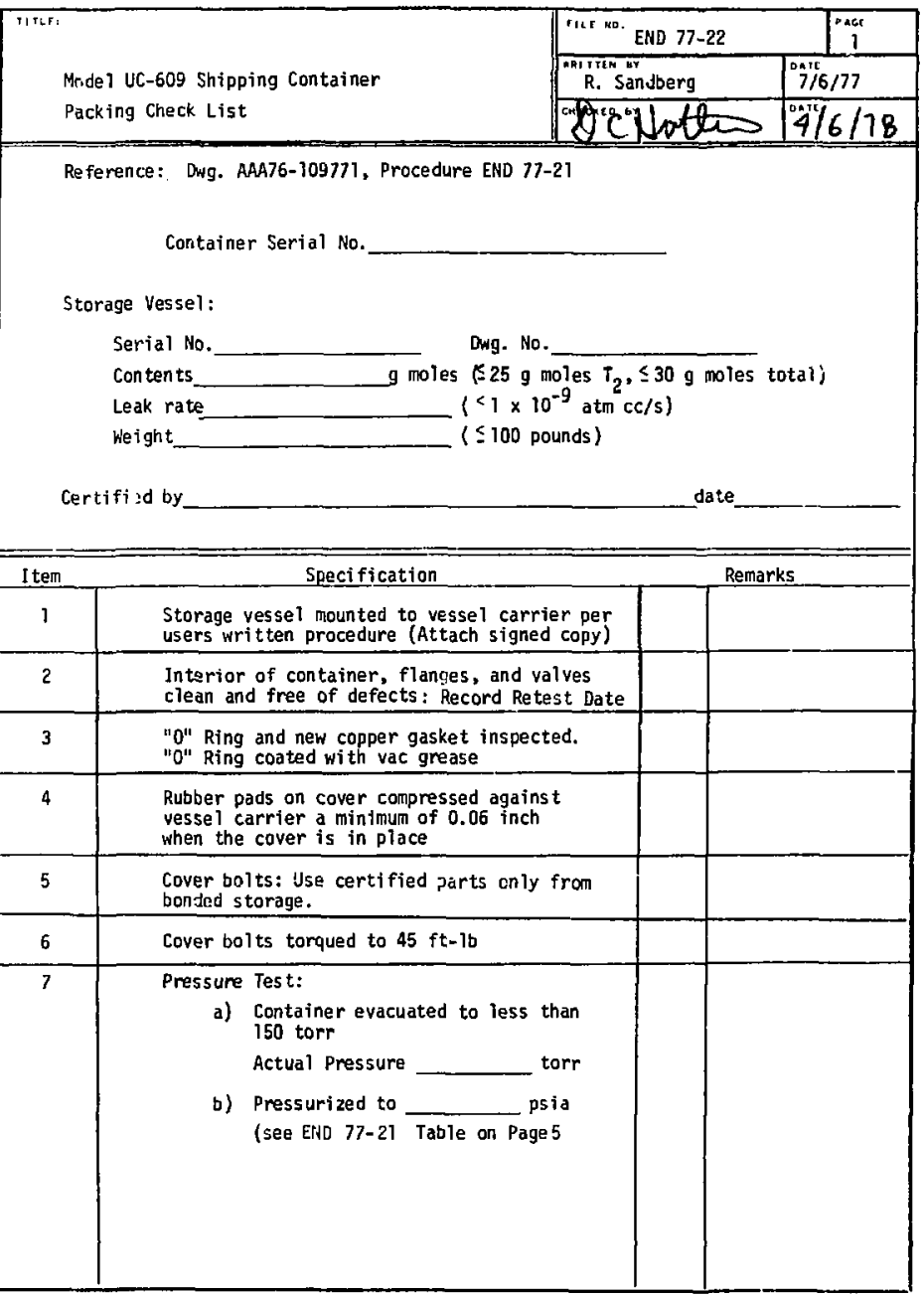




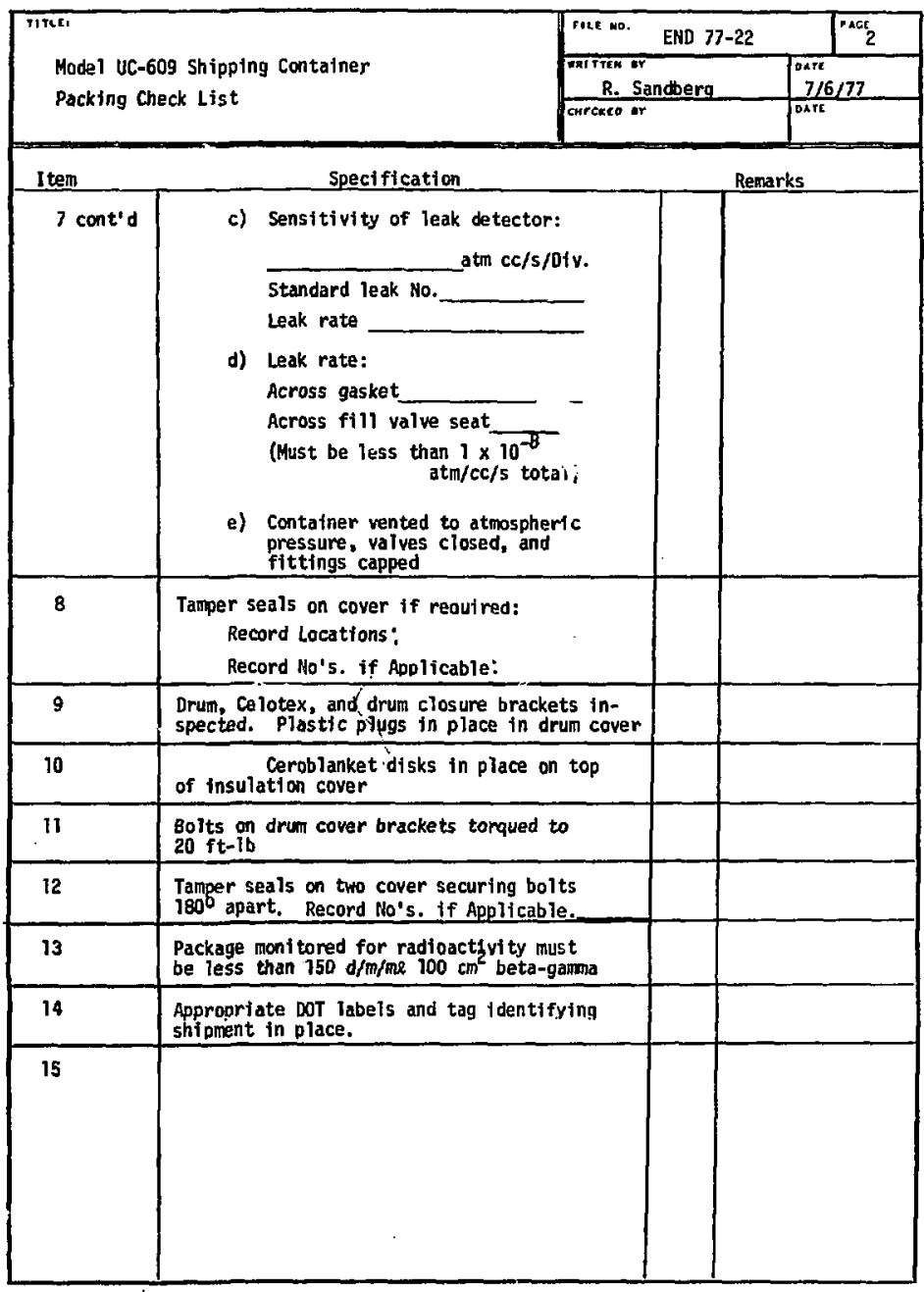




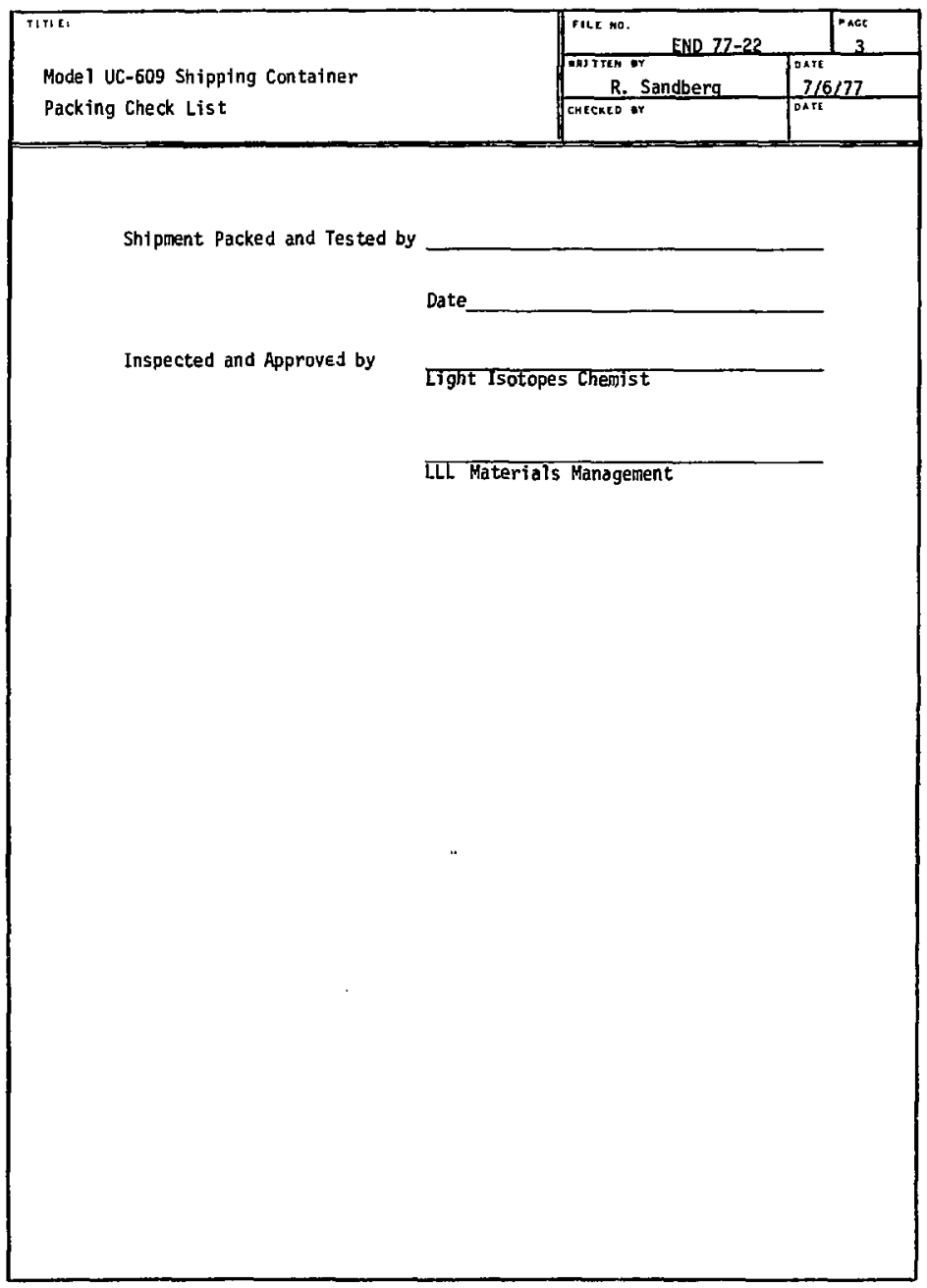

$\therefore$

61 


\section{APPENDIX B: FABRICATION DRAWINGS}



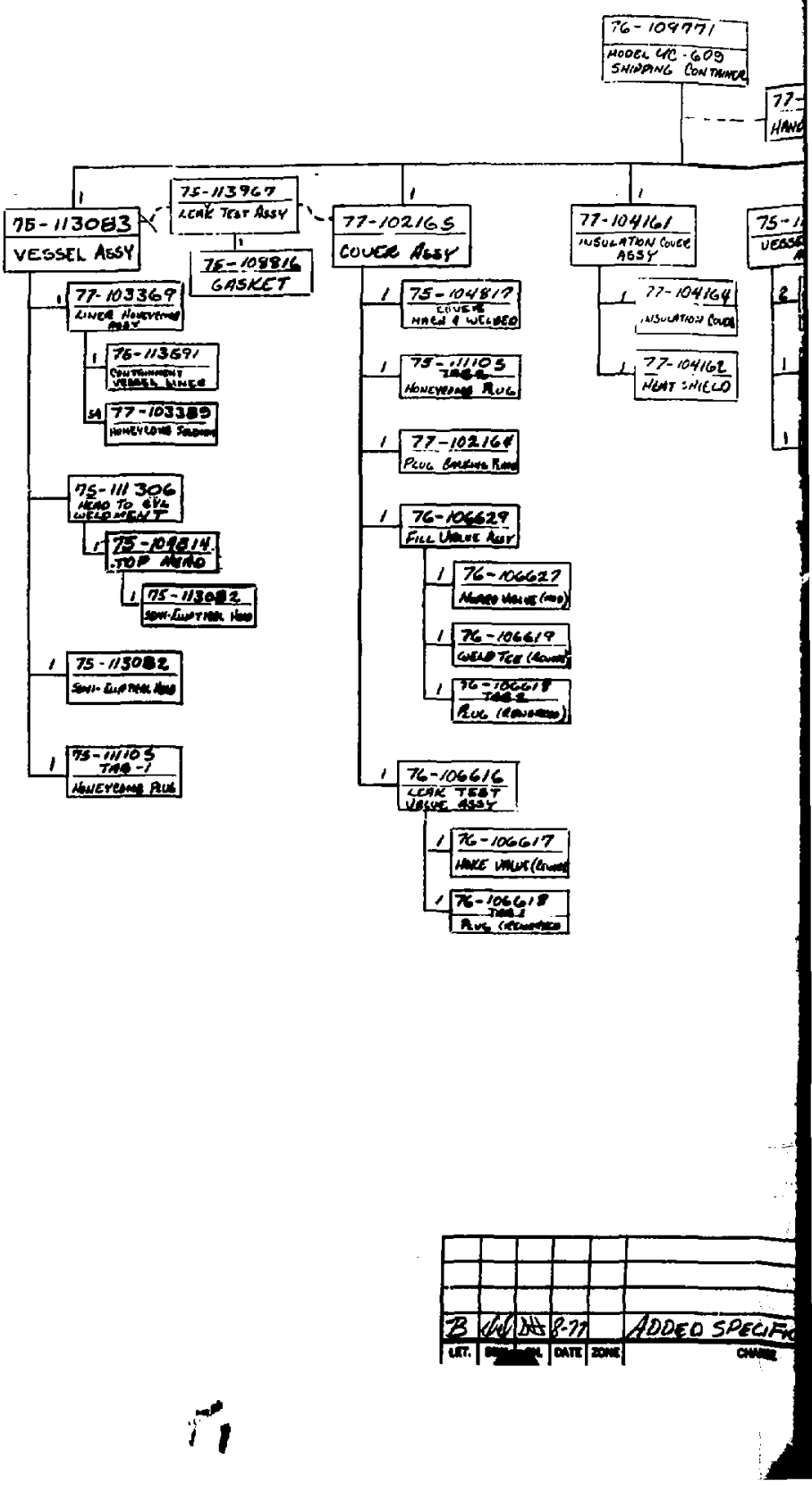


\section{$77-101635$}

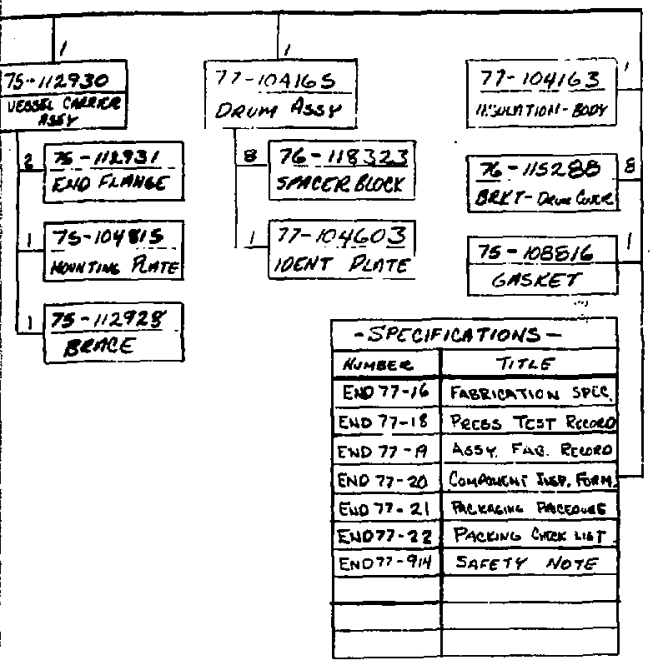

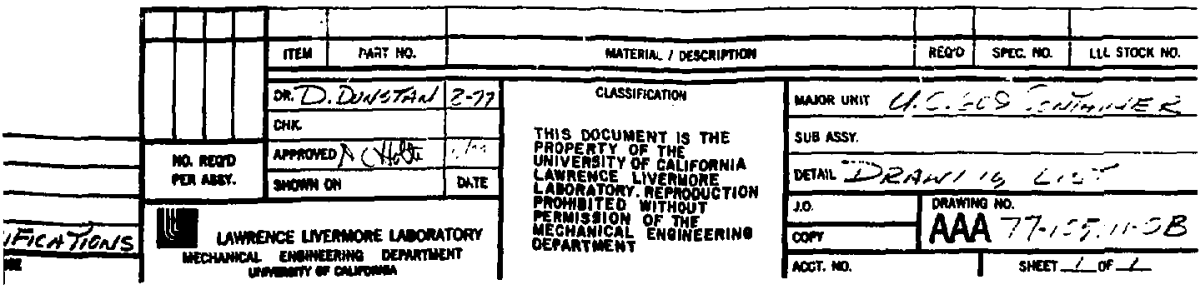




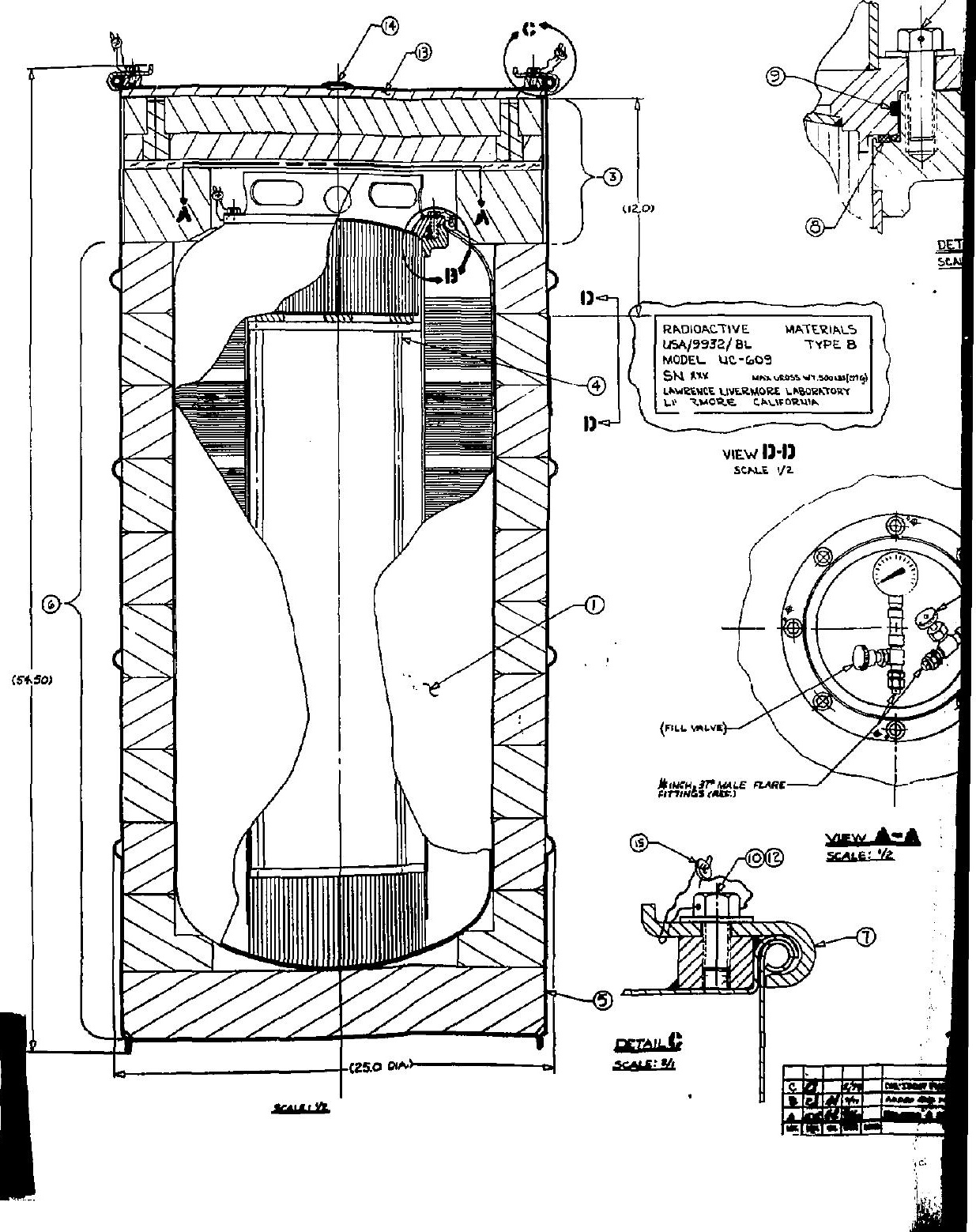




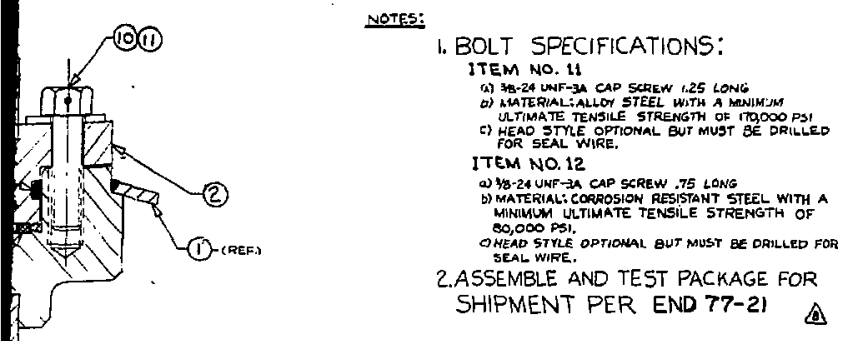

DETAIL 13

SCALE 2/4
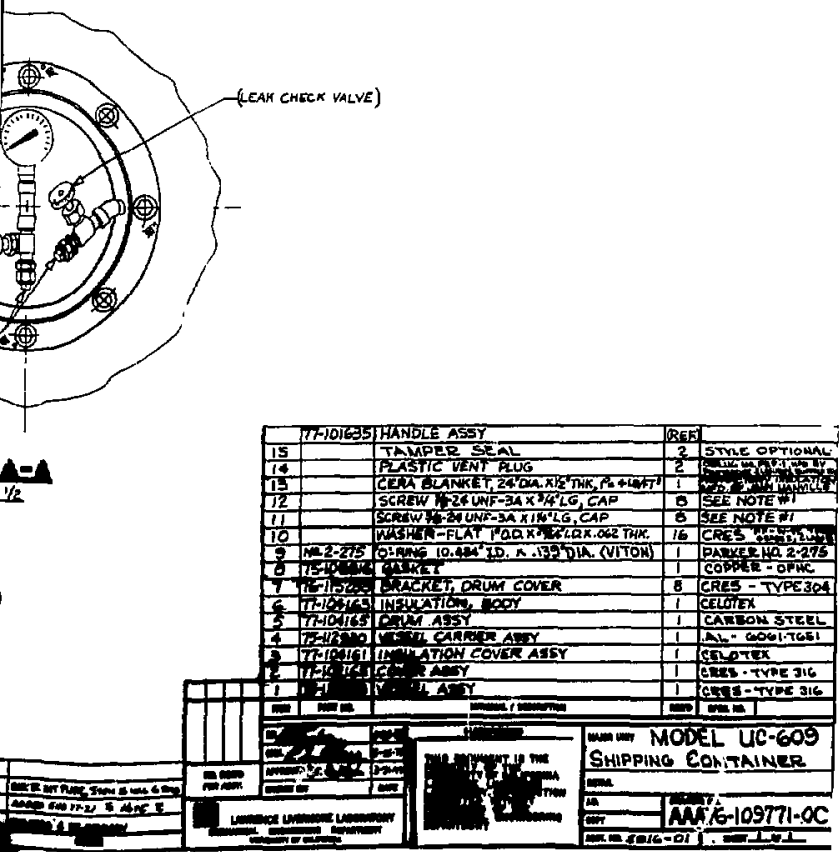


\begin{tabular}{|c|c|c|c|}
\hline LET DO & ex & Daxe zon & CHANGE \\
\hline B. Tes & $D$ & \&in & 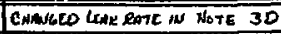 \\
\hline B. $\mid Q_{1}$ & $\overline{D N}$ & $4 / 78$ & 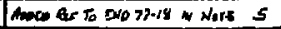 \\
\hline & & & \\
\hline & & & \\
\hline
\end{tabular}
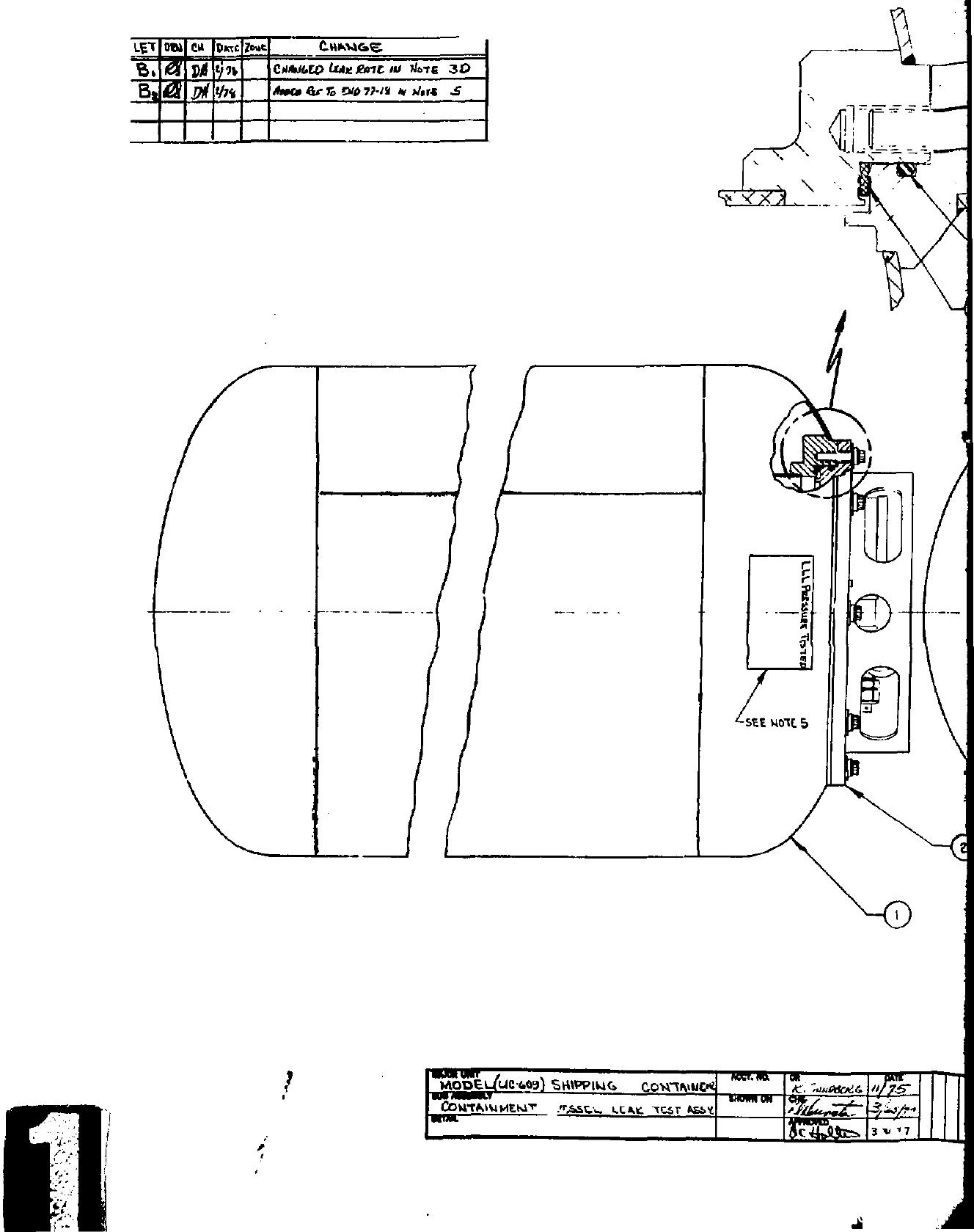


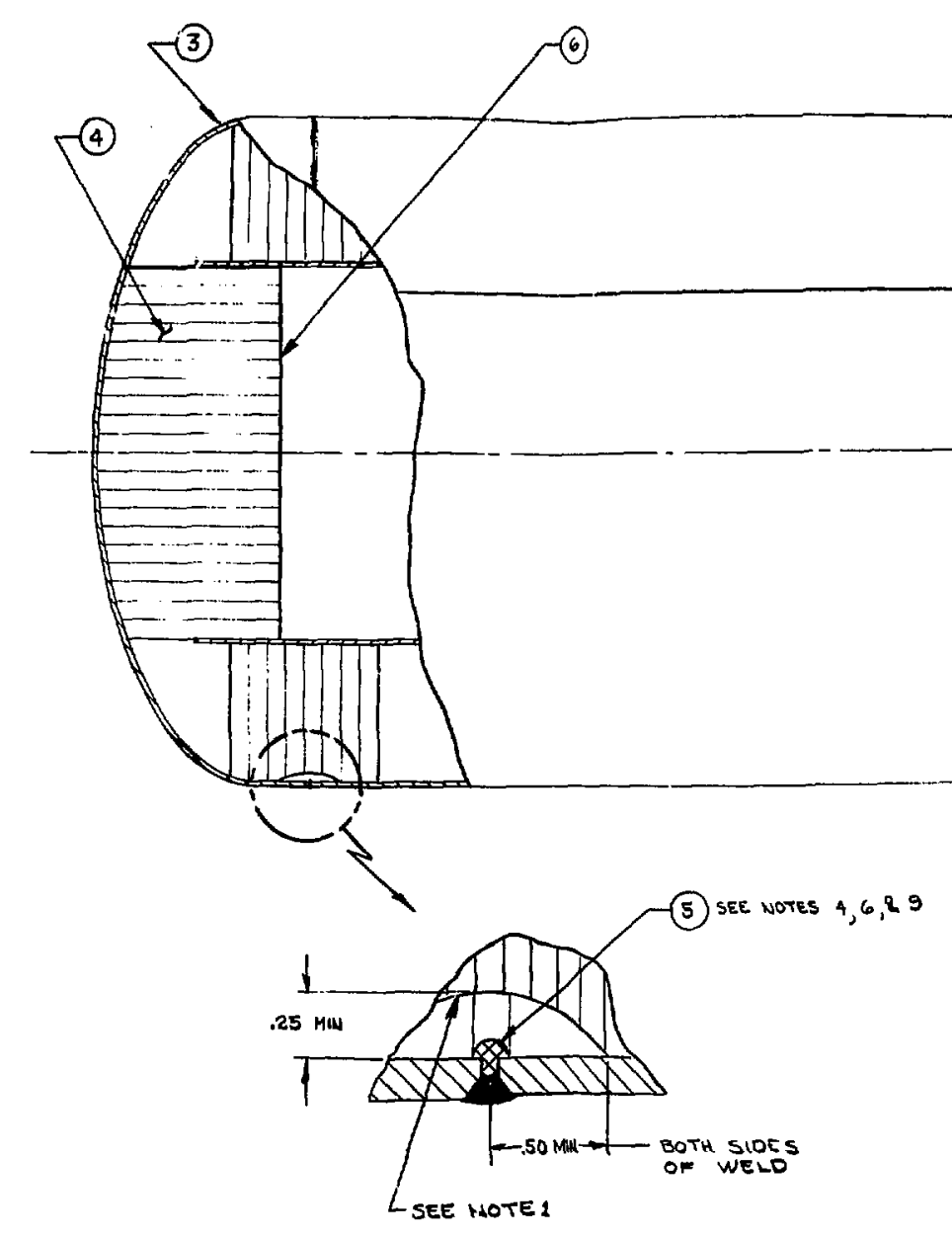



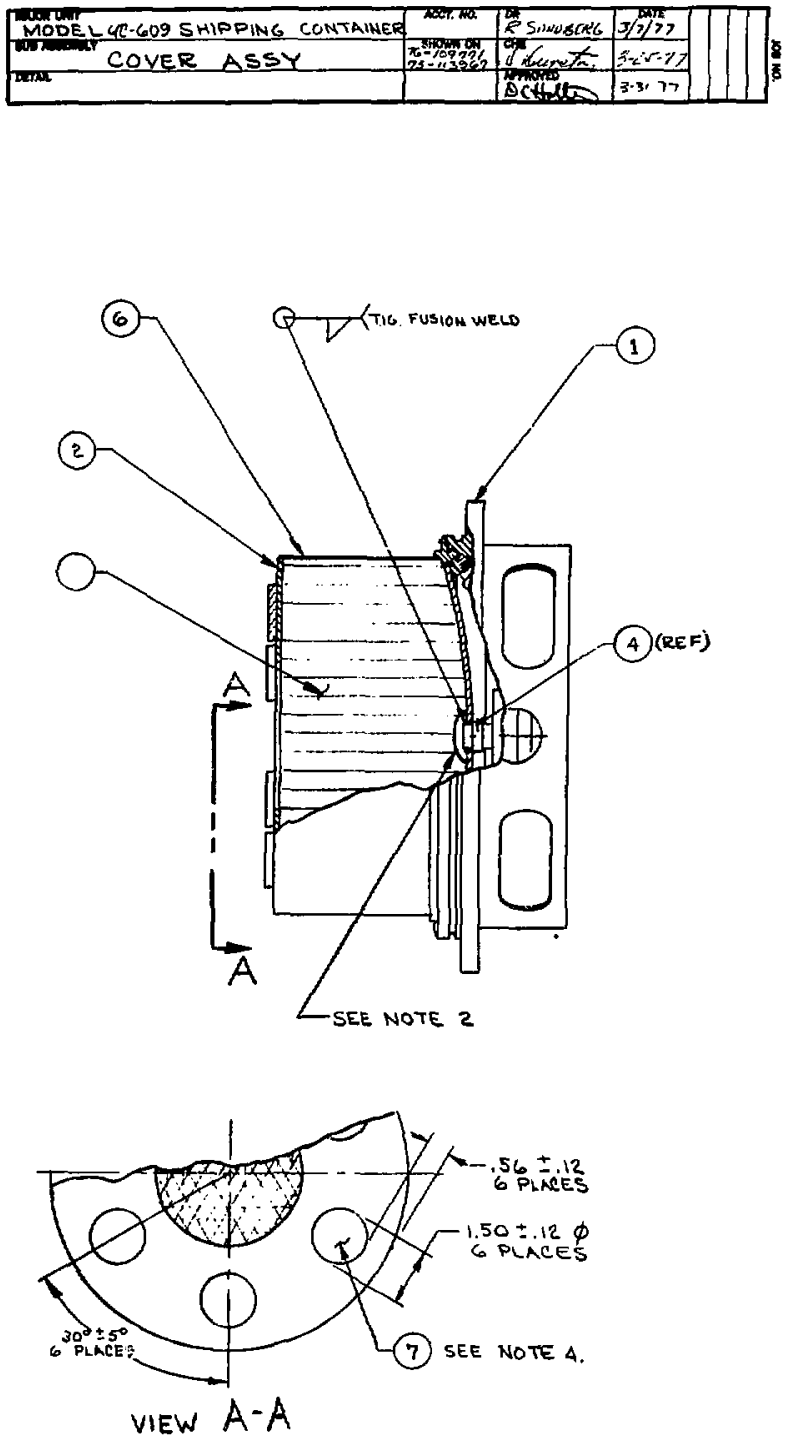

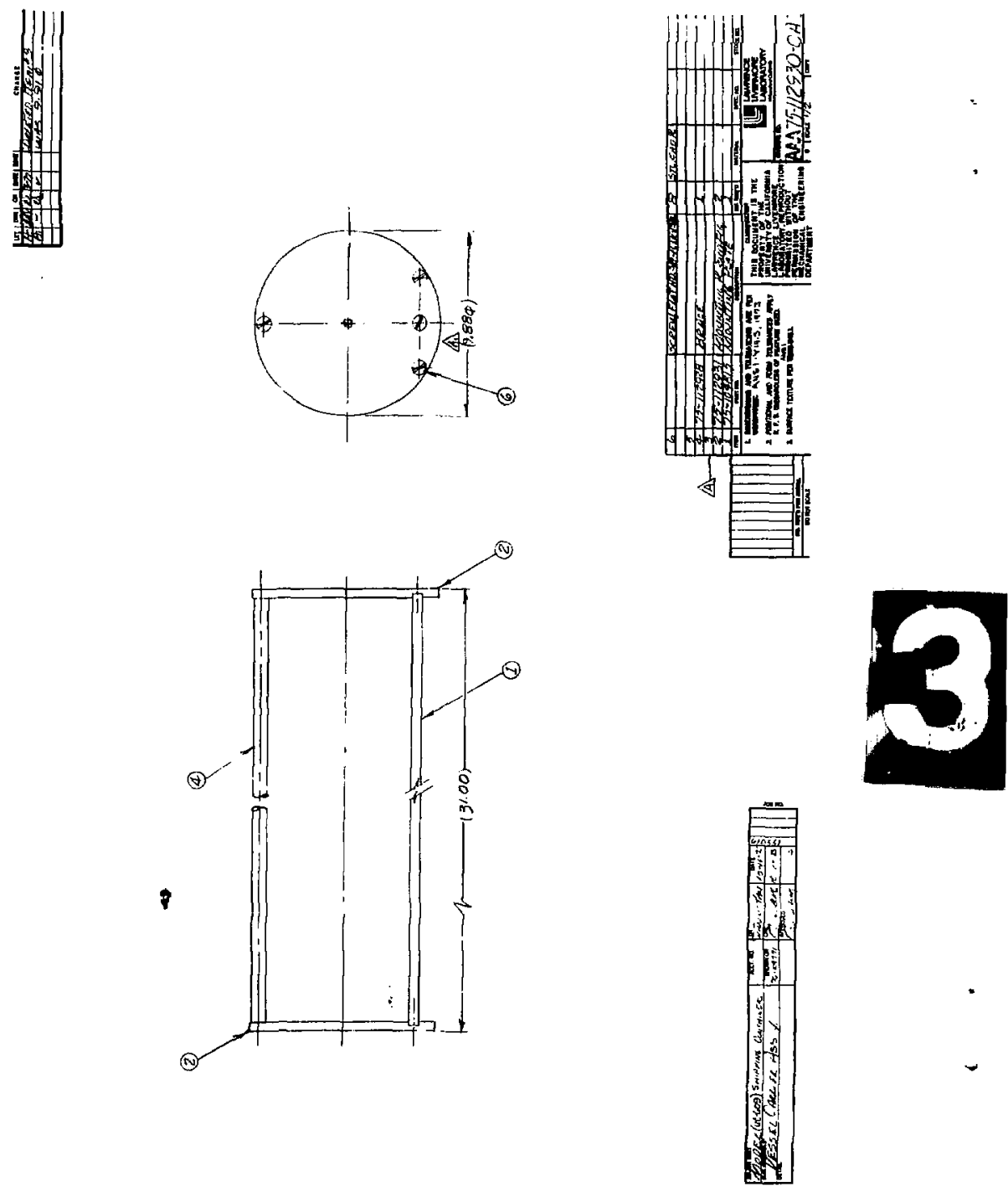

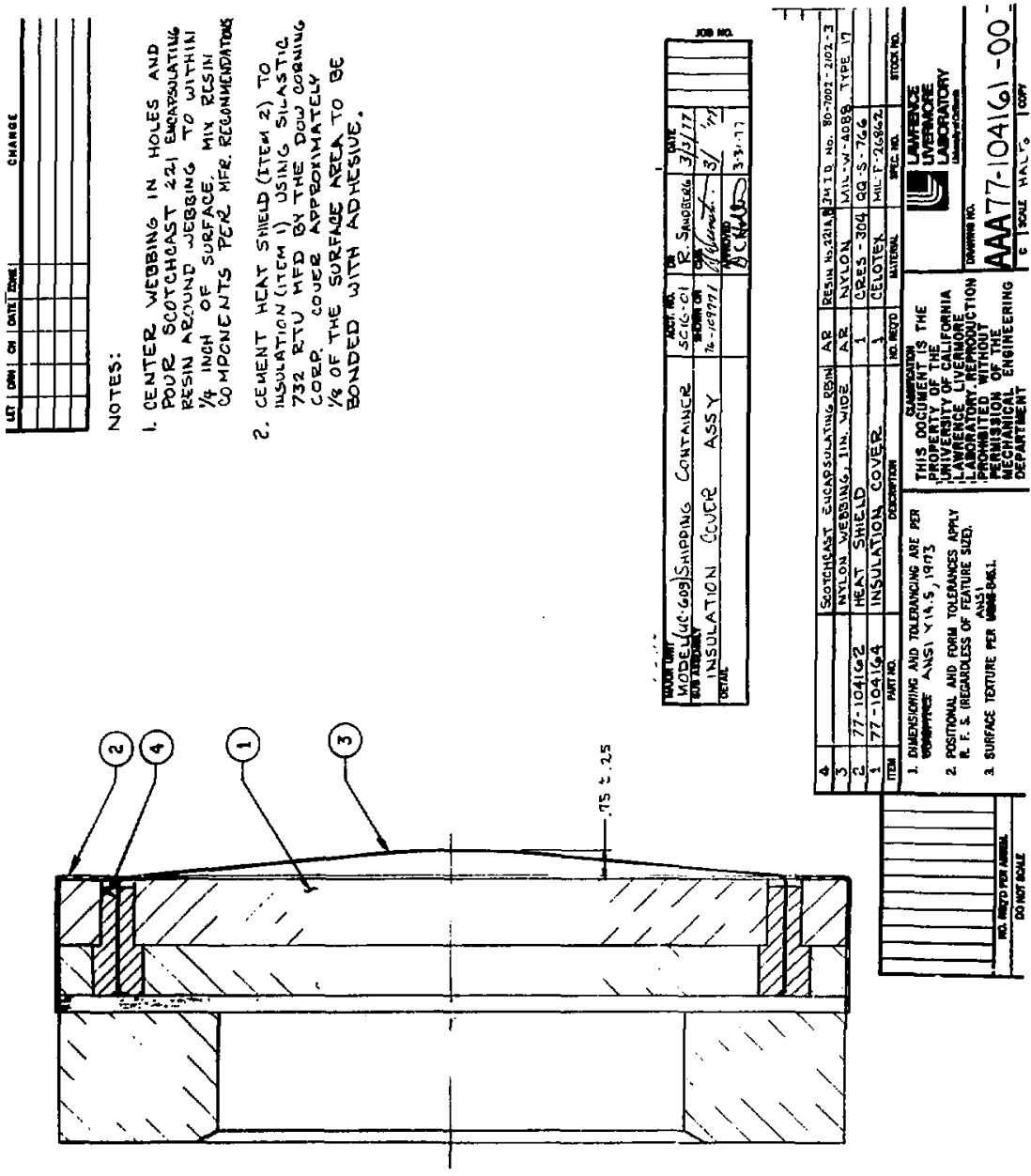


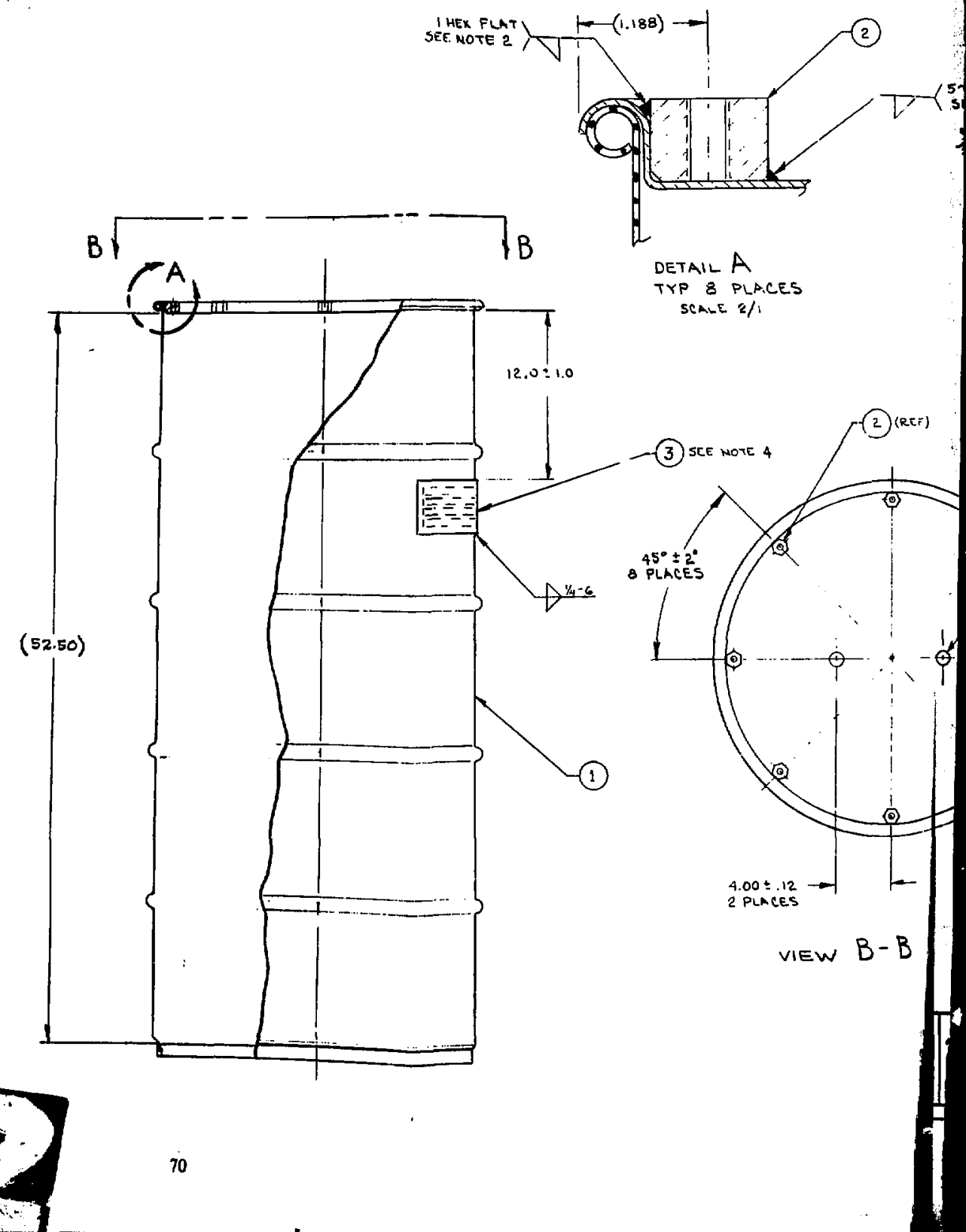



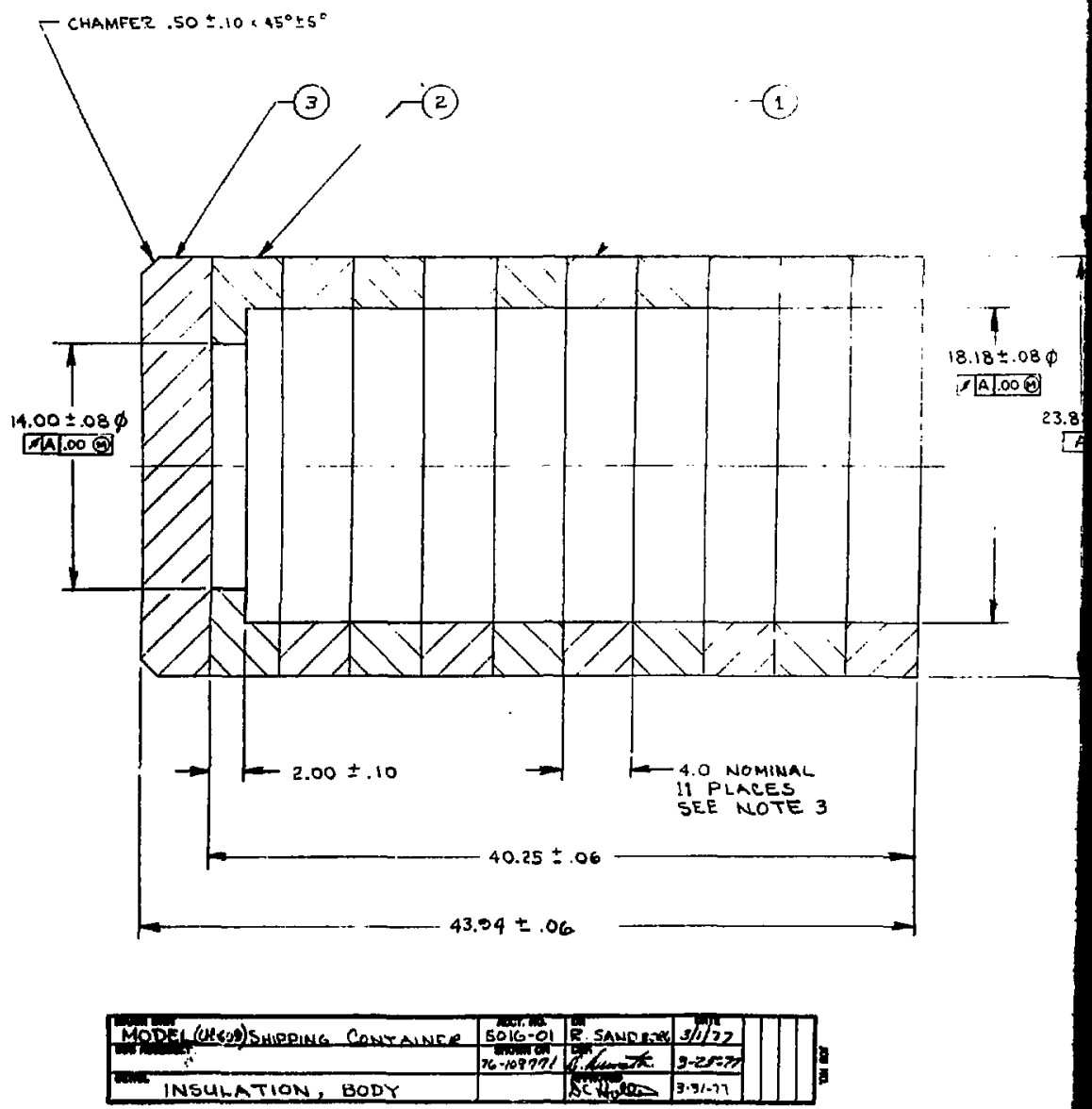


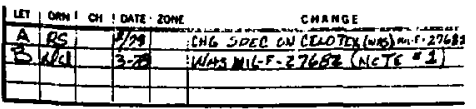

MCTES:

(B) - MATERIAL: CELOTCK NDUSTRIAL BUARD PER MIL-F- 2 :862 ERCEPT PAEAGRAPHS I7 WATER ADSORPTION, 3.10 .10 MODULUS CF RUPTURE WET, 3.11 FUNGUS

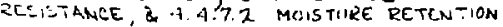

c. TARRUATOR WIADE JOINTS TC

IGIAL FACTCRY LAMIWATICNS. DO HOT AHINATC THE 4 wOH THICK RINGS a DISK TIGCTHCR

3. THE IHEINIOUAL RINGS AND THE DISC ARE TC EE NCIMINALLY 4.C .M. THICK. TO ADJUST THE TOTAL LENGTH SF THE STACK, ONE CR MIRC RINGS MAY DE FROM 3.5 TO 5 INCHES THICK AS REQD.

4. PACKACE ASSEMBLY TC PREUCNT SEPARATICN ER DAMAGE DURING - MIIPFMCNT.

5. HATERIAL CLRTIFICATICN RERD FCR

GECTEX USED IN ASSY.
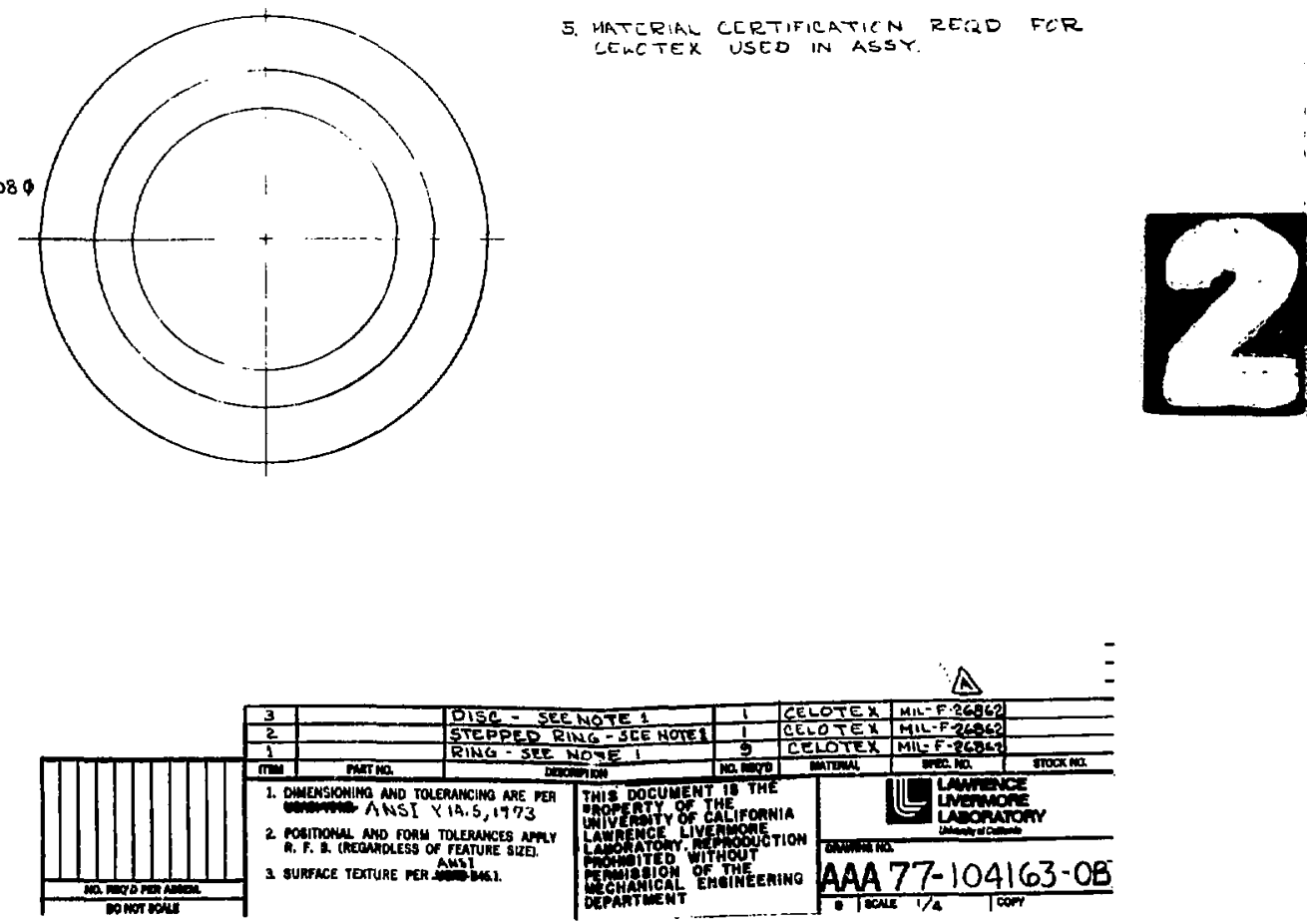